\title{
Public Values Associated with Nuclear Waste Disposal
}

by

William S. Maynard

Stanley M. Nealey

John A. Hébert

Michael K. Lindell

June 1976

Prepared for the Energy Research and Development Administration under Contract E(45-1):1830

\section{Battelle}

Battelle Memorial Institute

Human Affairs Research Centers

Seattle, Washington 98105 


\section{DISCLAIMER}

This report was prepared as an account of work sponsored by an agency of the United States Government. Neither the United States Government nor any agency Thereof, nor any of their employees, makes any warranty, express or implied, or assumes any legal liability or responsibility for the accuracy, completeness, or usefulness of any information, apparatus, product, or process disclosed, or represents that its use would not infringe privately owned rights. Reference herein to any specific commercial product, process, or service by trade name, trademark, manufacturer, or otherwise does not necessarily constitute or imply its endorsement, recommendation, or favoring by the United States Government or any agency thereof. The views and opinions of authors expressed herein do not necessarily state or reflect those of the United States Government or any agency thereof. 


\section{DISCLAIMER}

Portions of this document may be illegible in electronic image products. Images are produced from the best available original document. 


\section{NOTICE}

This report was prepared as an account of work sponsored by the United States Government. Neither the United States nor the Energy Research and Development Administration, nor any of their employees, nor any of their contractors, subcontractors, or their employees, makes any warranty, express or implied, or assumes any legal liability or responsibility for the accuracy, completeness or usefulness of any information, apparatus, product or process disclosed, or represents that its use would not infringe privately owned rights.

PACIFIC NORTHWEST LABORATORY

operated by

BATTELLE

for the

ENERGY RESEARCH AND DEVELOPMENT ADMINISTRATION

Under Contract EY-76-C-06-1830

\begin{tabular}{|c|c|}
\hline \multicolumn{2}{|c|}{$\begin{array}{l}\text { Printed in the United States of America } \\
\text { Available from } \\
\text { National Technical Information Service } \\
\text { U.S. Department of Commerce } \\
5285 \text { Port Royal Road } \\
\text { Springfield, Virginia } 22151\end{array}$} \\
\hline Printed Cop & -; Nicrofich \\
\hline *Pages & $\begin{array}{c}\text { NTIS } \\
\text { Selling Price }\end{array}$ \\
\hline $001-025$ & $\$ 4,50$ \\
\hline $026-050$ & $\$ 5.00$ \\
\hline $051-075$ & $\$ 5.50$ \\
\hline $076-100$ & $\$ 6.00$ \\
\hline $101-125$ & $\$ 6.50$ \\
\hline $126-150$ & $\$ 7.00$ \\
\hline $157-175$ & $\$ 7.75$ \\
\hline $176-200$ & $\$ 8.50$ \\
\hline $201-225$ & $\$ 8.75$ \\
\hline $226-250$ & $\$ 9.00$ \\
\hline $251-275$ & $\$ 10.00$ \\
\hline $275-300$ & $\$ 10.25$ \\
\hline
\end{tabular}


William S. Maynard, Stanley M. Nealey, John A. Hébert, Michael K. Lindell

June 1976

Battelle Memorial Institute Human Affairs Research Center Seattle, Washington 98105 
THIS PAGE

\section{WAS INTENTIONALLY LEFT BLANK}




\section{CONTENTS}

I. INTRODUCTION

II. METHOD

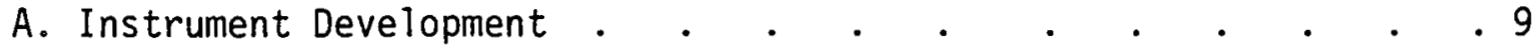

B. Nuclear Waste Disposal Filin . . . . . . . . . . . . . . 20

C. Sampling and Data Collection . . . . . . . . . . . 22

III.RESULTS •

A. Description of Respondent Groups . . . . . . . . . 25

B. Clustering of Respondent Groups . . . . . . . . . . . . . $\quad . \quad 30$

C. Importance of Nuclear Waste Disposal Factors . . . . . . 32

D. Evaluation of Levels of Risk and Cost . . . . . . . 60

E. Supporting Results: Attitude and Belief Measurement . . . 77

F. Supporting Results: Respondents' Evaluation of Survey . . . 90

IV. SUMMARY OF RESULTS . $. . . \quad . \quad . \quad . \quad . \quad . \quad . \quad . \quad . \quad . \quad .105$

V. CONCLUSIONS •

REFERENCES • $. \quad . \quad . \quad . \quad . \quad . \quad . \quad . \quad . \quad . \quad . \quad . \quad . \quad . \quad .119$

APPENDIX A - Survey Questionnaire . . . . . . . . . . . . 121

APPENDIX B - Film Script . . . . . . . . . . . . . . . . 147

APPENDIX C - Attitude Response Frequencies for Total Sample.. . . 155

APPENDIX D- Marker Items for Seven Factors . . . . . . . . . . . . . . . . . 59

APPENDICES E TO I - Representative Write-in Comments . . . . . 163 
THIS PAGE WAS INTENTIONALLY LEFT BLANK 


\section{FIGURES}

1. Average rankings of importance of the four factors--total sample 33

2. Distribution of ranks for total sample

3. Average rankings of importance of the four factors by six respondent 37 clusters

4. Distribution of ranks for environmentalists 39

5. " " " " nuclear technologists 40

6. " " " jr. high and high school students 41

7. " " " public utility employees 42

8. " " " " church members/civic organizations 43

9. " " " " university students 4.

10. Average ratio estimates of importance for total sample 46

11. Average ratio estimates of importance for six respondent clusters 48

12. Average regression weights for total sample 50

13. Average regression weights for six respondent clusters 52

14. Comparison of importance estimates from three measurement methods 54 --total sample

15. Average responses to levels of short-term safety--total sample 61

16. " " " " Tong-term safety--total sample 62

17. " " " " cost--total sample 63

18. " " " " accident detection and reduction 64 --total sample

19. Average responses to levels of short-term safety by the six 68 respondent clusters

20. Average responses to levels of long-term safety by the six 69 respondent clusters

21. Average responses to levels of cost by the six respondent clusters 70

22. Average responses to levels of accident detection and reduction 71 by the six respondent clusters 
FIGURES (contd)

23. Sample individual respondent profile to levels of short-term safety

24. Attitudes toward nuclear waste disposal factors

82

25. Perceived severity of nuclear waste problem $\quad 85$

26. Perceived safety of nuclear power 86

27. Perceived need for nuclear power and need for power in general 87

28. Perceived efficacy of alternatives to nuclear power 88

29. Percent answering YES to question: "Do you think it is wise to 92 consult the general public in the United States about decision making on nuclear waste disposal?".

30. Respondents' self-reported level of knowledge concerning nuclear waste disposal

31. Percent answering YES to the question: "Is the approach used in this study (movie and questionnaire) an effective way to gather public input about nuclear waste disposal?"

32. Respondent ratings of $\mathrm{film}$

33. Respondent ratings of questionnaire

34. Percent answering YES to the question: "Were the four factors emphasized in this study a satisfactory way to think about nuclear waste disposal?"

\section{$\underline{\text { TABLES }}$}

Table 1 - Characteristics of Respondent Groups

Table 2 - Clustering of Respondent Groups Based on Discriminant Analysis

Table 3 - Intercorrelations Among Factors and Methods of Importance Measurement. 


\section{INTRODUCTION}

This report presents the major findings from a study designed to assess public attitudes and values associated with nuclear waste disposal. The research is viewed as one step in a continuing effort to obtain information about societal values and concerns which may be incorporated into decisionmaking processes on complex, technological issues. Three general objectives have guided the planning and conduct of this project. The first objective was to obtain from selected individuals and organizations value and attitude information which would be useful to decision makers charged with deciding the ultimate disposal of radioactive waste materials. Large-scale decisions on technological questions are typically a result of blending data from the technical community with the judgments and values from public and elected officials. This project was designed to yield a third potential source of input to this decision-making blend: values and attitudes from key respondent groups and from members of society-at-large.

Another research objective was to obtain information that could be structured and quantified for integration with technical data in a computerassisted decision model. A description of this model appears in a companion report (Litchfield \& Hansen, 1975). Briefly, this decision model is based on utility theory assumptions, and allows estimates of the technical performance of generic waste disposal methods to be weighed by social value information obtained from sub-groups of the population.

A third general objective of this research was to test several attitudevalue measurement procedures for their relevance and applicability to nuclear waste disposal. This topic constitutes a representative example of a technological problem in which, (1) key decisions regarding systems characteristics 
remain open and engineering/scientific information is incomplete, (2) there is relatively little awareness or knowledge among the general population, and (3) there are profound ethical, moral, and societal implications. The assumption is made that public involvement in this topic is a valid and realistic objective. The study allows for comparisons of several attitude measurement procedures for determing the best approaches in subsequent research.

\section{scope}

Sample. The results presented in this report are based on questionnaire responses from 465 study participants. A total of 22 groups of respondents in five regions of the United States were surveyed including: junior high, high school, and university classes; men's and women's professional, civic, religious, and service organizations; recreationist and environmental activist organizations; and scientists and public officials with technical backgrounds in nuclear engineering and physics. The objective of the sampling strategy was to obtain responses from a broad spectrum of the public such that there would be variation across groups with respect to age, sex, occupation, specialized technical training, environmental orientation, and geographic area.

Questionnaire. The survey instrument focused on measuring the relative importance which respondents attached to four aspects of nuclear waste disposal:

- Short-term safety

- Long-terin safety

- Cost

- Accident Detection and Recovery

The selection of these four issues was dictated by the need to gather information which would be of value to decision-makers and planners as well as the need to. use issues or dimensions which would be relevant and meaningful to participants in the study. In this study, "importance" of issues was defined 
as the concern which respondents felt for these four nuclear waste disposal issues, and the priority they attached to them in planning a system of waste disposal.

The questionnaire contained six parts. Three sections were devoted to measuring the relative importance of the four issues cited above using different measurement procedures. Other parts of the questionnaire focused on cost/ benefit and risk/benefit issues and were designed to answer the question, "How safe is safe enough?" This study represented an initial effort to measure public values, attitudes, and perceptions toward risk, defined in terms of fatality rates.

A fifth section of the questionnaire focused on respondents' attitudes toward the broader issue of nuclear energy as an acceptable source of electrical power; alternatives of nuclear power; and the relationship between the needs for energy, on the one hand, and the econoriic health of the nation on the other. These issues form the context within which nuclear waste disposal must be considered.

The sixth section of the questionnaire consisted of evaluation and critique by respondents of the methodological approach used in the study. Specific and general reactions to the survey were solicited and respondents were invited to add suggestions and comments of their own. The intent of this last section was to obtain information which would indicate the appropriateness of the overall methodology for obtaining public input on complex issues as well as to identify those areas of methodology where improvements or modifications would enhance follow-on research efforts.

\section{Context of Study}

This study can be viewed from several perspectives, but to better establish the context and rationale for the research, two broad issues are addressed 
in this section: public involvement in technological decision making and social science research methodologies.

Survey research methodology constitutes only one of many levels and approaches for obtaining public involvement or input in decision-making processes. From the standpoint of the growing movement for citizen participation in decision making, this research can probably be categorized as a form of "public consultation." At this level of involvement, attitudes and opinions are solicited from members of the public who may be affected by the decisions. Data obtained are then used by planners in evaluating decision alternatives.

From a broader context, the public consultation level of citizen partictpation represents an intermediate point on a public involvement continuum. At one end of this continuum, the affected citizenry would have total control over the planning and implementation. At the other end of the continuum, affected parties would have neither the necessary information nor the power to influence planning or implementation of programs.

Much of the thinking about citizen participation arose during the 1960's in response to federally funded programs which were designed to ameliorate social problems. Part of the rationale for public participation in such programs was that individuals who were recipients of and who were affected by such programs were among those who should be involved in the planning and implementation of these programs. "Consultation" in that context took on an almost pejorative meaning, in the sense that citizens would have the opportunity to hear and be heard, but would lack the power to insure that their views were heeded (Arnstein, 1969).

Technological decision making probably differs from the type of decision making just described, partly because the outcomes of these decisions may be less immediate and less direct. In any case, delegation of power to the 
general public in technical decision making has not occurred to any great extent. Whether it is possible to generalize directly from citizen participation, as it was originally conceived, to public involvement in technological decision making remains an open question.

Public involvement in technological decision making, in particular decisions concerning development of nuclear energy, has traditionally occurred via public hearings, legal procedures, and planning bodies. The research described in this report is not a substitute for other public involvement mechanisms, but rather should be viewed as a step toward the development of an important supplementary avenue for public input. One potential advantage of this type of approach is that it allows for public input to come from a poten-. tially broader segment of society than is allowed for by other procedures. Moreover, this approach is probably less politicized than other public involvement mechanisms which have usually been initiated in an arena in which issues are completely polarized and in which battle lines are clearly drawn between advocates and opponents.

Another potential advantage of the approach used in this study derives from the timing and stage of planning in which such input may be obtained. Planning and decision making on technological change usually occurs over an extended period of time, but traditionally, public interest and involvement in such decisions occurs relatively late in the decision-making process (frequently after a final or near-final course of action has been decided upon). In the case of nuclear energy dectsions, public involvement late in the decision process has resulted in costly changes or delays and considerable foment. The research methodology employed in the current study constitutes an effort toward developing procedures for obtaining input at a much earlier stage of program planning. 
One of the problems in obtaining early input on a given issue is that awareness and interest levels in a population generally do not arise until decision alternatives are well crystallized and a final course of action has been decided. Obtaining informed public opinion at an earlier stage of the decision process has its difficulties because it occurs at a time when awareness and knowledge levels may be relatively low.

In order to overcome this difficulty it is necessary to communicate a body of information to respondents before soliciting their input. In the current study, a short movie was shown prior to the questionnaire administration. The intent of the film was to describe the problem of nuclear waste disposal and highlight some of the major considerations involved.

A final consideration in establishing the context of this study was the choice of research design and social science methods for measuring attitudes, beliefs, and values. The choice of methodology determines to some extent the selection of material on which to base survey questionnaire content, the selection of survey respondents, and the nature of the conclusions that can be drawn from the results. Runkel and McGrath (1973) make a distinction between two research strategies--sample surveys and complex judgment tasks, which may be helpful in viewing the research strategy employed in this study. The research described in this report probably strikes a balance between the two research strategies.

Sample surveys, of which public opinion polling is an example, usually require respondents to deal with a small number of relatively simple stimuli. For example, questions in public opinion polling are generally of the form, "For which candidate would you vote?" The form of such questions is familiar to respondents. The formats for answering questions are also familiar, such as 
preference for one object over another, and agreement or disagreement with a statement. The objective in sample survey research is usually to form broad generalizations based on responses from the sample of respondents and to extend these generalizations to larger populations from which the respondents have been drawn. Random sampling or a variant of it is frequently the strategy for identifying and selecting respondents.

By contrast, the typical strategy employed in complex judgment research calls for the presentation to respondents of more complex, numerous and perhaps esoteric stimuli or questions. The types of responses required are often complex and unfamiliar to the respondent, and might take such forms as, "Which two of these three are most alike?" and "How certain are you of your answer to the previous question?". The objective in complex judgment research usually is to form broad generalizations about the phenomenon or subject matter and to accomplish this objective by careful and intensive sampling of stimulus materials. Systematic sampling of judgment tasks is of primary interest and the sampling of respondents is more secondary to the research objective.

The research described in this report resembles the sample survey approach inasmuch as an attempt was made to sample broadly and systematically across a wide spectrum of respondents. The sampling approach called for the inclusion of individuals and groups with differing orientations toward nuclear energy and for the selection of a large number of respondent groups who differed with respect to other important characteristics such as age, educational level, sex, and geographic region. However, no attempt was made to select a sample that would be proportionately representative of the public at large. Nuclear engineers and environmental activists each form an extremely small proportion of the total population. These groups were "overrepresented" in the current study because their influence on decisions involving nuclear waste disposal is great. 
This study also resembled the complex judgment research since respondents were presented with a number of esoteric and unfamiliar sets of stimuli. Two considerations dictated the choice of stimulus material. First, stimuli were chosen in an attempt to learn more about the way in which people react to cost/ benefit and risk/benefit considerations, and about reasons underlying the ways in which they make priority, and value judgments. The second consideration arose from a concern for establishing the validity and stability of the results obtained. More specifically, the values or weights which respondents attached to nuclear waste-related issues might be dependent upon the method or way the weights were obtained. Consequently, niultiple, independent methods for assessing priority weights were included in the questionnaire. Comparison of the weights from different measurement procedures would permit a verification of the stability of results across the various methods.

To summarize, the research strategy employed was designed to meet two equally important, but somewhat competing objectives. These objectives were (1) to gather attitude value information about nuclear waste disposal from a rather broad segment of the population, and (2) to obtain accurate information in such a way that knowledge and understanding of human attitudes and perceptions concerning risk, technology, and orientations toward energy-environmental issues could be extended. 


\section{METHOD}

\section{A. Instrument Development}

Factor Selection. The survey questionnaire developed for this study was designed to obtain social value information about the relative importance of four aspects of nuclear waste disposal as well as information concerning some broader issues associated with the subject of nuclear waste disposal. The four nuclear waste disposal aspects or factors which formed the backbone of the questionnaire were described as follows:

Short-Term Safety: Those risks involved in the storage, transportation, and emplacement of nuclear waste materials. These risks are largely borne by the people who used the electrical power which created the wastes. These risks would occur during a few years following the creation of the waste.

Long-Term Safety: That portion of total risk which would begin after the wastes were finally emplaced or disposed and which would continue for the next 250,000 years. These risks would be due to geologic changes and other "Acts of God," and possibly to negligence. by man.

Cost: The dollar cost required for a given waste disposal method. Accident Detection and Recovery: Steps that could be taken to reduce the consequences of an accident if it does occur after final disposal.

The decision to use these four factors as a basis for questionnaire development was preceded by an exhaustive review of numerous other issues which. were considered. Other issues considered and ultimately rejected as suitable factors included:

Distance: Remoteness of disposal site from nearest person 
Population Density: Remoteness of disposal site from population centers Emplacement Operations: Reliability and safety of procedures used in transporting and disposing of wastes

Retrievability: Ease with which waste materials could be recovered for emergency procedures or for further processing and the time required to retrieve wastes Long-Term Stability: Length of time the waste would remain in their disposal location; resistance to acts of nature and acts of man Detectability: Extent to which detection of waste leakage would be possible; length of time before leaks could be delected

Protective Reaction: Extent to which population could be protected if leaks occurred

Emplacement Costs: Dollar costs involved in transport and disposal of wastes

R and D Costs: Dollar costs required to develop the disposal technology Time Required for $R$ and $D$ : Number of years required to develop and evaluate a given disposal method

National versus International: Whether wastes would be disposed of within U.S. borders or outside of U.S.

The final choice of the four factors described earlier was dictated by several considerations. First, we wished to have a set of factors which would be useful in describing any nuclear waste disposal method currently under consideration as well as any methods which might be proposed in the future. It was necessary to use factors for which both technical data and social value data could be obtained.

A second consideration was that the factors chosen must be meaningful and salient to participants in the study, and further, that the factors reflect the 
ethical-philosophical issues associated with nuclear waste disposal. Many of these latter issues arise because of the high radiation levels and the extremely long half-lives which characterize radioactive waste materials. Factors such. as Short-Term Safety and Long-Term Safety allow for a portrayal of some of the societal and moral aspects of nuclear wastes disposal and also offer a bas is for obtaining value-attitude information.

A final consideration in factor selection was what might be described as "scalability," or the extent to which the factors could be operationally defined in psychologically relevant terms and then presented along a graduated continuum. As an example, the factor, Short-Term Safety was operationally defined in terms of differring fatality rates over various periods of time. This final consideration also allowed for the development of attitude scales to measure respondent perceptions of "How safe is 'safe enough'?"

Survey Questionnaire. The survey instrument contained six major parts. (The complete questionnaire, as administered, is included as Appendix A.) In Part I, respondents read definitions of the four factors, Short-Term Safety, Long-Term Safety, Cost and Accident Detection and Recovery, and rank ordered them according to the importance they felt should be attached to each.

Part II: Ratio Estimation

Part II was a ratio estimation procedure (Stevens, 1968) in which respondents were asked to indicate the size of the intervals or the distance between the importance of each of the four factors as they had been ranked in Part I. The results of Part I show that some factors were seen as more important than others, but give little indication of how much more important one factor is in comparison to the others. The ratio estimation procedure allows respondents to indicate the size of the intervals among the factors. 
To illustrate, the factors might be rank ordered in Part I as follows:

(most important) 1. Short-Term Safety

2. Long-Term Safety

3. Cost

(least important) 4. Accident Detection and Recovery

In the ratio estimation procedure, pair-wise comparisons of the factors are made, comparing 1 with 2, 2 with 3, and 3 with 4, and numbers are assigned to the factors in each pair to indicate how important the second factor in the pair is in relation to the first factor in that pair. The following example illustrates the form of the task and shows how the ratios are calculated:

Sample Ratio Estimates

1. Short-Term Safety (STS)

2. Long-Term Safety (LTS)

2. Long-Term Safety (LTS)

3. $\operatorname{cost}(\$)$

3. $\cos t(\$)$

4. Accident Detection \& Recovery ( $A D \& R$ )

Ratios

100

90

100

50

100

90

The first factor in each pair is arbitrarily assigned a value of 100 and the respondent is asked to assign a number of the second factor which shows how important it is when compared to the first. In the example shown, LTS was judged to be almost as important as STS (90 vs. 100), cost was only half as important as LTS (50 vs. 100), and AD \& R was almost as important as cost (90 vs. 100). These pairings are then used to compute the intervals or distance between each of the factors. The most important factor is assigned a value of 100, and importance values for the remaining factors are computed as 
indicated in the example. The result is a scaling of the factors as a $0-100$. point scale. In the example shown, STS and LTS are quite close together in perceived importance, cost is seen as considerably less important by comparison, and $A D \& R$ is seen as much less important when compared with the other three factors. To summarize, the ratio estimation procedure allows for more finely graduated judgment of importance, yields more information since interval data are produced, and probably yields data which are more useful for decision making than are ordinal ranked data.

Part III: Evaluation of Levels of Risk and Cost

In Part III, respondents were asked to consider Short-Term and Long-Term Risk, Cost, and Accident Detection and Recovery, and to indicate how satisfactory several levels of risk and cost were to them. The instructions and explanatory material accompanying this section were designed to focus respondents' attention on cost/benefit and risk/benefit questions. Specifically, respondents were asked to judge those risk levels and costs they felt were satisfactory and justifiable to society and those which were unsatisfactory. to society in relation to the benefits from nuclear generated electricity. Since the thrust of this study was upon risk and safety related attitudes and perceptions, it was important to obtain information which might explain how people evaluate various possible fatality rates. Would people feel that even one death is an unacceptable price to pay for nuclear power? How would acceptability vary as a function of variation in risk of death? Even though risks are commonly debated in terms of possible fatalities, a literature search revealed virtually no previous efforts to measure risk-benefit perceptions where risk was operationalized in terms of fatality rates. However, Starr (1968) uses a historical approach to determine the risks that societies apparently are willing to assume to obtain certain benefits, e.g., comparing fatality rates from automobile acciderits with automobile usage rates. 
The first step in constructing these cost/benefit-risk/benefit scales was to obtain a consensus estimate from nuclear waste technologists of the realistic range of possible risks and cost associated with each waste disposal factor. This range was then arbitrarily extended at both ends to provide respondents with a very wide set of risks and costs. The respondent task is described for each factor as follows.

Short-Term Risks. Short-Term Risks were defined as those risks which would be borne largely by the generation of people who used the electrical power from which nuclear wates were a by-product. Short-Term Risk was operationalized as number of possible fatalities in the U.S. per unit of time. Annual fatality rates in the U.S. from various accidents and diseases were displayed for comparison. The range of Short-Term Risks chosen for presentation was bounded by 1,000 deaths per year as the highest level of risk and one death in 100 years as the lowest level of risk. Five intermediate levels of risk were included between the end points on the scale, resulting in a Short-Term Risk scale composed of seven risk levels. Beside each risk level was a 10-point response scale where "1" represented "Very Unsatisfactory" and "10" represented "Satisfactory," Respondents were asked to judge each level of short-term risk and place an "X". at a point on the 10-point scale which best described their evaluation of each risk level. Identical response scales were used for evaluation of the remaining three factors. Inng-Term Risk.s. Long-Term Risks were defined as those residual and diminishing risks which could persist after the period for Short-Term Risks ended. These risks are smaller than those for Short-Term, but span a longer period of time in the future. Like Short-Term Risks, Long-Term Risks were operationalized as fatality rates in the U.S. per unit of time. Eight levels of risk were presented, with the lowest level equal to one death per 100,000 years and the highest level equal to 100 deaths per year. 
Cost. Cost was operationalized as a range of potential increases in the cost of electricity that might be attributable to the costs of disposing of nuclear waste materials. These estimates were described as average increases in a family's cost of all electrical power, both direct and as a portion of the increased price of goods and services. Seven levels of cost increase were presented ranging from a minimum of a $10 \phi$ increase per month to a maximum increase of $\$ 15$ per month.

Accident Detection and Recovery $(A D \& R) . A D \& R$ was defined as a set of risk-reduction measures which could be incorporated into the design of a nuclear waste disposal system. Risk is often defined as: Risk $=P(e) \times M(e)$, where

$$
\begin{aligned}
& \text { Risk is the product of } \\
& P(e) \text {, probability of occurrence of an event } \\
& \text { times } \\
& M(e) \text {, the magnitude of the event. }
\end{aligned}
$$

In this schema, $A D \& R$ measures would serve to mitigate against or to reduce the magnitude of an event, (a leakage of nuclear waste into man's environment). Three design mechanisms were aggregated under the heading of $A D$ \& R: detection of leaks (early vs. late detection); protective reaction measures for protecting affected populations (extent to which protective measures could be taken); and retrievability of wastes (time required to retrieve and difficulty level involved in retrieva1). For measurement and scaling purposes, $A D \& R$ was operationalized as a per cent reduction in the magnitude of an event which might be achieved by incorporating various amounts of the three mechanisms into the design of a nuclear waste disposal system. As a reference point, an "event" (nuclear waste leak) with the potential for causing 100 fatalities was arbitrarily chosen, and respondents were asked to evaluate several levels of reduction in the magnitude of this event. Reductions ranged from 100 deaths to one death at the best, to no reduction from the 100 death event at the worst. 
Part IV: Policy Capturing Procedure

In Parts I \& II of the questionnaire, respondents were asked to judge the relative importance of the four waste disposal factors by first ranking them (Part I) and then by indicating the distance or interval which existed between them (Part II). Part IV consisted of an al ternative method for obtaining importance estimates which was independent of the measurement methodology used in Parts I \& II. The method has been referred to as a "policy-capturing" technique (Naylor and Wherry, 1965; Slovic and Lichtenstein, 1971). This methodology will be briefly described and then its applicability to the topic of this study will be discussed.

The objective of policy-capturing methods is to discover how people weight information in making global judgments about a set of factors or stimuli. For example, members of an admission committee with responsibility for reviewing applications for graduate school enrollment may have several test scores and ratings of potential taken from the applicants' letters of recommendation. Policy capturing methods can help by determining those cues which receive the most emphasis in making admission decisions about the candidates. A second example: a site selection committee charged with choosing the best of several locations for building a new manufacturing plant probably have available several pieces of information about each potential site--land costs, tax rates, availability of natural resources, proximity to markets, etc. If the overall favorability of each potential site is rated by each committee member, it. is possible to determine the emphasis or weights given by each member to each element of site information in arriving at the overall favorability rating of each site.

The topic of nuclear waste disposal and specifically, the four waste disposal factors of interest in this project, were subjected to policy capturing analysis to discover the relative weight or importance of each of the four factors. 
This method produced results which could be compared with those obtained in Parts I \& II. The policy capturing was accomplished by a series of 27

'hypothetical' waste disposal designs which were characterized by scores representing their standing on the four factors: Short-Term Safety, Long-Term Safety, Economical (Cost), and Accident Detection \& Recovery. Respondents examined each hypothetical design and then made a judgment as to its overall "acceptability." Multiple regression analysis was then applied across the 27 methods, using the designs' scores on each factor as independent variables and the respondents' acceptability judgment as dependent variables. The sizes of regression weights for each factor represented the importance the respondent attached to each factor. This method of measuring factor importance is methodologically independent of the ranking and rating performed in Parts I and II of the questionnaire.

A relatively high regression weight for a factor indicated the factor was important to the respondent in making judgments about the waste disposal designs. Smaller regression weights indicated factors of less importance to the respondent. To sumarize, the way in which information was weighted to form a global judgment was captured in the form of a multiple regression equation. This equation describes the relative importance of the factors in making overall judgments of the acceptability of waste disposai designs.

Hypothetical waste disposal designs were generated by combining varying amounts of the four factors to form "composite" disposal systems. These systems were presented schematically in the questionnaire as shown in Example 1.

\section{Example 1}

\begin{tabular}{|l|l|}
\hline \multicolumn{1}{|c|}{ Factors } & Scores \\
\hline Safe for the Short-Term & \\
\cline { 2 - 2 } Safe for the Long-Term . \\
Economical \\
Accident Detection and Recovery
\end{tabular}


The longer the horizontal line beside each factor the greater the extent to which the factor would be present in that design. To illustrate, the waste disposal system described in Example 1 would be very safe for the short-term and would be very economical. It would be moderately safe for the long-term, and would contain very little provision for accident detection and recovery.

A second example shown below would be very low in safety for the shortterm, quite safe for the long-term, very uneconomical, but very high in provision for accident detection and recovery.

Example 2

\begin{tabular}{|l|l|}
\hline \multicolumn{1}{|c|}{ Factors } & Scores \\
\hline Safe for the Short-Terin \\
Safe for the Lonq-Tern \\
Economical \\
Accident Detection and Recovery
\end{tabular}

As the examples illustrate, three levels of each factor were used: low, moderate, and high. Given three levels of four factors, the total number of combinations of factor levels was $3^{4}$, or 81 possible hypothetical designs.

To prevent the task from becoming too tiresome, a one-third fractional factorial representation of the 81 possible combinations was used, i.e., 27 designs. This set of 27 stimuli had the following characteristics: each level (high, moderate, low) of each factor was presented nine times; and the intercorrelation among the four factors was zero. Both of these characteristics helped to insure that the weights, or importance estimates which resulted from the multiple regression analysis would reflect the actual importance weights of the respondents rather than any systematic bias attributable to the way in which the levels of factors were combined to form disposal designs. Respondents were instructed to examine each of the 27 designs, and based on the way each design was characterized by the four factors taken together, to 
judge the acceptability of each. Below each design was a 10-point rating scale where 1 = "very unacceptable" and "10" = "very acceptable." Respondents marked this scale to indicate the acceptability of each design.

At the end of Part IV, three blank waste disposal designs were shown. These had no lines beside the factors. Respondents were asked to draw in lines to describe: (1) the best or most ideal design; (2) the design which would just meet their minimum standards for an acceptable system; and (3) the design most like the one which they felt would actually be put into practice in the United States.

\section{Part V: Attitude Questions}

Part $V$ of the questionnaire consisted of 30 attitude statements with which respondents were asked to indicate their agreement or disagreement. The statements were designed to cover the following nine content categories:

- Short-Term Risks

- Long-Term Risks

- Cost

- Accident Detection and Recovery

- Salience and Severity of the Nuclear Waste Issue

- Perceived Need for and Efficacy of Nuclear Power

- Need for Electrical Power

- Efficacy of Alternatives to Nuclear Power

- Value Orientations of Respondents

Approximately half of the statements were worded with a positive inflection and half with a negative inflection. Responses to the statements were made on a five-point scale which ranged from "Strongly Agree" to "Strongly Disagree." The attitude statements which dealt with the four waste disposal factors were intended to serve as another independent measure of the importance 
estimates obtained in Parts I, II and IV. The other statements were included for their potential explanatory value in interpreting the results of Parts I-IV. They also provided an opportunity for respondents to express their attitudes and values on a variety of issues related to nuclear waste disposal.

\section{Part VI: Respondent Evaluation of Survey}

Part VI provided respondents with the opportunity to evaluate and comment upon the rationale for this study and upon the procedures which were utilized. This section included rating scales and open-ended questions concerning: the quality and appropriateness of the questionnaire and film; respondents' selfratings of knowledge about nuclear waste disposal prior to and after participating in the survey; the reasonableness of the study objectives; and the effectiveness of the methods used to reach these objectives. Four biographical information items about the respondents were included. Like Part V, the information in Part VI was included for its potential explanatory value in accounting for the results obtained in the earlier sections of the survey.: In addition, this evaluative information would be helpful in assessing the "face validity" of the methodology by indicating whether the approach was viewed by respondents in an unfavorable or favorable light. Questions of this type are useful in improving the methodology in future research.

\section{B. Nuclear Waste Disposal Film}

Prior to administering the questionnaire, a 15 -minute film was shown to respondents. This film presented a brief overview of the nuclear waste disposal issue and highlighted the four waste disposal factors emphasized in the questionnaire. Presentation of filmed information was based on the assumption that there was a relatively low level of awareness and knowledge about the topic among the majority of the respondents. One mechanism for obtaining more informed opinions about the topic is to communicate a body of information about the topic to respondents prior to soliciting their input. 
An obvious issue concerning the approach is whether such information may predetermine or bias the questionnaire data. Two general strategies were used to minimize and account for any bias in the information-questionnaire approach. First the script on which the film was based was written with the objective of communicating a balanced body of information about the topic rather than presenting a single perspective to the exclusion of other points of view. (The script as it appeared in the film is included as Appendix B.) The script underwent several revisions and was edited substantially in an effort to el iminate persuasive or biased information. Reviewer comments were solicited from researchers and officials with expertise in nuclear technology, from social scientists, from communications specialists, and from researchers who were independent of the study and who had no vested interest in the topic under consideration.

Both the film and the questionnaire emphasized a set of issues (the four factors) which were thought to underlie all potential waste disposal methods. Respondents were asked to make value and opinion judgments about these issues rather than making technical judgments or evaluations of specific waste disposal methods. The assumption behind this approach was that while most study participants would not possess the knowledge necessary to make technical judgments, they could (with a broad introduction to the topic) make informed priority and value judgments about some of the issues associated with nuclear waste disposal.

Second, as noted in the previous section, one part of the questionnaire was devoted to respondents' evaluation of the survey procedures. Questions directed toward the film content were included so that estimates of the film's bias and persuasive content could be incorporated into the interpretation of of results. 
The film was developed as a collaborative activity between HARC social scientists, BNW nuclear waste technologists, and the BNW Photography Department. The version used in the study was a narrated $16 \mathrm{~mm}$ color film which covered the following issues: the importance of public input to the subject; an introduction to the topic of nuclear waste disposal; definitions and descriptions of the four waste disposal factors; and illustrations of the four factors as they would apply to two generic waste disposal methods (sea-bed disposal and geologic disposal).

\section{Sampling and Data Collection}

The survey was administered to 22 groups of respondents in five geographic regions of the United States. The results presented in this report are based on a total sample size of 465 . Characteristics of each respondent group are presented in the Results section, but the 22 groups may be briefly categorized as follows:

Number

of Groups

Nuclear Technologists and Public Officials

Public Utility Employees

Environmental Interest Groups

Womens' Organizations

Church Groups

Civic Organizations:

Recreationist Groups

Undergraduate Humanities Classes

Undergraduate Engineering/Physics $\mathrm{Cl}$ asses

$\mathrm{High}$ School Classes

Jr: High School Classes 
The general sampling objectives were to obtain survey responses from (1) individuals who would constitute a relatively broad cross-section of the U.S. public, and (2) selected individuals characterized by special interests (e.g., environmental organization members) or characterized by specialized technical training (e.g., nuclear technologists). More specific sampling objectives were to insure that there would be variation among groups with respect to age, sex, occupation, specialized technical training, environmental orientation, and geographic region of the U.S.

The survey was administered in the Pacific Northwest (Seattle and Richland, Washington), West (Orange County, California), Midwest (Ann Arbor, Michigan), Northeast (New Haven, Connecticut), and South (Atlanta, Georgia). Administration of the survey in the Northwest was conducted by HARC and BNW staff members. Data collection activities in the other four regions were conducted by university-based colleagues who administered the survey to selected respondent groups as specified by the overall sampling plan.

Questionnaires were administered in a group setting, the nature and purpose of the study was explained, and time was allotted for questions and discussion. Participants then viewed the film, and received copies of the survey questionnaire. Respondents were instructed to proceed at their own pace. The average time required for completion of the questionnaire was approximately 45 minutes. 


\section{THIS PAGE WAS INTENTIONALLY LEFT BLANK}




\section{RESULTS}

\section{A. Description of Respondent Groups}

Two types of information will be used to characterize the participants in the study: quantified demographic information and somewhat more impressionistic observations about the response groups and/or the conditions under which the surveys were administered.

Table 1 presents some summary characteristics of each response group. For all the samples, a total of 548 questionnaires were returned. Incompleted questionnaires containing large blocks of missing information were excluded from subsequent analyses. Eighty-three such questionnaires, or 15 percent of the total, were not included in the analyses because of missing data. Write-in comments from these questionnaires, however, were recorded and included in the analysis of responses to open-ended questions and general comments. Thus, the major findings reported here are based on a sample of 465 respondents.

Referring again to Table 1, the average age varied across the groups; for the total sample, the age span was 71 years, from 12 years to 83 years of age. Sixty-two percent $(N=288)$ of the total sample was male and 38 percent $(N=177)$ was female. The mean education levels for respondent groups ranged from eight years (Group 15) to near Ph.D./M.D. level (Group 4). When the student groups (15-22) are set aside, however, the average education level for Groups 1-14 was quite high compared to U.S. population norms. A substantial number of respondents in Groups 1-14 had completed four or more years of college.

The questionnaire did not contain a "test" of respondent knowledge about nuclear waste disposal. Respondents were asked, however, to self-rate their level of awareness and knowledge about the topic. Table 1 shows that the respondent groups covered a fairiy broad range of self-rated knowledge 
TABLE ।

Characterist!es of Kespondent Groups

\begin{tabular}{|c|c|c|c|c|c|c|c|c|c|}
\hline . & $\begin{array}{l}\text { Responden: } \\
\text { Group }\end{array}$ & $\begin{array}{c}\text { Mumber of } \\
\text { Completed } \\
\text { Question- } \\
\text { naires }\end{array}$ & $\begin{array}{c}\text { Incom- } \\
\text { piete } \\
\text { Question- } \\
\text { natres } \\
\end{array}$ & $\begin{array}{l}\text { Average } \\
\text { Age }\end{array}$ & $\begin{array}{c}\text { Age } \\
\text { Range }\end{array}$ & $\begin{array}{l}\text { Male/Female } \\
\text { Ratio }\end{array}$ & $\begin{array}{l}\text { Average } \\
\text { Years of } \\
\text { Education }\end{array}$ & $\begin{array}{c}\text { Average } \\
\text { Knowiedye, } \\
\text { of Topic } \\
\end{array}$ & $\begin{array}{l}\text { Orientation } \\
\text { Toward } \\
\text { Nuclear } \\
\text { Power" }\end{array}$ \\
\hline 1. & $\begin{array}{l}\text { Engineering } \\
\text { Scientists and } \\
\text { Fublic off1- } \\
\text { cidis (mW) }\end{array}$ & 20 & 0 & 41.6 & $27-62$ & $19 / 1$ & 16.2 & 6.55 & 4.25 \\
\hline 2. & $\begin{array}{l}\text { Corporation } \\
\text { Engtneers (NW) }\end{array}$ & 31 & 1 & 44.6 & $29-60$ & $31 / 0$ & 18.4 & 5.42 & 4.45 \\
\hline 3. & $\begin{array}{l}\text { Nationial Environ:- } \\
\text { mental Organiza- } \\
\text { tion (MW) }\end{array}$ & - & 1 & 27.0 & $25-30$ & $4 / 1$ & 18.0 & 5.00 & 2.00 \\
\hline 4. & $\begin{array}{l}\text { National Environ- } \\
\text { mental Organiza- } \\
\text { tion/Local } \\
\text { Enviromental } \\
\text { Activists (NE) }\end{array}$ & 12 . & 0 & 30.6 & $22-48$ & $9 / 3$ & 19.3 & 4.63 & 2.17 \\
\hline 5. & $\begin{array}{l}\text { National Environ- } \\
\text { nental Organiza- } \\
\text { tion (s) }\end{array}$ & 8 & 1 & 28.5 & $24-36$ & $5 / 3$ & 17.8 & 3.62 & 2.75 \\
\hline 6. & $\begin{array}{l}\text { Local Environ- } \\
\text { mental Organtiza- } \\
\text { tion (W) }\end{array}$ & 18 & 1 & 50.6 & $22-78$ & $2 / 16$ & 15.9 & 4.56 & 2.50 \\
\hline 7. & $\begin{array}{l}\text { Public Interest } \\
\text { Lobbyists (MN) }\end{array}$ & 6 & 0 & 23.3 & $19-30$ & $6 / 0$ & 16.0 & 5.33 & 1.33 \\
\hline 8. & $\begin{array}{l}\text { Womens' Univer- } \\
\text { sity Organiza- } \\
\text { tion (Ni) }\end{array}$ & 20 & 3 & 41.2 & $26-63$ & $0 / 20$ & 16.7 & 4.05 & 2.95 \\
\hline 9. & $\begin{array}{l}\text { Hunting Organt- } \\
\text { axtion (MN) }\end{array}$ & 9 & 3 & 40.1 & 2364 & $8 / 1$ & 14.9 & 4.23 & 3.78 \\
\hline 10. & $\begin{array}{l}\text { Public Ut1lyty } \\
\text { Enployees }(S)\end{array}$ & 23 & 2 & 33.4 & $22-55$ & $19 / 4$ & 14.8 & 3.52 & 3.87 \\
\hline 11. & $\begin{array}{l}\text { Cfvic Organi- } \\
\text { zation }(W)\end{array}$ & 18 & 0 & 45.3 & $27-65$ & $15 / 3$ & 16.1 & 4.0 & 3.78 \\
\hline 12. & $\begin{array}{l}\text { Civic organi- } \\
\text { zation (M) }\end{array}$ & 10 & 2 & 33.1 & $22-50$ & $9 / 1$ & 16.0 & 2.90 & 3.10 \\
\hline 13. & Church Members ( $M$ ) & 26 & 4 & 44.6 & $29-60$ & $12 / 14$ & 16.7 & 3.77 & 3.38 \\
\hline 14. & Church Menbers (NE) & 28 & 9 & 45.5 & $23-83$ & $8 / 20$ & 16.7 & 3.55 & 3.13 \\
\hline 15. & $\begin{array}{l}\text { Juntor High School. } \\
\text { Students }(\mathrm{HH})\end{array}$ & 32 & 3 & 13.8 & $12-15$ & $18 / 14$ & 8.7 & 3.50 & 3.22 \\
\hline 16. & $\begin{array}{l}\text { Advanced Placement } \\
\text { lligh iwhni Phystris } \\
\text { Class (MW) }\end{array}$ & 15 & 1 & 17.8 & $17-18$ & $10 / 5$ & 12.0 & 4.50 & 3.23 \\
\hline 17. & $\begin{array}{l}\text { High School Environ } \\
\text { menta! Science } \\
\text { Class (S) }\end{array}$ & $n-$ & 7 & 15.9 & $14-19$ & $23 / 12$ & 10.5 & 2.37 & 3.26 \\
\hline 18. & $\begin{array}{l}\text { Undergraduate } \\
\text { Physics } \\
\text { Students (H) }\end{array}$ & 19 & 2 & 21.5 & $17-28$ & $17 / 2$ & 15.1 & 5.21 & 3.26 \\
\hline 13 & $\begin{array}{l}\text { Undergyeduate Cfrl\} } \\
\text { Engineertng: } \\
\text { Class (s) }\end{array}$ & 23 & 1 & 19.9 & $18-32$ & $23 / 0^{\circ}$ & 13.7 & $3.39^{\circ}$ & 3.04 \\
\hline 20. & $\begin{array}{l}\text { Undergraduate } \\
\text { Peychnlngy } \\
\text { Class (NE) }\end{array}$ & 20 & 1 & $20 . \dot{9}$ & $18-28$ & $6 / 14$ & $14 . \ddot{8}$ & 3.0 & 2.90 \\
\hline 21. & $\begin{array}{l}\text { Contfnuing Eduea- } \\
\text { tion College } \\
\text { Students (NE) }\end{array}$ & 12 & 0 & 31.2 & $21-50$ & $4 / 8$ & 16.1 & 3.5 & 2.83 \\
\hline 22. & $\begin{array}{l}\text { Undergraduate } \\
\text { Civil Ennineering } \\
\text { Class (NW) }\end{array}$ & $\frac{75}{465}$ & $\frac{41}{83}$ & 22.5 & $18-41$ & $\frac{40 / 35}{288 / 177}$ & 15.2 & 3.95 & 3.19 \\
\hline
\end{tabular}

'Region of U.S. is shown in parentheses following group name. Nis = Northwest; Mh = Midwest; $S$ - South; $W$ - West: NE - Rortheast.

2Number of incomplete questionnaires not included in analyses.

'Knowledge based on participants' response to question. "Before you participated In this study, how well-informed were you about the subject of nuclear waste disposal?", where 1 " Hot at ali informed; 7 . Very well informed.

"Nuclear power orfentation is based on extent of ayreement with the statement. "Bascd on past operatini experience, nuclear enerijg has been deninnstrated to be J clcan alld safn scurce of electrical power." $i$ " Strongly disaụree: 2 = Disagrue; 3 " veither agree nur disitigree;

$t=$ Auret:: 5 = Stronily agrec. 
concerning the topic. The far-right column of Table 1 presents the average response for each group to an attitude question concerning the extent to which nuclear power was seen as a safe and clean source of electrical power. Response averages varied from favorable to unfavorable concerning this issue.

To summarize, the sampling strategy appeared to achieve most of the study objectives, e.g., representation of both sexes, and several levels of age, knowledge about the topic, and general orientation toward nuclear power. Aside from the student groups, however, non-college level respondents are underrepresented in the sample, at least in comparison to educational levels for the adult U.S. population.

The descriptive paragraphs presented next are intended to give the reader a clearer and fuller picture concerning the membership of each group and, where possible, some characterization of the environments in which the study was administered.

1. Engineering Scientists and Public Officials (NW). This group consisted of staff members of a field office of the Energy Research and Development Administration, the sponsor of this study. Administration of the film and questionnaire to this group served a dual purpose--sponsor review and clearance to proceed with data collection from other groups, and data collection from a relevant respondent group. The survey was conducted at a called meeting during working hours. All respondents had ample time to complete the questionnaire.

2. Corporation Engineers (NW). Respondents were nuclear engineers and scientists employed by a corporation conducting research for the Energy Research and Development Administration. Most of the respondents were department managers. The film was shown during working hours and the respondents took the questionnaires, completed them at home, and returned them in 1-3 days.

3. National Environmental Organization (MW). Participants were members of a local chapter of a national environmental interest/ recreationist organization. The survey was included as part of the program agenda for a regular meeting. Occupations of members included: physician, engineer, oceanographer, computer scientist, commercial artist, and meteorologist. 
4. National Environmental Organization/Local Environmental Activists (NE). Two smal7 respondent samples were surveyed and then combined to form this group. One group $(N=7)$ consisted of members of the local chapter of a national environmental interest/recreationist organization. The other group $(N=5)$ could be described as environmental intervenors who were challenging some of the proposed land use planning in their locality. Most members of both groups were affiliated with a university, as faculty, researchers, and graduate students. Disciplines represented in this group included: biochemistry, molecular biology, neurochemistry, law and medicine.

5. National Environmental Organization (S). Participants were members of a local chapter of a national environmental interest/recreationist organization. Administration of the survey was the final item on the agenda for a monthly evening meeting. Presentation of the film and distribution of the questionnaire occurred late in the evening. A few members reacted negatively to the study, partially as a result of the hour, but also because of strong reservations about sponsor utilization of study results. A number of people declined to participate further. Several members did take copies of the questionnaire with them to complete and return by mail. Nine surveys were returned and eight of these were included in data analyses. Occupations represented in this group included: chemical engineer (3), college professor, environmental chemist, dog groomer, and psychologist.

6. Local Environmental Organization (W). Members of this group were concerned with the protection of nearby coastal waters from 0 il pollution as well as environmental issues in general. Board members of the organization participated in the study, which was conducted at the home of the administrator, who was also a member of the group. Occupations included housewife, real estate broker, student, teacher, engineer, and store manager. There were no time constraints and all members had the opportunity to finish the questionnaire.

7. Public Interest Lobbyists (MW). Participants were members of a state-wide, university student-run organization which was politically active in a variety of issues such as utility rate increases, nonreturnable bottles, and the transportation of nuclear wastes across the state.

8. Womens' University Organtzation (NW). This group was characterized by three areas of mutual interest to members: cultural activities; environmental-social concerns; and legislative-governmental concerns. The survey was conducted at a special called meeting. All participants had ample time to finish the questionnaire. Most of the participants were housewives, but several held part-time jobs. All had completed four years of college.

9. Hunting Organization (MW). This group was a local recreational gun and hunting club. Occupations represented were student, carpenter, repairman, engineer, cost estimator, and die maker. 
10. Public Utility Employees ( $S$ ). Members of this group were primarily non-supervisory personnel holding staff positions. The survey was conducted during working hours and there were no time constraints.

11. Civic Organization (W). Most of the respondents in this group were business and civic leaders. The survey was administered to a subcommittee whose interest area was energy-environmental issues. Occupations represented in this group included sales manager, corporation executive, attorney, accountant, property management, public and government relations consultant, physician, business owner, and tugboat captain.

12. Civic Organization (MW). Respondents were drawn from the local chapter of two national civic/service organizations. Occupations included banker, teacher, secretary, electrical engineer, real estate and insurance sales, and hotel manager.

13. Church Members. (NW). Respondents were members of a suburban church who met at a called meeting to participate in the study. There was ample time for all to finish the survey. Occupations included clergy, retail store buyer, physician, housewife, credit manager, research engineer, and systems analyst.

14. Church Members (NE). Respondents in this group volunteered in response to an announcement describing the study. Occupations included in this group included university faculty members, graduate students, housewives, church workers and retirees.

15. Jr. High School Students (NW). Most of the respondents were eighth grade students in a parochial school located in a community whose major industry was research and development activities in the engineering and physical sciences. The survey was conducted during school hours and all participants had time to complete the questionnaire.

16. Advanced Placement High School Physics Class (MW). Participants were twelfth grade students in an advanced curriculum physics class. The survey was given during a 50-minute class period; all but two students were able to complete the questionnaire.

17. High School Environmental Science Class (S). Respondents were students taking an ecology class. Not all students finished in the allotted time, but were able to finish at a later time and return the completed surveys.

18. Undergraduate Physics Students (W). Respondents were university students who were members of a physics society. The survey was conducted at a called meeting. 
19. Undergraduate Civil Engineering Class (S). This sample was composed of engineering majors. The survey was given during a laboratory session associated with an engineering course.

20. Undergraduate Psychology Class (NE). Participants completed the survey during one of the class sessions.

21. Continuing Education Students (NE). Members of this group were students in the psychology class above $(\# 20)$. They differed from Group 20 in that most were somewhat older, held full-time jobs, and in some instances already possessed college degrees.

22. Undergraduate Civil Engineering Class (NW). Most respondents were non-engineering majors taking a course orlented towards humanities/sucial science majors. The content of the course was directed towards the study of man-caused pollution of the environment. There were serious time constraints because of the large class size (150) and short time period (45 minutes). As Table 1 indicates, a substantial number of respondents in this group (35\%) were unable to complete the questionnaire.

\section{B. Clustering of Respondent Groups}

The relatively large number of response groups together with the length and complexity of the questionnaire posed data management problems both in presenting the results as well as in interpreting the findinys. A slatistical technique, discriminant analysis (Cooley \& Lohnes, 1971), was used to combine the respondent groups into a few major categories so that groups within each category would be relatively similar to one another, yet distinct from the groups in other categories. The data used in the analysis were: the responses to attitude statements from Part $V$ of the questionnaire (i.e., respondent attitudes concerning waste disposal, nuclear power, and related energy issues) and responscs to the questions in part VI, respondents" evaluation of the goals of this study and the procedures employed to reach these goals.

Table 2 presents the results of the discriminant analysis. Beneath the major category or "cluster" heading are shown the respondent groups comprising the cluster. To the right of Table 2 are shown the sample sizes for each of the 22 respondent groups, the sample sizes of the newly formed clusters, 
I. ENVIRONMENTALISTS

Local Environmental Organization (West) . 18

Women's University Organization (Northwest) 20

Public Interest Lobbyists (Midwest) 6

National Environmental Organization (Midwest) · 5

National Environmental Organization (Northeast) . 12

National Environmental Organization (South)

II. NUCLEAR TECHNOLOGISTS

Public officials (Northwest) 20

Corporation Engineers (Northwest) $\quad \frac{31}{51}$

III. JR. HIGH AND HIGH SCHOOL STUDENTS

Jr. High School Students (Northwest) . 32

High School Environmental Science Class (South) $\frac{35}{67}$

IV. PUBLIC UTILITY EMPLOYEES

Public Utility Employees (South) : · 23

Hunting Club (Midwest)

V. CHURCH MEMBERS/CIVIC ORGANIZATIONS

$\begin{array}{ll}\text { Church Members (Northeast) } & 28\end{array}$

Church Members (Northwest). · 26

Civic Urganization (Midwest) 10

Civic Organization (West) $\quad \frac{18}{82}$

VI. UNIVERSITY STUDENTS

Undergraduate Civil Engineering Class (Northwest) - 75

Undergraduate Physics Class (West) 1.9

Undergraduate Civil Engineering Class (South) 23

Undergraduate Psychology Class (Northeast) 20

Continuing Education Class (Northeast) 12

Advanced Placement High School Physics Class (Midwest) $\frac{15}{164}$

TOTAL $\quad 465$ 
and the percentage of total sample size represented by each cluster of respondents.

The percentages beside each cluster are helpful in reviewing the sampling mix obtained in this study. Roughly half of the total sample was composed of students (Clusters III and VI), one-fourth was made up of special interest groups (Cluster I) and special competence groups (Cluster II), and the remaining one-fourth (Clusters IV and V) constitute a broader cross-section of national interests.

\section{Importance of Nuclear Waste Disposal Factors}

This section presents the results from three procedures for measuring the relative importance which respondents attached to the four factors, Short-Term Safety, Long-Term Safety, Cost, and Accident Detection and Recovery. Results are presented both for the total sample of respondents and for the six respondent clusters which were described in the previous section.

1) The first measurement procedure, ranking, simply required the respondents to arrange the four factors in order of importance from "Most Important" to "Least Important".

The average rankings of importance for the total sample of respondents are shown in Figure 1. Long-Term Safety (LTS) received the highest average rank, closely followed by Short-Term Safety (STS) and Accident Detection and Recovery (ADR). Cost was ranked lowest in importance by a wide margin. The average values for LTS, STS, and ADR indicate that for the total sample, these three factors were all seen as being relatively important. By comparison, Cost was viewed as being relatively unimportant.

The results shown in Figure 1 are useful in that they give a general impression of the relative priority or importance attached to each of the 
FIGURE 1

AVERAGE RANKINGS OF IMPORTANCE

FOR TOTAL RESPONDENT SAMPLE

$\mathrm{N}=465$

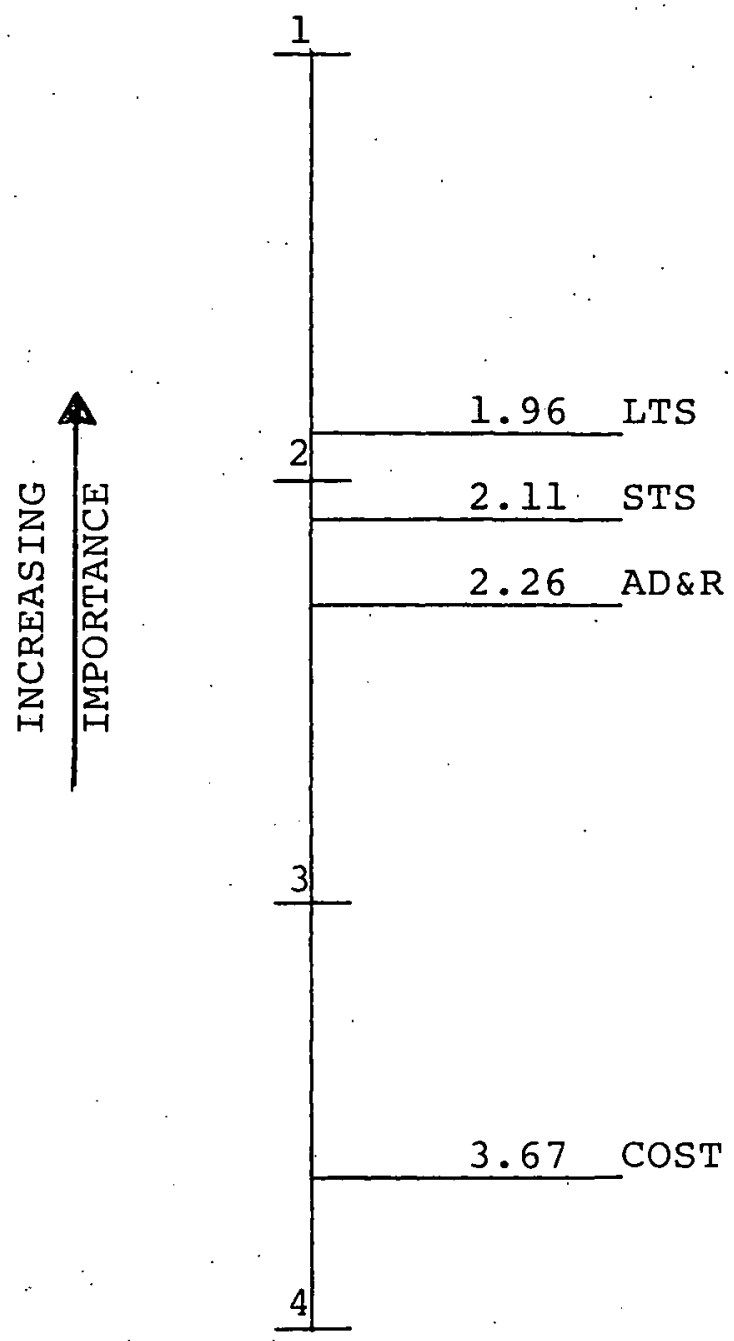


four factors. Figure 1 however, does not reflect the variation of responses within the total sample; for example, the average value of 3.67 for Cost indicates that some respondents assigned it a higher value than "4".

The way that the four factors were ranked by the total sample of respondents is shown in Figure 2. The four factors are presented on the horizontal axis, and the vertical axis shows the percentage of respondents who assigned each factor a given rank. The number of respondents assigning each factor the rank of $1,2,3$ or 4 is shown above the darkened vertical bars. Considering Short-Term Safety, responses for the total sample were fairly evenly distributed across the ranks of 1,2 and 3 . Less than 10 percent $(N=33)$ of the sample felt that Short-Term Safety was "Least Important". Long-Term Safety was ranked first in importance by nearly half the total sample, but the vertical bars also indicate that it received a rank of " 2 " and " 3 " a considerable number of times. Like Short-Term Safety, Long-Term Safety was seen as least important by about 10 percent of the sample. Cost was seen as least important by roughly 80 percent of the total sample, and only two percent felt it should be most important. Finally, Accident Detection and Recovery was seen as most important by about 20 percent of the sample. This factor was ranked second and third in importance by roughly equal percentages of the sample (35\%).

To summarize, Long-Term Safety was generally seen as the most important of the four factors. Arrnss the total sample, there was considerable variation as to the relative importance which should be attached to Short-Term Safety and Accident Detection and Recovery. There were significant numbers of respondents who saw LTS, STS and ADR as requiring the highest priority. Although the differences among LTS, STS, ADR are statistically significant, it is not obvious 
FIGURE 2

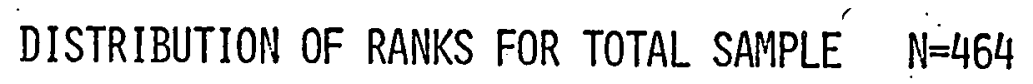

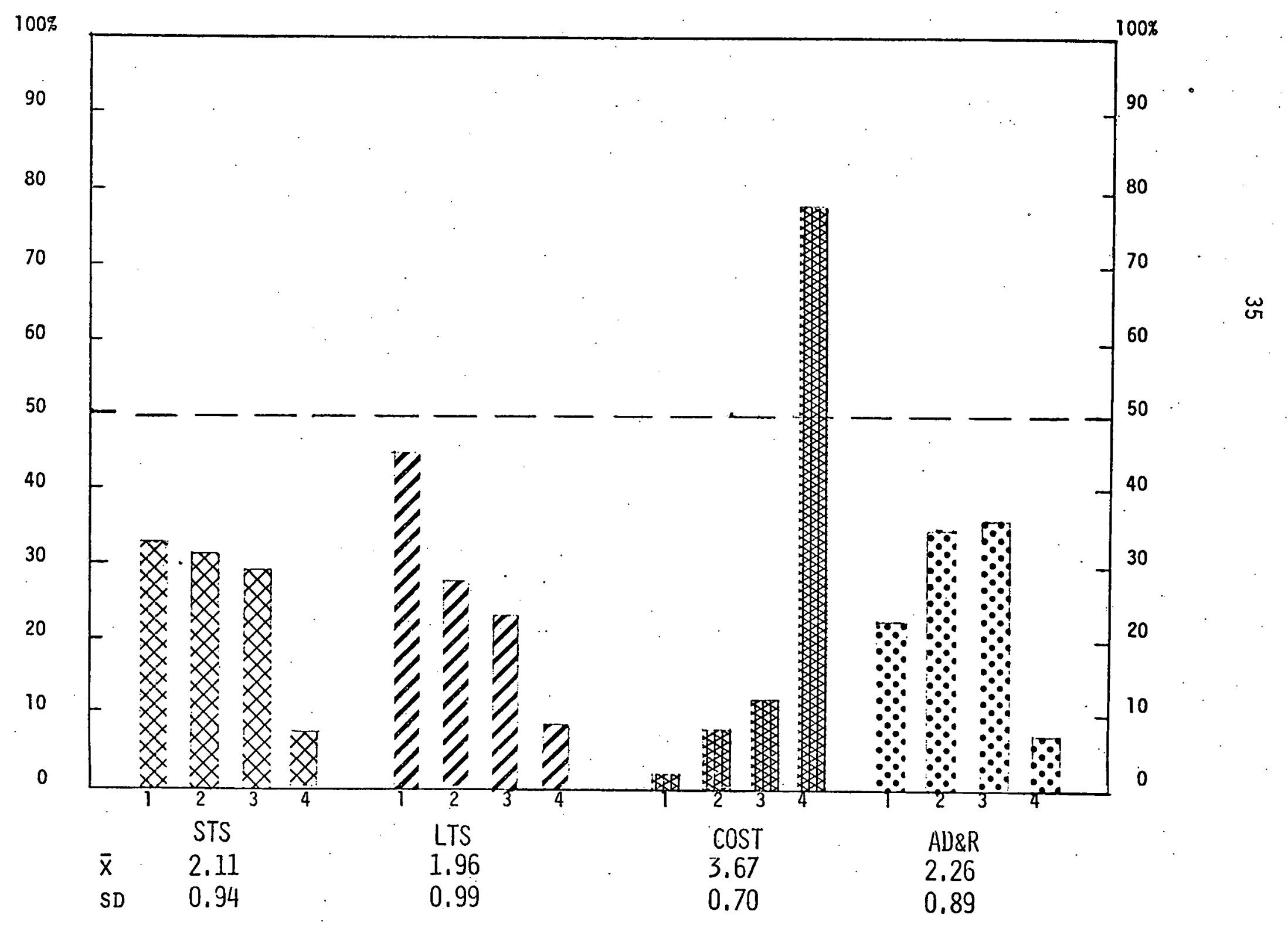


that these averaged relative ranks differ from one another in a practical sense. The results of the ranking procedure do indicate that cost was perceived as distinctly less important than the other three factors. The difference between cost and the other three factors was both statistically and practically significant.

Average rankings of the four factors by each of the six clusters of respondents are shown in Figure 3. By scanning across the six groups of respondents, one can see that LTS, STS, and ADR all tended to receive considerable emphasis while cost was seen as much less important. Long-Term Safety had the highest average rank for five of the six respondent groups. The cluster of Nuclear Technologists, by contrast, placed higher emphasis on Short-Term Safety. The average rank assigned to Cost was quite low for these same five groups of respondents. While the average rank for cost for the Nuclear Technologists was also below that of the other three factors, this group placed more relative emphasis on Cost than did the other five respondent groups. Applying the standard of statistical significance, the average ranks for Cost were significantly different from the other factors for all six clusters. Comparing among the average ranks for STS, LTS and ADR, a few points are noteworthy. First, the Environmentalists attached the greatest emphasis to Long-Term Safety, while the Nuclear Technologists attached greater cmphasis to Short-Tarm Safety. The nther gap between importance estimates was revealed by the rank orderings for the Junior High and High School Students group; for this group, STS received somewhat less emphas is than LTS or ADR. For the remaining three respondent groups, the average ranks for the factors STS, LTS, and ADR were quite close together; all three of these factors were given considerable emphasis as reflected in the average ranks. 
FIGURE 3

AVERAGE RANKINGS FOR SIX RESPONDENT CLUSTERS

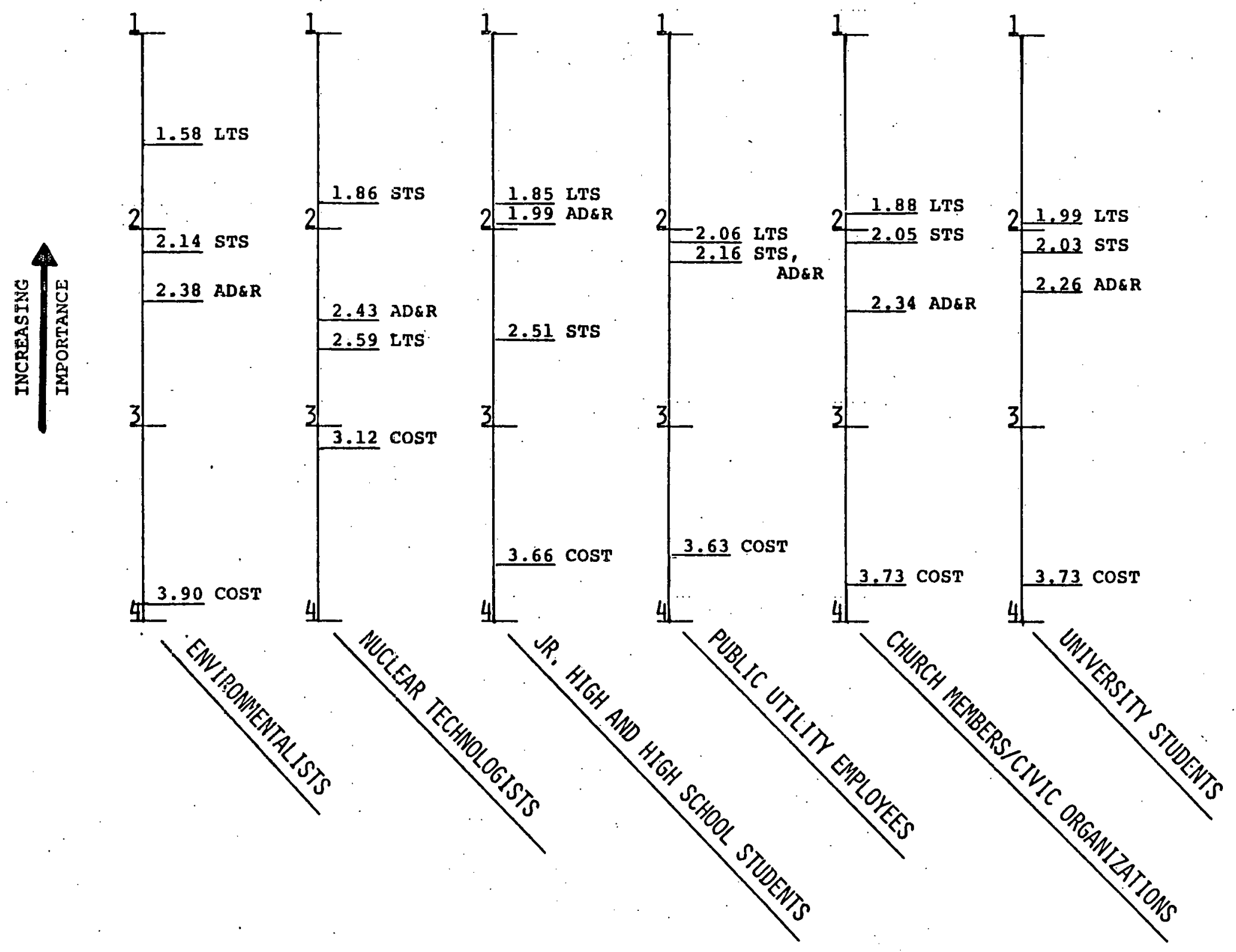


As in the case of the average ranks for the total sample, the average ranks shown in Figure 3 do not present the full picture of how respondents evaluated the four factors. Specifically, individual variation within each group tends to be masked somewhat by the use of summary measures such as the mean. Accordingly, Figures 4-9 show the number and percent of respondents' rankings of the four factors.

As shown by Figure 4, the Environmentalists strongly endorsed cost as the least important factor; over 90 percent of this group ranked cost as fourth in importance. About 60 percent of this group felt that Long-Term Safety was most important and another 30 percent felt it was second most important. Rankings for the other two factors by this group were more evenly distributed over the first, second and third in importance.

In Figure 5, the Nuclear Technologists varied considerably in their rankings of the four factors. This variation is seen to some extent in that none of the factors was assigned a given rank by 50 percent or more of this group.

Figure 6 indicates that the majority of the Ir. High/High School students attached the least importance to cost, and more than half of this group felt that Long-Term Safety should be first in importance. Rankings for the other two factors tended to be somewhat more evenly distributed.

Approximately three-fourths of the Public Utilities Employees (Figure 7) attached the least importance to Cost. Their evaluations of the other three factors tended to be more eveniy distributed across the first three ranks.

In Figures 8 and 9, the Church/Civic Organization Members and the University Students show similar patterns of rankings for the four factors. The majority of these respondents placed cost in fourth place. Considerable numbers of respondents felt that Long-Term Safety and Short-Term Safety 
FIGURE 4

DISTRIBUTION OF RANKS FOR ENVIRONMENTALISTS $N=69$

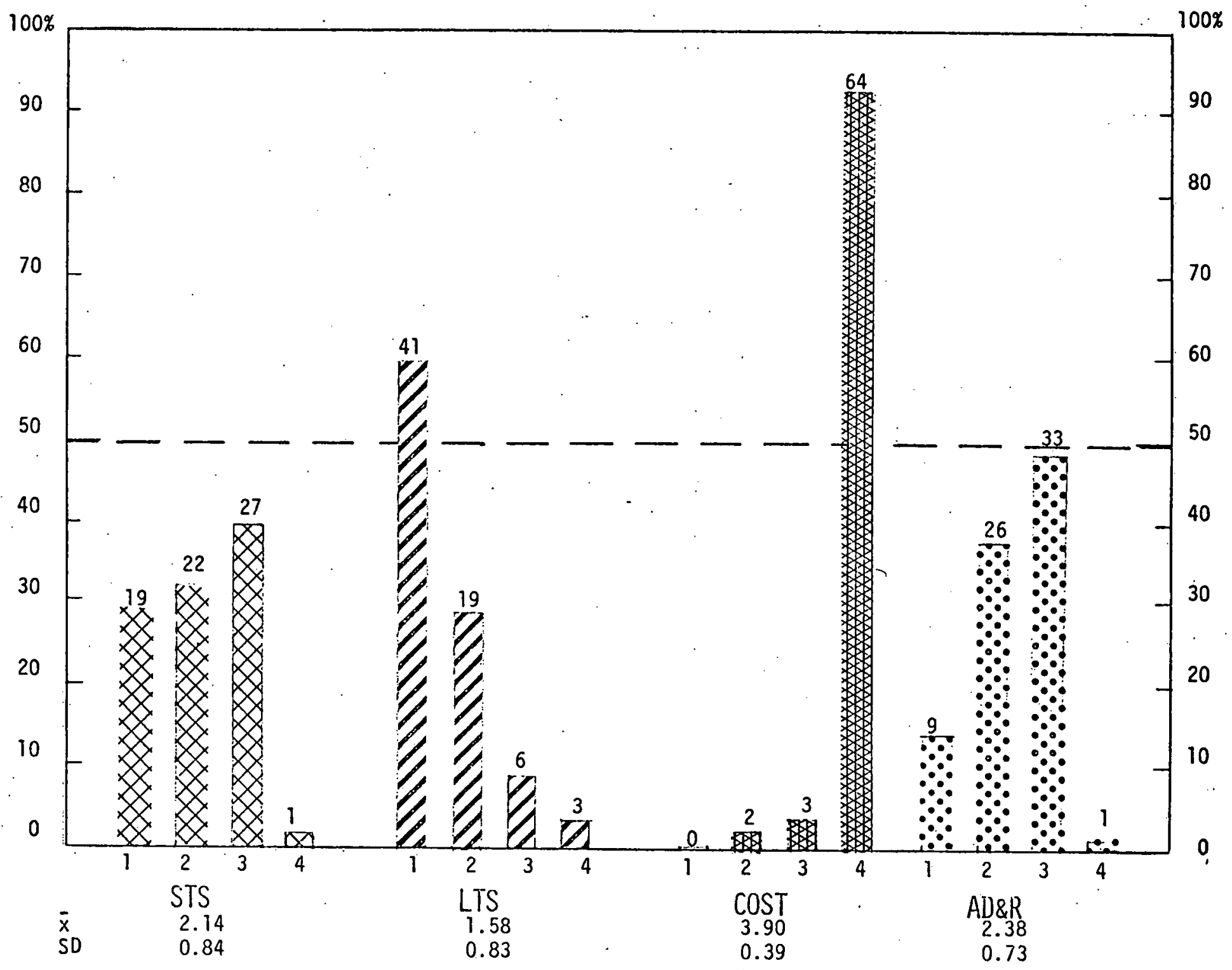


FIGURE 5 .

DISTRIBUTION GF RANKS FOR NUCLEAR TECHNOLCGISTS $N=51$

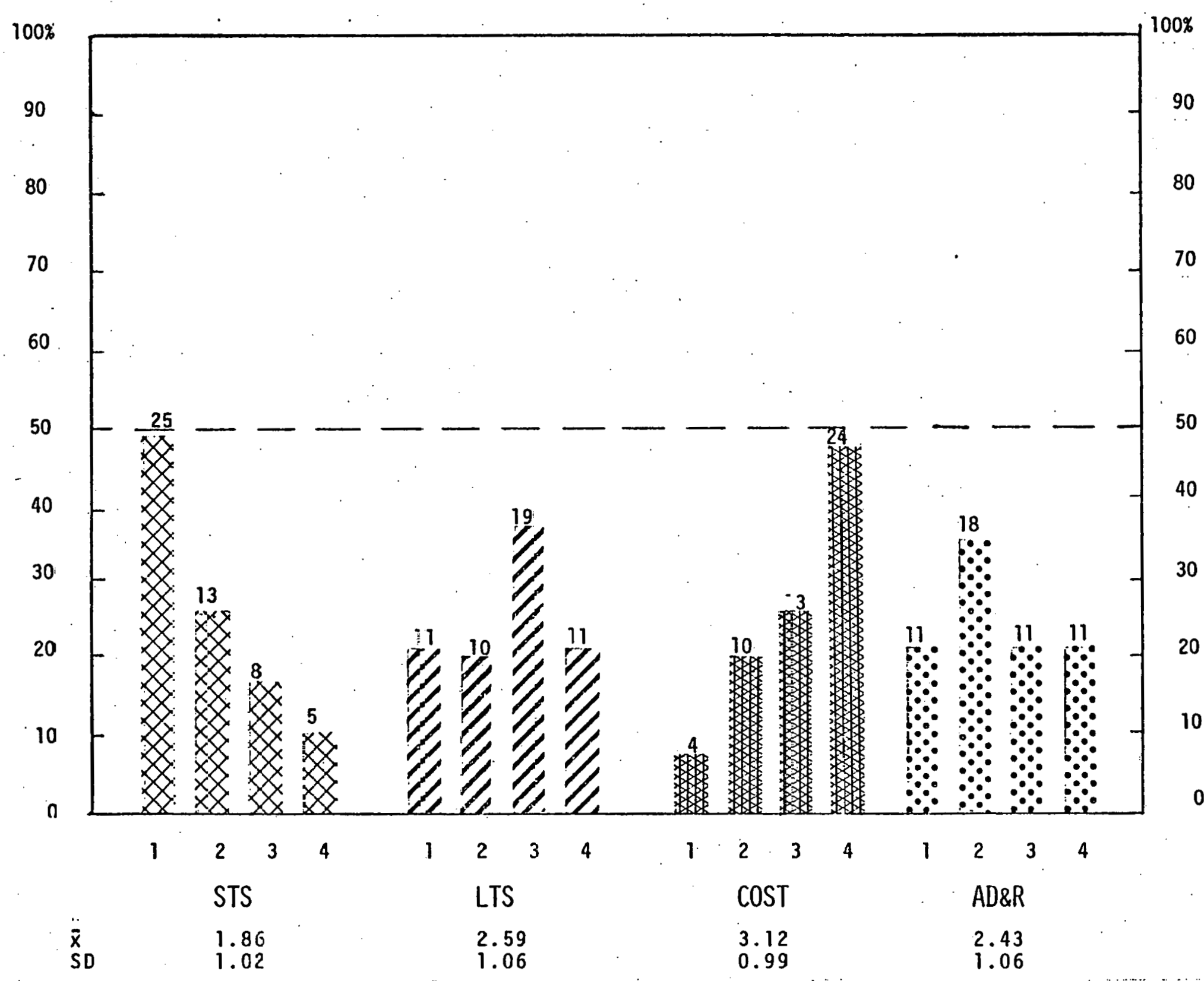


FIGURE 6

DISTRIBUTION OF RANKS FOR JR. HIGH AND HIGH SCHOOL STUDENTS N=67

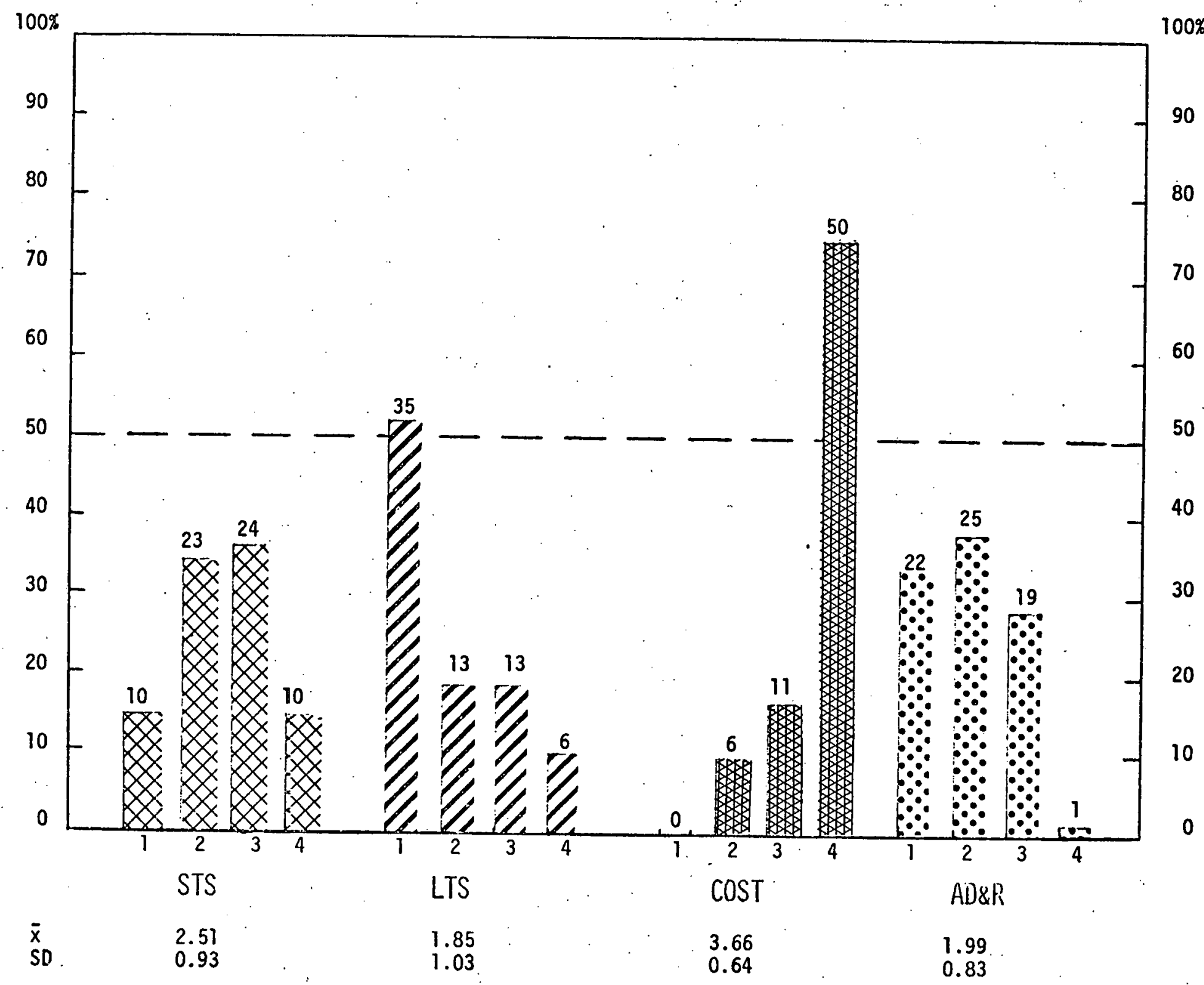


FIGURE 7

DISTRIBUTION OF RANKS FOR PUBLIC UTILITY EMPLOYEES $\quad N=32$

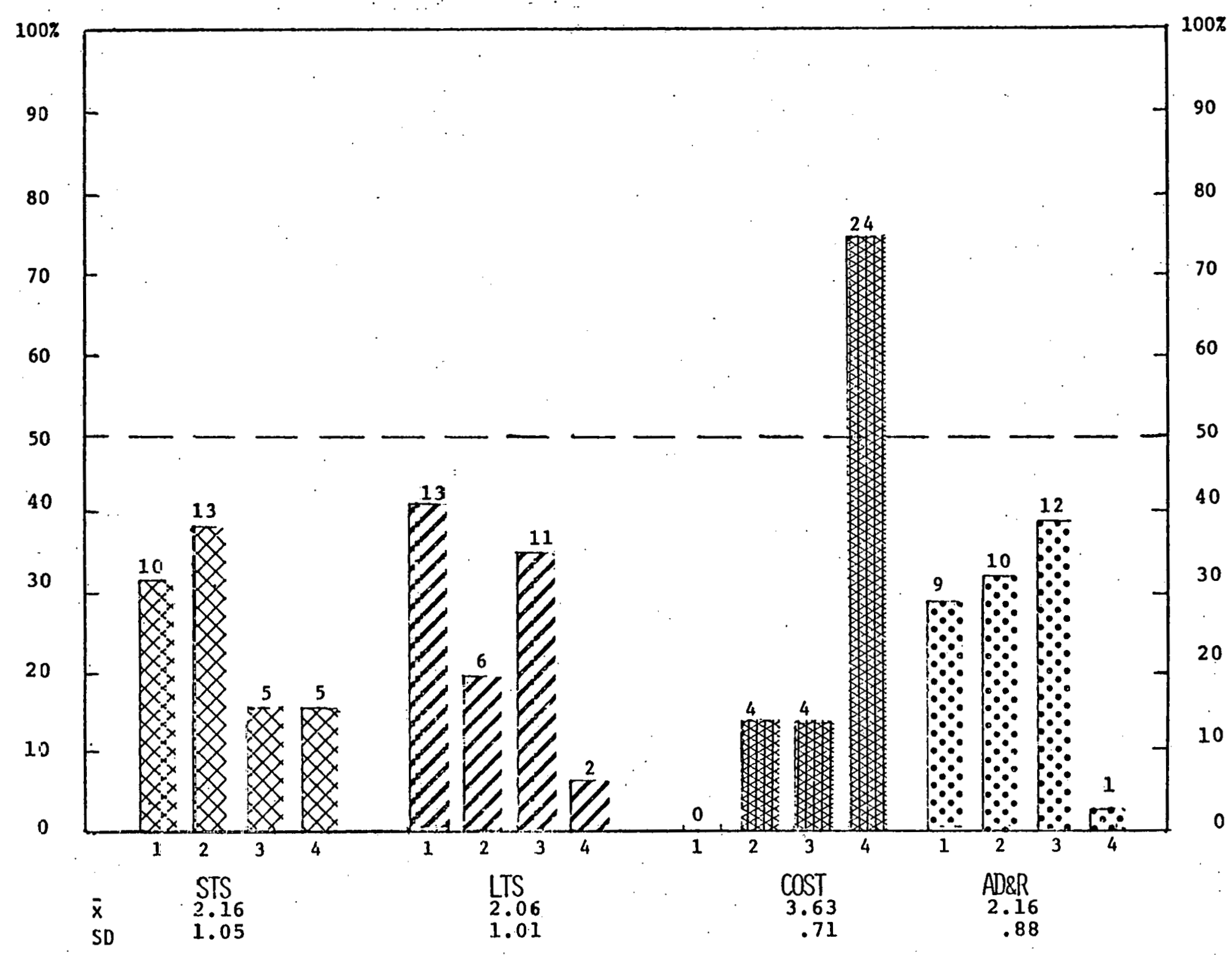


FIGURE 8

DISTRIBUTION OF RANKS FOR CHURCH MEMBERS/CIVIC ORGANIZATIONS $N=82$

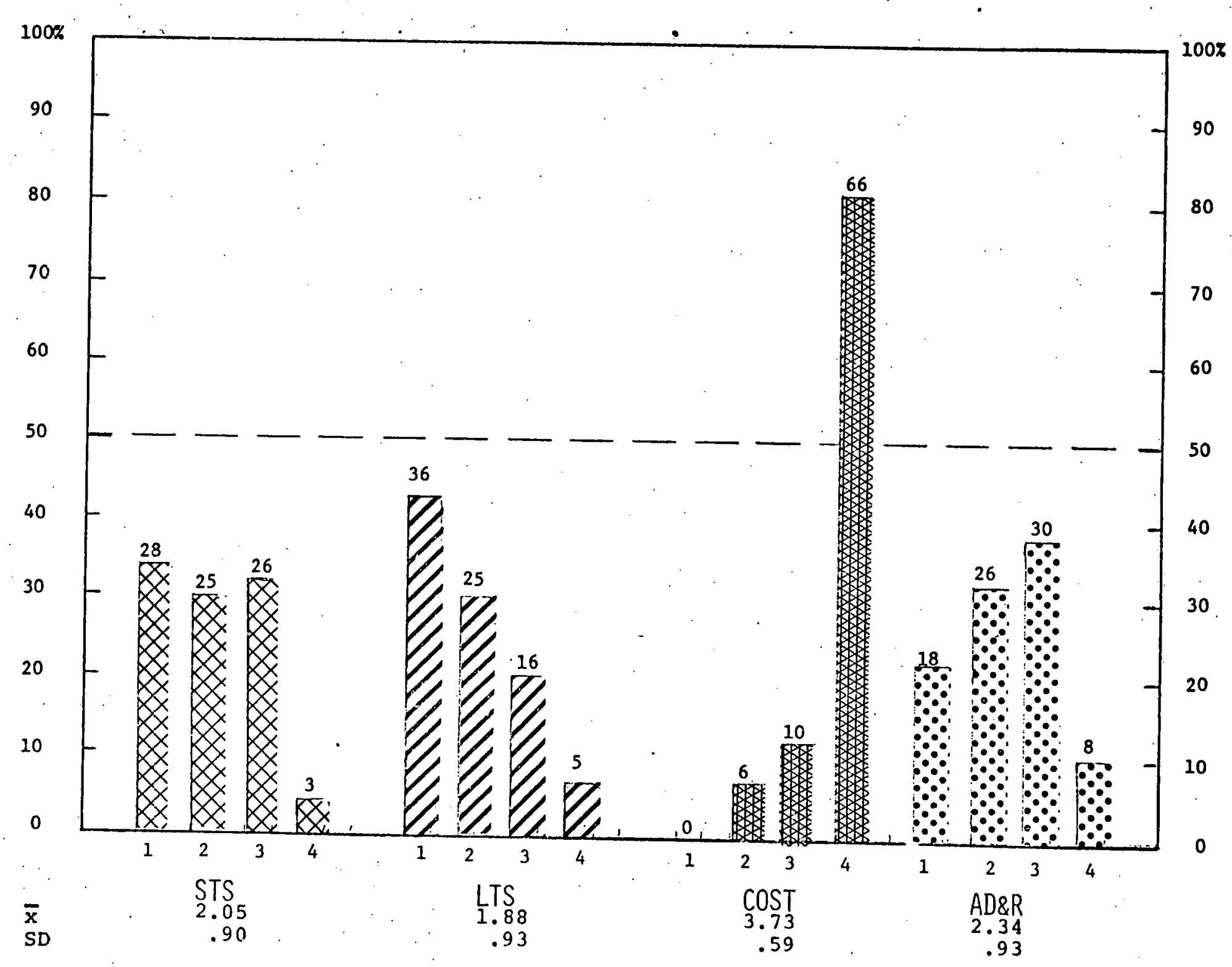


FIGURE 9

DISTRIBUTION OF RANKS FOR UNIVERSITY STUDENTS $\quad N=164$

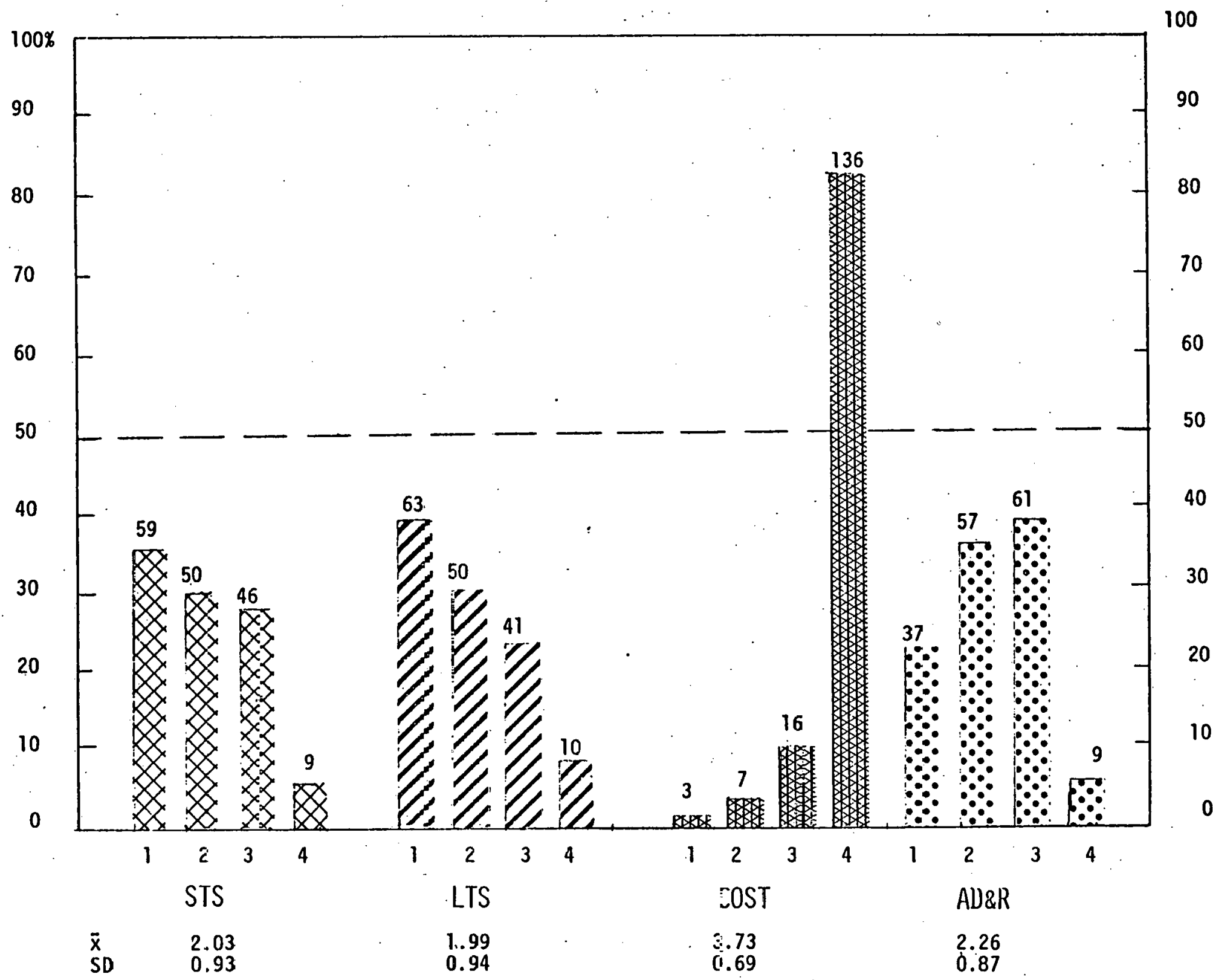


should receive first priority. Accident Detection and Recovery was ranked second and third in importance by large numbers of these respondents. Finally, Long-Term Safety received somewhat more emphasis than the other factors.

2) The ratio estimation procedure (Part II of the questionnaire) was the second method of obtaining importance estimates for the four waste disposal factors. In this task, respondents were asked to carry the ranking procedure a step further and to indicate the distance or interval which existed between each of the four factors with respect to importance. These distances were obtained by having respondents make pair-wise comparisons between the factors they ranked first versus second in importance, second versus third in importance, and third versus fourth in importance. The number 100 was arbitrarity assigned to the first factor of each pair, and the respondent was then asked to assign a number between 0 and 100 to the second factor of the pair to indicate its relative importance to the first factor. These paired comparisons were then used to generate ratio scales for each respondent. The computational procedures for obtaining these interval scales were described in Chapter 2. This procedure yielded four scale values for each respondent. These values fall on a scale from 0 to 100 . This scale is a ratio scale and the scores may be interpreted accordingly, e.g., a scale value of 80 for a factor indicates that factor is judged to be twice as important as a factor with a scale value of 40 . These ratio scores were then averaged for each group of respondents and for the total sample.

The average ratio estimates of importance for the total sample of respondents are shown in Figure 10. Long-Term Safety received the highest score (85), but was followed very closely by Short-Term Safety, and Accident Detection 
FIGURE 10

AVERAGE RATIO ESTIMATES OF IMPORTANCE

FOR TOTAL RESPONDENT SAMPLE

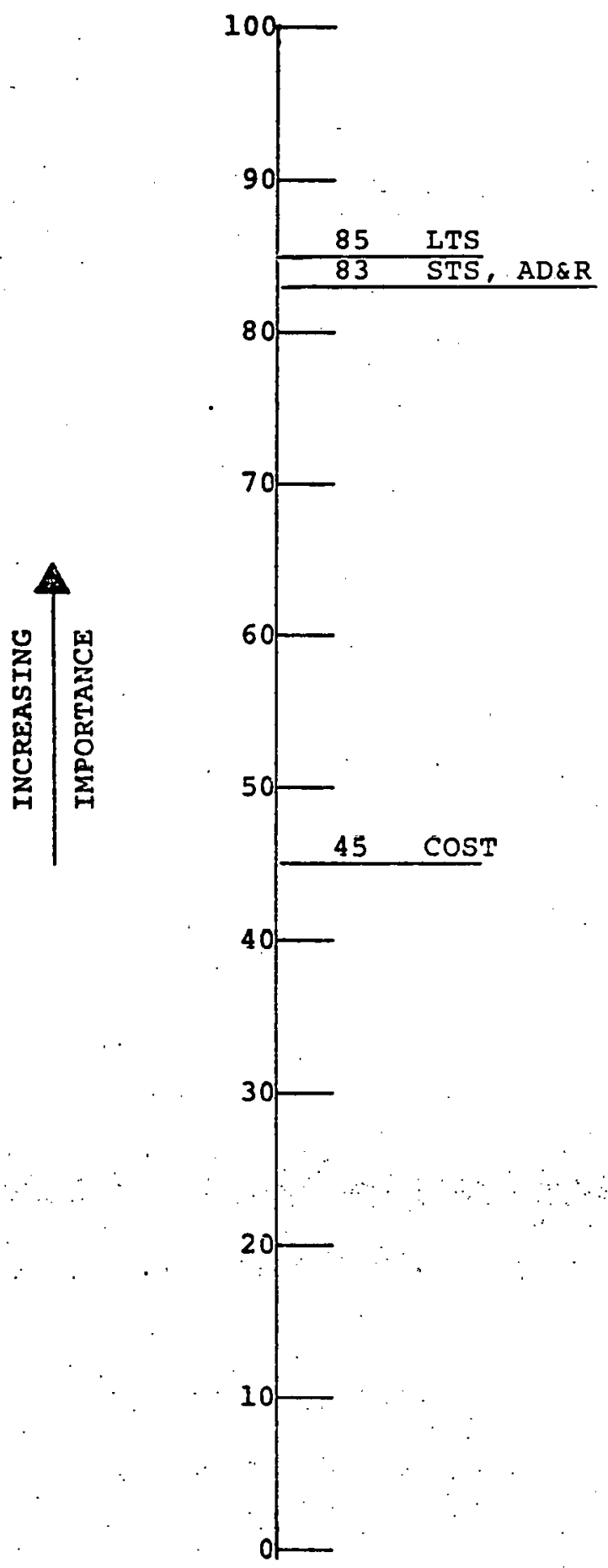


and Recovery, which both received values of 83 . Cost received a value of 45 , just over half the values for the other three factors. From a statistical and practical standpoint, cost was seen as less important than the other three factors. The other three factors do not differ appreciably from one another.

The average ratio estimates of importance for each of the six respondent clusters are presented in Figure 11. Cost was again seen by all respondents groups as less important than the other three factors. Two of the respondent groups, Nuclear Technologists and Public Utility Employees, placed somewhat more emphasis upon cost than did the other four respondent groups. All respondent groups tended to attach considerable importance to the factors Short-Term Safety, Long-Term Safety and Accident Detection and Recovery. The mean ratio scores for these three factors were quite close together for four respondent groups, Environmentalists, Public Utility Employees, Church/Civic Organizations, and University Students. The differences among the three factors for these four groups are probably not significantly different from a practical standpoint. On the other hand, the Nuclear Technologists, while attaching considerable importance to all four factors, placed much more importance on Short-Term Safety. The Jr. High/High School Students attached somewhat less importance to Short-Term Safety than they did to Long-Term Safety or Accident Detection and Recovery. As a rough guide for comparing the importance of the factors within each respondent group, or for making comparisons among different groups of respondents, a scale unit difference of 8 is usually significant from a statistical standpoint.

3) Multi-regression/policy capturing. The third procedure for obtaining importance estimates was based on a wholly different measurement methodology in comparison to the previous two procedures. In the third approach, rather 
FIGURE 11

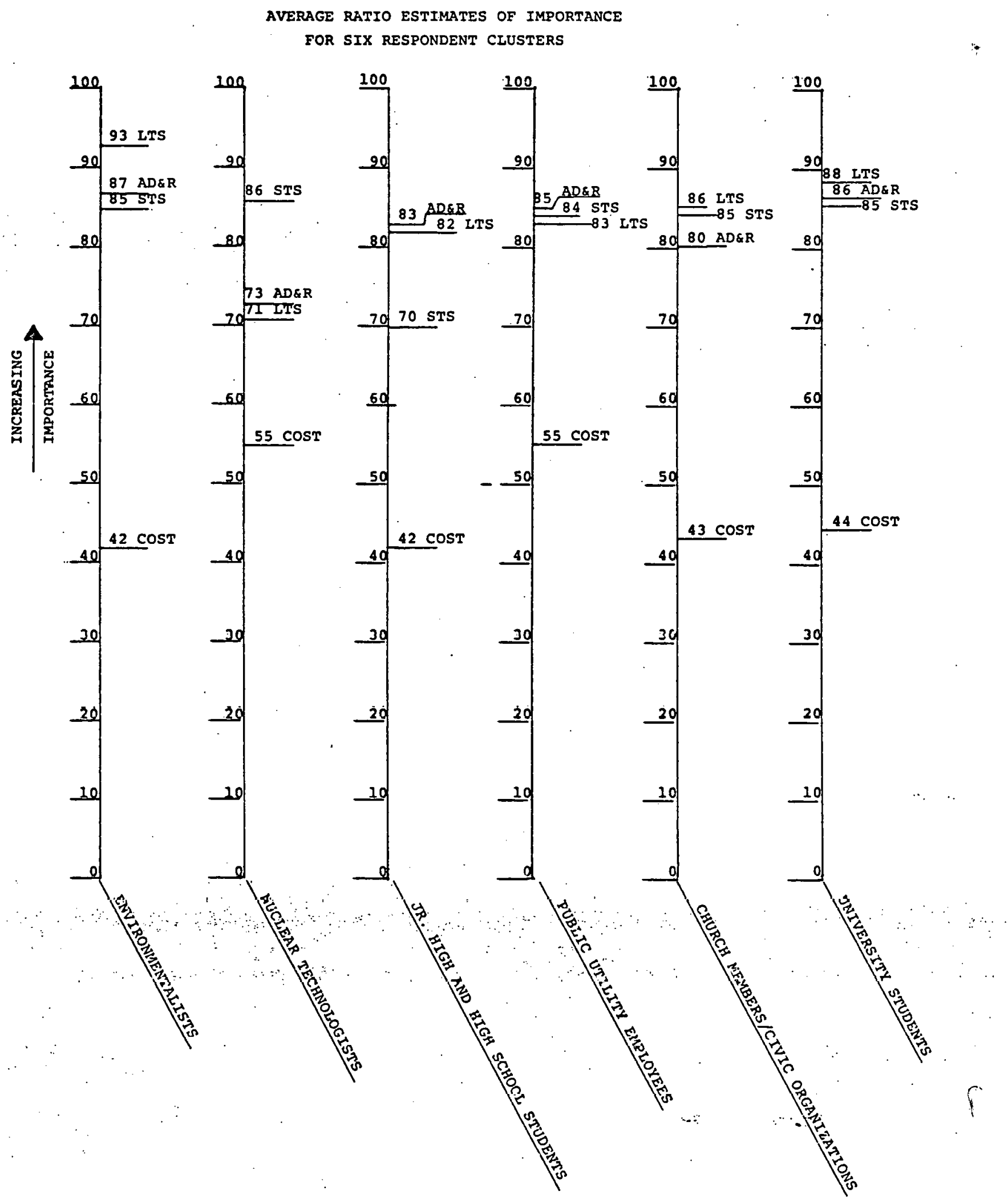


than directly asking respondents to indicate their relative priorities among the four factors, the measurement model generated importance estimates based on the respondents' judgments about a series of hypothetical waste disposal designs. These designs differed from one another in the extent to which each of the four waste disposal factors was present. The manner in which a respondent judged the acceptability of 27 hypothetical disposal designs was used as the basis for determining the extent to which each factor influenced the respondent's overall judgments. A multiple regression analysis procedure (Kerlinger \& Pedhazur, 1973) yielded a regression weight for each of the four factors. This regression weight indicates the extent to which the respondent's judgments were influenced by each factor. These regression weights varied on a scale from 0.00 to 1.00 . Regression weights for each individual were transformed using Fisher's $r$ to $z$ technique (DuBois, 1965) and then used to compute group means.

Average regression weights for the total sample of respondents are shown in Figure 12. For the total sample of respondents, Long-Term Safety emerged as the most important factor, followed rather closely by Accident Detection and Recovery and Short-Term Safety. The low average regression weight for Cost indicates that respondents paid relatively little attention to this factor as they judged the 27 hypothetical waste disposal designs. In other words, Cost was of little importance in judging the acceptability of a design. More will be said later about the location of the weights for the four factors in the lower half of the 0.00 to 1.00 scale. In general, the results shown in Figure 12 suggest that the factor, Long-Term Safety, had the largest impact upon respondents' evaluations of waste disposal methods. Accident Detection and Recovery and Short-Term Safety were also fairly influential in determining 
FIGURE 12

AVERAGE MULTIPLE REGRESSION WEIGHTS. FOR TOTAL RESPONDENT SAMPLE

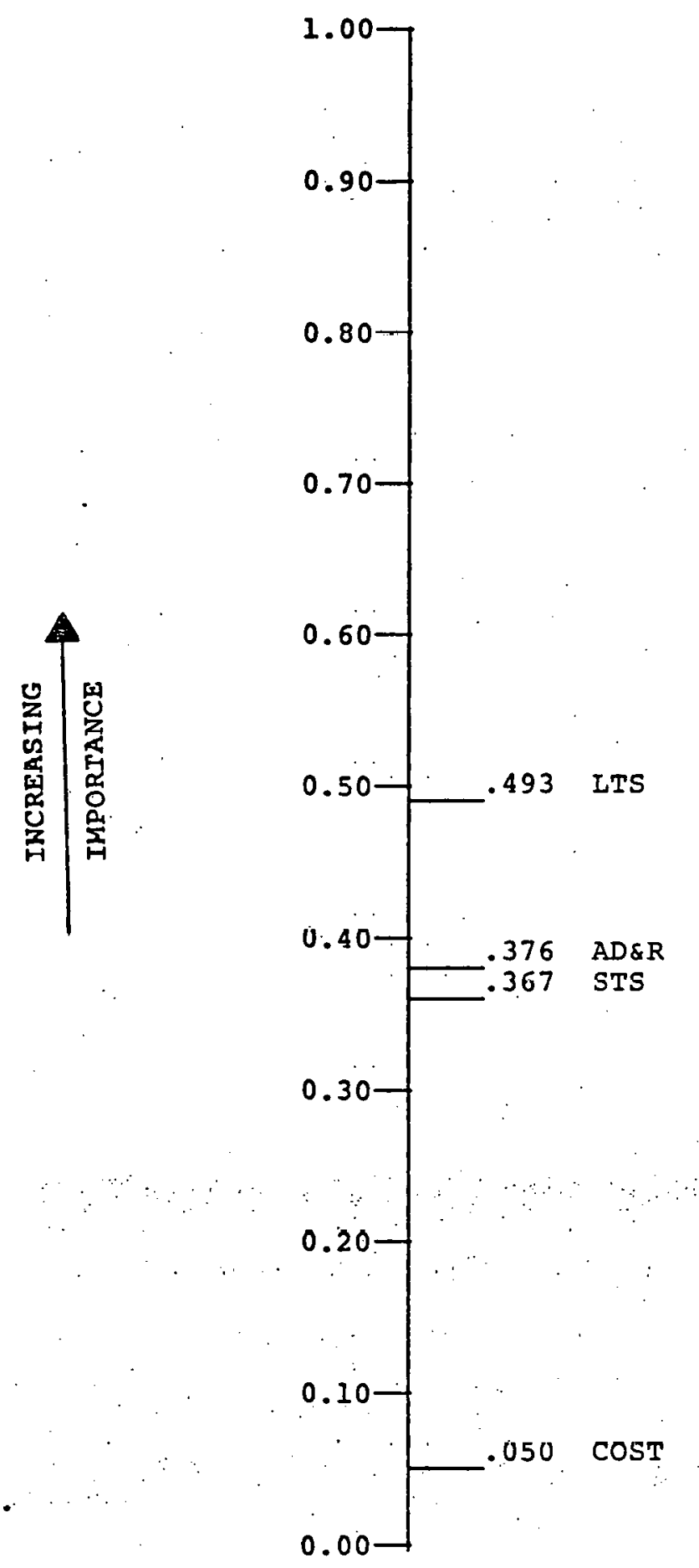


the way in which respondents judged the disposal methods. For the total sample of respondents, cost played a minor, if not insignificant, role in the respondents' judgments.

Average regression weights for each of the six respondent groups are presented in Figure 13. For all six respondent groups, the weights for cost are relatively insignificant. Long-Term Safety was the most influential factor for four of the six groups. The Environmentalists, in particular, paid considerable attention to this factor in making their judgments. By scanning across Figure 13, it is clear that all waste disposal factors except cost were important in the minds of respondents. One departure from this trend was the relatively minor weight attached to Short-Term Safety by the Jr. High/High School Students.

Another trend appearing in Figure 13 was the tendency for three of the waste disposal factors (STS, LTS, ADR) to be rather close together in their relative weights. The major exception to this clustering tendency was the greater weight which the Environmentalists attached to Long-Term Safety.

Agreement Among Measurement Methods

One of the major objectives of this research was to obtain indices of the importance or priority which people attached to four issues associated with nuclear waste disposal. In evaluating the results of value and attitude research, questions are generally asked about the validity of the measuring instruments. The approach used in this study for gauging the validity of the results was to use multiple, independent measurement procedures. To the extent that different measurement methods produced similar results, confidence in the validity and fidelity of the measurement procedures would be increased. 
FIGURE 13

AVERAGE MUITIPLE REGRESSION WEIGHTS

FOR SIX RESPONDENTS CIUSTERS

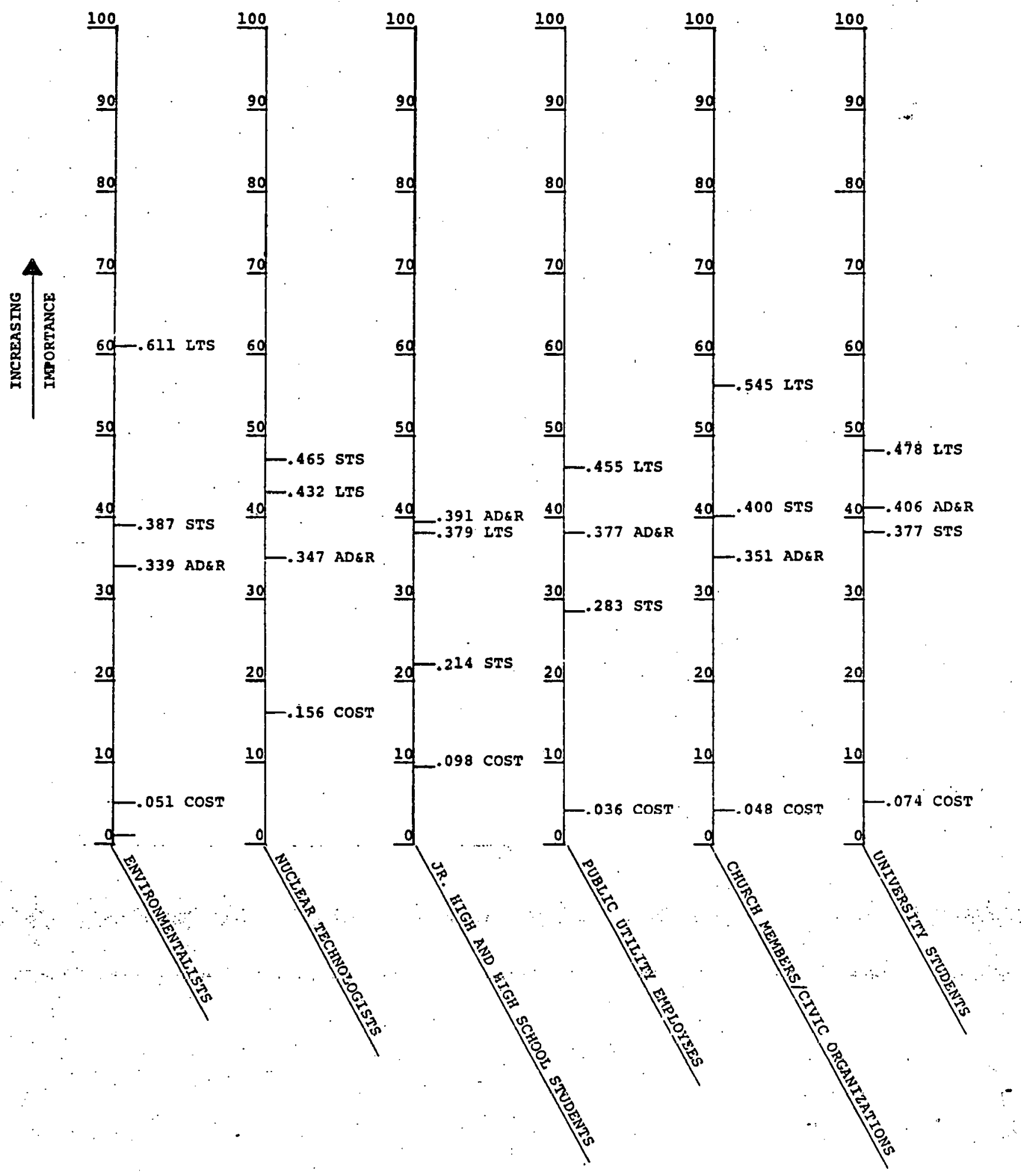


Two types of information are presented which bear on the question of agreement among methods. The first source of information deals with agreement among methods using averaged data for the entire study sample. The second source of validity information is based on the extent to which the individual respondents in the study sample had similar results across the different methods.

The average importance estimates from the three measurement procedures for the total respondent sample are shown in Figure 14. For all three methods, Long-Term Safety was most important and Cost was least important. The factors LTS, STS, ADR were all seen as relatively important in all three methods, and there were no appreciable differences in importance for these factors although LTS received somewhat more emphasis using the multiple regression procedure.

In comparing the location of the average scores on the scales for each method, it is necessary to review the respondent's task in each method. In the ranking procedure, the respondent was simply asked to arrange the four factors in order of importance, making no allowance for possible interval differences between them. This represents a fairly constrained task with respect to the respondent's placement of the four factors. For example, once a person has rank-ordered the top three factors, the remaining factor automatically is relegated to fourth place. By comparison, the ratio estimation procedure allowed respondents considerably more freedom in judging the importance to be attached to each factor. The respondent was able to specify the actual intervals which should exist among the factors. Using this procedure, it is interesting to note that the factor, cost, received considerably more emphasis. 
FIGURE 14

COMPARISON OF

AVERAGE IMPORTANCE ESTIMATES

FROM THREE MEASUREMENT:. METHODS

(TOTAL SAMPLE)

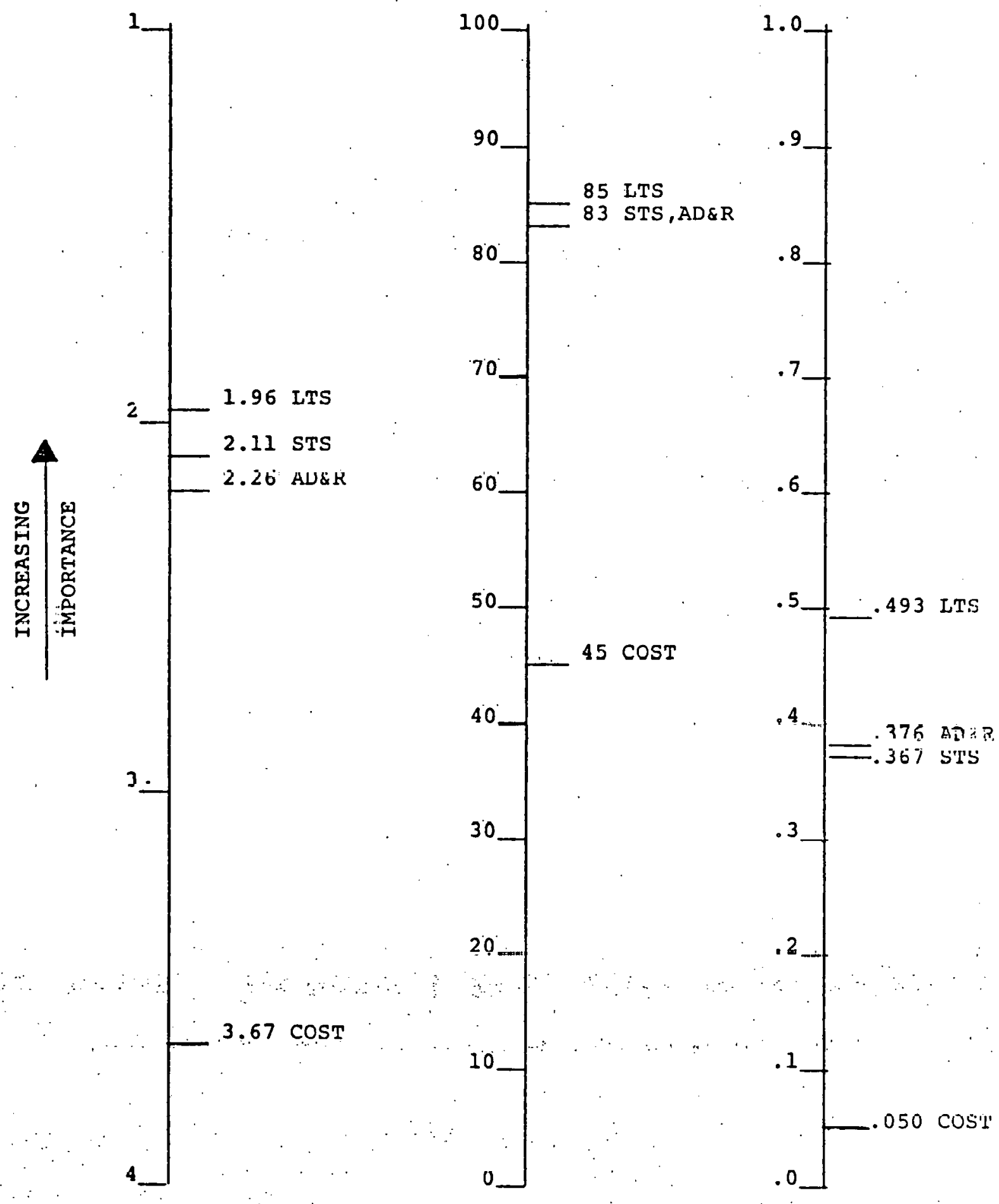


The multiple regression or "policy capturing" procedure constituted a totally different task than either the ranking or ratio estimation procedure. Here, the respondent was asked to judge the acceptability of several hypothetical disposal methods using information about each method's standing on the four factors. The judgment task then, was to combine four pieces of information (scores for the four waste disposal factors) and to make an overall judgment about the acceptability of each disposal system. The results shown in Figure 14 reflect the way in which information about each waste disposal factor was used in making these judgments. Three of the four factors were important in shaping the respondents' judgments. The fourth, cost, appeared to have negligible impact. There are two possible explanations for the low weight attached to cost. First, respondents may have felt that cost was truly unimportant and simply excluded this factor from consideration as they evaluated each of the hypothetical disposal methods. Or, in formulating their judgment "policies", respondents may have found it helpful or necessary to pay minimal attention to one or two of the factors and concentrate instead on the way each waste disposal method stood with respect to the two or three factors they considered of greatest importance. Examination of Part IV of the questionnaire (Appendix A) may be heipful in better understanding the judgment task.

Another approach to evaluating measurement validity is based on all of the intercorrelations resulting from the measurement of each of the four factors by each of the measurement procedures. These intercorrelations, which are indices of the agreement or the strength of relationship between any two variables, are based on each respondent's judgments of importance of the four factors as measured by the three methods. Table 3 presents all the intercorrelations among factors and methods. 
TABLE 3

INTER-CORRELATIONS AMGNG METHODS FOR MEASURING IMPORTANCE

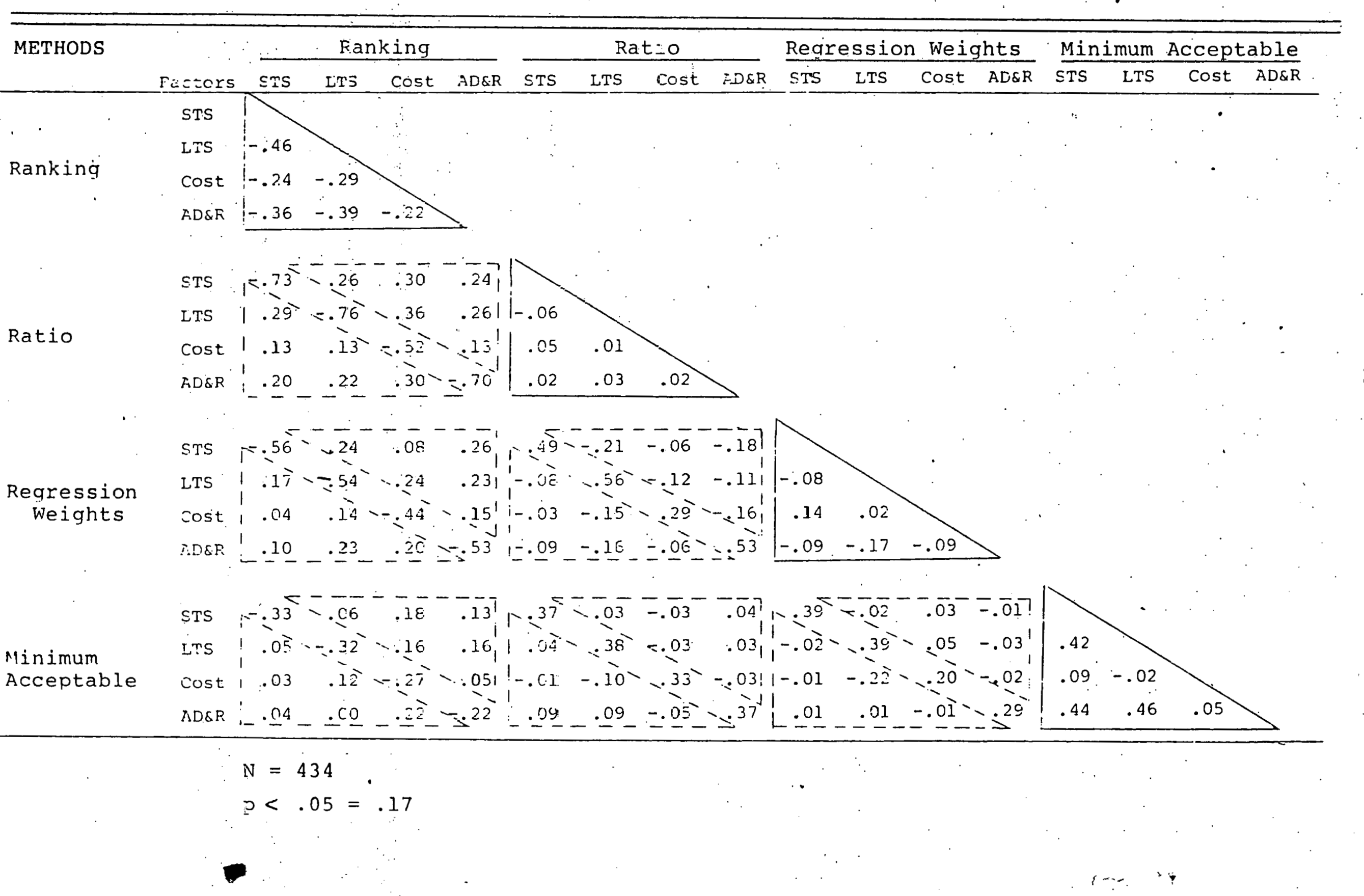


It should be noted that Table 3 , in addition to presenting information for the ranking, ratio estimation, and regression weight methods for measuring importance, shows information about a fourth method for measuring importance. In Table 3, this fourth method is labeled "Minimum Acceptable". A subtask in Part IV of the questionnaire asked respondents to sketch their own conceptions of how the four factors contributed to waste disposal designs. They were asked to sketch three designs: one which they felt would be "most ideal", a design which would just meet their "minimum standards for acceptability", and a design which they felt was "most likely" to be implemented. Respondents' scores for their Minimum Acceptable method were included in the calculations for Table 3 as a fourth possible method for assessing importance. The word "importance" was not used in the instructions to respondents, and consequently this method constituted an indirect measure: The assumption behind this method was that respondents who set higher "minimum standards" for a factor were in effect stating that the factor was important to them. Inferences might then be drawn about the relative importance of each of the four factors by comparing the minimum standards set for each.

Two general types of validity information are contained in Table 3: convergent validity and discriminant validity. Convergent validity is established when it can be shown that independent measurement procedures show high agreement among one another with respect to the measurement of a given set of factors. (Some evidence for convergent validity of the measurement methods is presented in Figure 14, where it is shown that three measurement procedures produce somewhat similar results in the average importance estimates for the total respondent sample.) 
Further evidence for convergent validity is presented in Table 3. Correlations in the diagonals which are not bounded by either solid or dotted triangles provide information to test for convergent validity. The test is simply that these values be significantly different from 0 ; for the respondent sample size used in this study, correlations greater than .17 are considered to be significantly greater than $0(p<.05)$. For example, the top, left-most validity diagonal shows the agreement between the ranking and ratio methods for the four factors (STS $=-.73$, LTS $=-.76$, Cost $=-.52$, ADR $=-.70$ ). A11 of these values are significantly different from 0 , and large enough to indicate convergent validity. (The negative relationship is due to the fact that "1" is a high rank, but a low ratio magnitude score.) In other words, the results from these two methods agree quite well. All six validity diagonals offer good evidence for convergent validity. To summarize, evidence for convergent validity is present since there is considerable agreement among the four methods with respect to the four factors.

The criteria for establishing discriminant validity are considerably more stringent than for convergent validity. Briefly, evidence for discriminant validity is present when it can be shown that more of the variation in the responses of the participant sample can be attributed to differences among the four factors than to differences or unique characteristics of the measurement methods.

Comparing each value in the validity diagonals with other correlations in its row and column provides a minimum test. That is, a factor should correlate with itself across two methods to a greater extent than with a different factor across two methods. In every instance but two, this condition is met. This is good evidence of discriminant validity. 
Another test for discriminant validity requires that the correlation between two methods measuring the same factor be greater than the correlation of two factors measured by the same method. For example, the correlation between ratio and ranking methods for STS is -.73 . This value is greater than the correlations of STS with the other factors for ranking $(-.46,-.24$, and -.36 in the top left solid triangle) and for ratio estimation $(-.02, .05, .02$ in the second to the top solid triangle). This test is met easily when only the ranking, ratio, and regression methods are considered, but the validity diagonals involving the Minimum Acceptable method failed to meet this test. This failure suggests that the correlation between different factors using the same method is greater than the correlation of the same factor using different methods, hardly a case for the validity of the factors. However, the Minimum Acceptable method is not really a measure of importance in the same sense as the other three methods. Recall that the respondents were asked to sketch the "minimum acceptable" level for the four factors. The non-zero validity diagonal values indicate that the method was measuring something related to importance, but that it was probably measuring something else as well.

By considering only the first three measures, ranking, ratio, and regression weights, there are strong indications of both convergent and discriminant validity for the four factors: STS, LTS, cost, ADR. The implications of these tests for validity are (1) the four factors were psychologically relevant and meaningful to respondents, (2) respondents were able to distinguish fairly well among the four factors, and (3) at least three of the measurement methods produced reasonably faithful portrayals of the relative importance the respondents attached to the four factors. 


\section{Evaluation of Levels of Risk and Cost}

In Part III of the questionnaire, respondents were asked to consider Short-Term and Long-Term Safety, Cost, and Accident Detection and Recovery, and to indicate how satisfactory several levels of risk and cost were to them. Instructions accompanying Part III defined risk and cost in the context of nuclear waste disposal; respondents were asked to judge those risks and costs they felt were satisfactory and those which were unsatisfactory in relation to the benefits from nuclear generated electricity.

Judgments of each level of each factor were made on 10-point scales, where "1" represented "Very Unsatisfactory" and "10" represented "Satisfactory". Satisfaction responses for each level of each factor were averaged, both for the total sample and for each of the six respondent clusters. Results are presented as profiles of average responses to the various levels of each factor. Figures 15 to 18 present summary profiles for the total sample of respondents.

In the instructions accompanying Short-Term Safety, levels of risk were expressed as number of fatalities per unit of time. The range of short-term risks from nuclear waste disposal were set within the context of National Safety Council statistics for accident and disease caused deaths in the U.S. These comparison risk levels are shown in Part III of the questionnaire (Apperidix A).

In Figure 15, average responses for Short-Term Safety are shown. The extent of rated satisfaction is depicted by the vertical axis and each of the risk levels is shown on the horizontal axis. The points connected by solid lines show the average satisfaction judgment for each level of risk. The points connected by broken lines above and below the solid line show the 
FIGURE 15

\section{SHORT-TERM SAFETY}

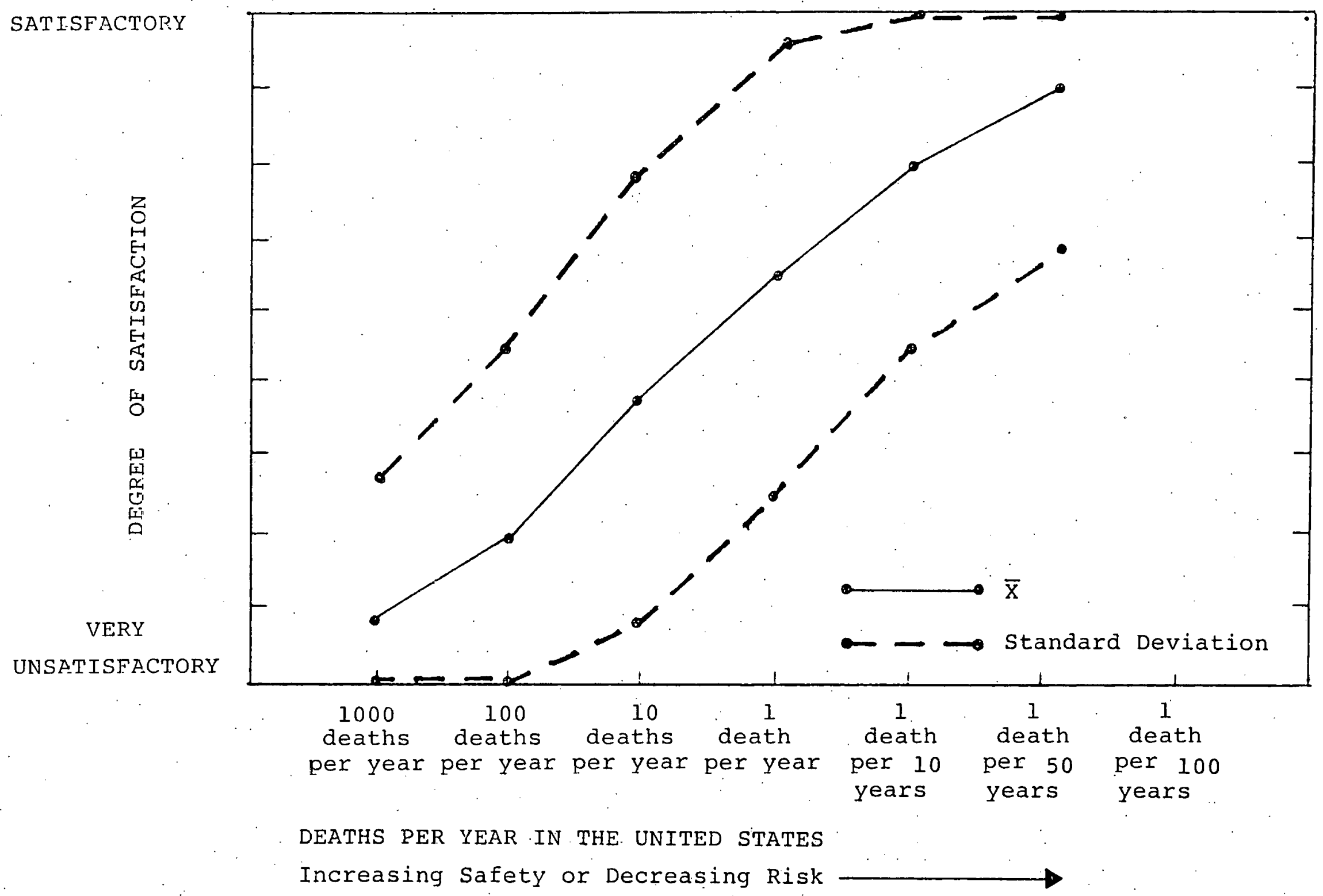




\section{LOI!G-TERM SAFETY}

\section{SATISFACTORY}

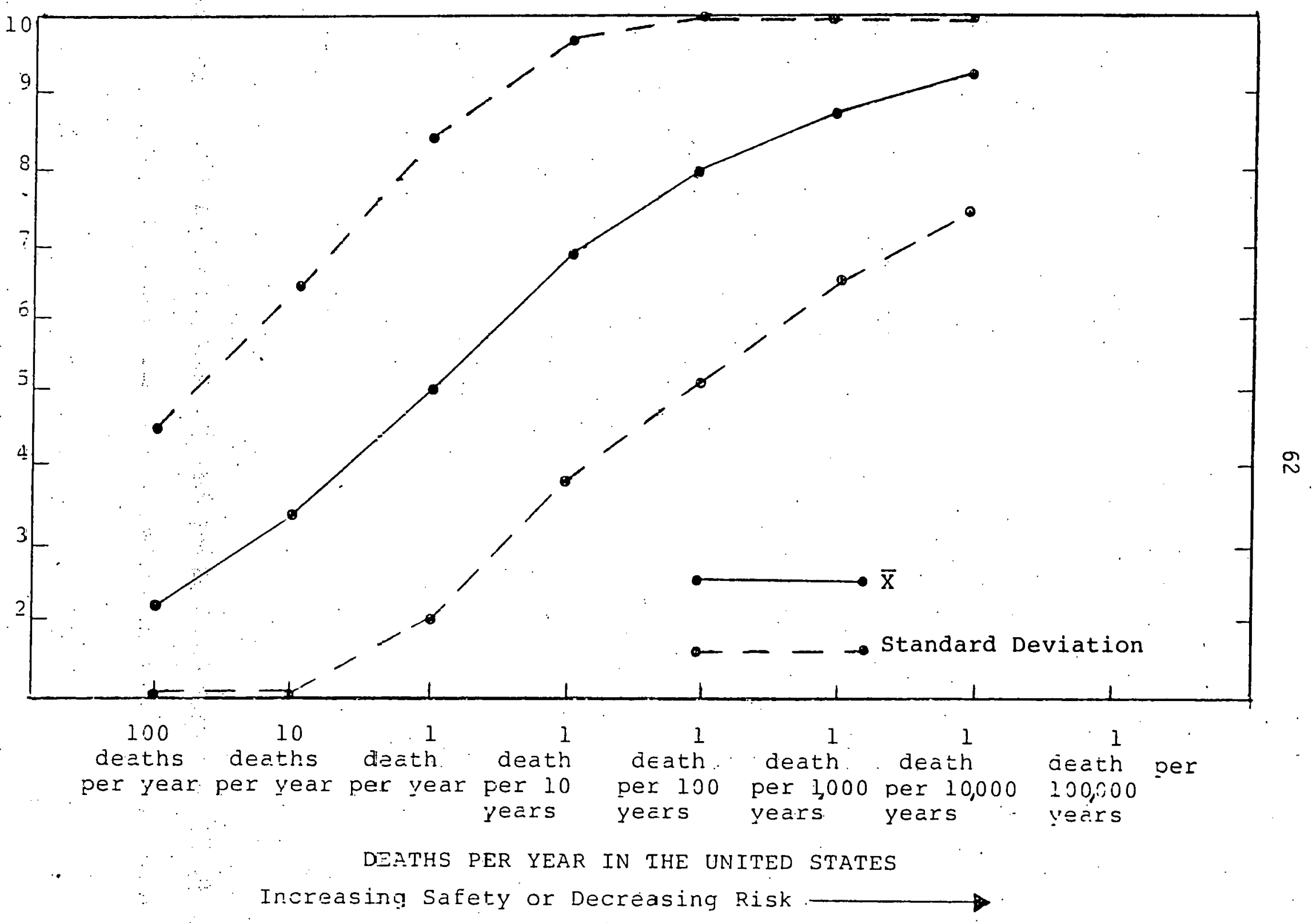


F IGURE 17

$\cos T$

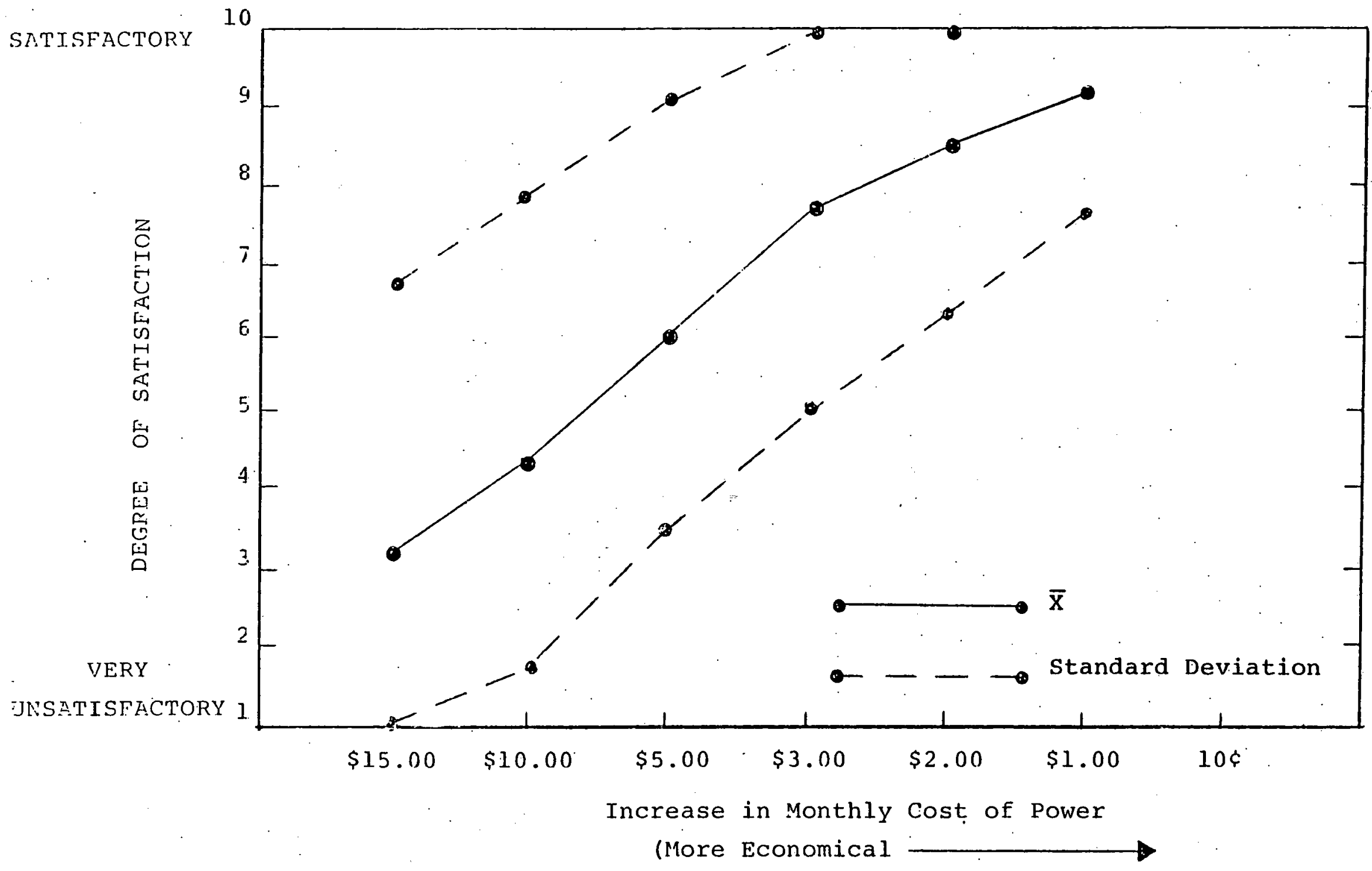


FIGURE 18

ACCIDENT DETECTION AND RECOVERY

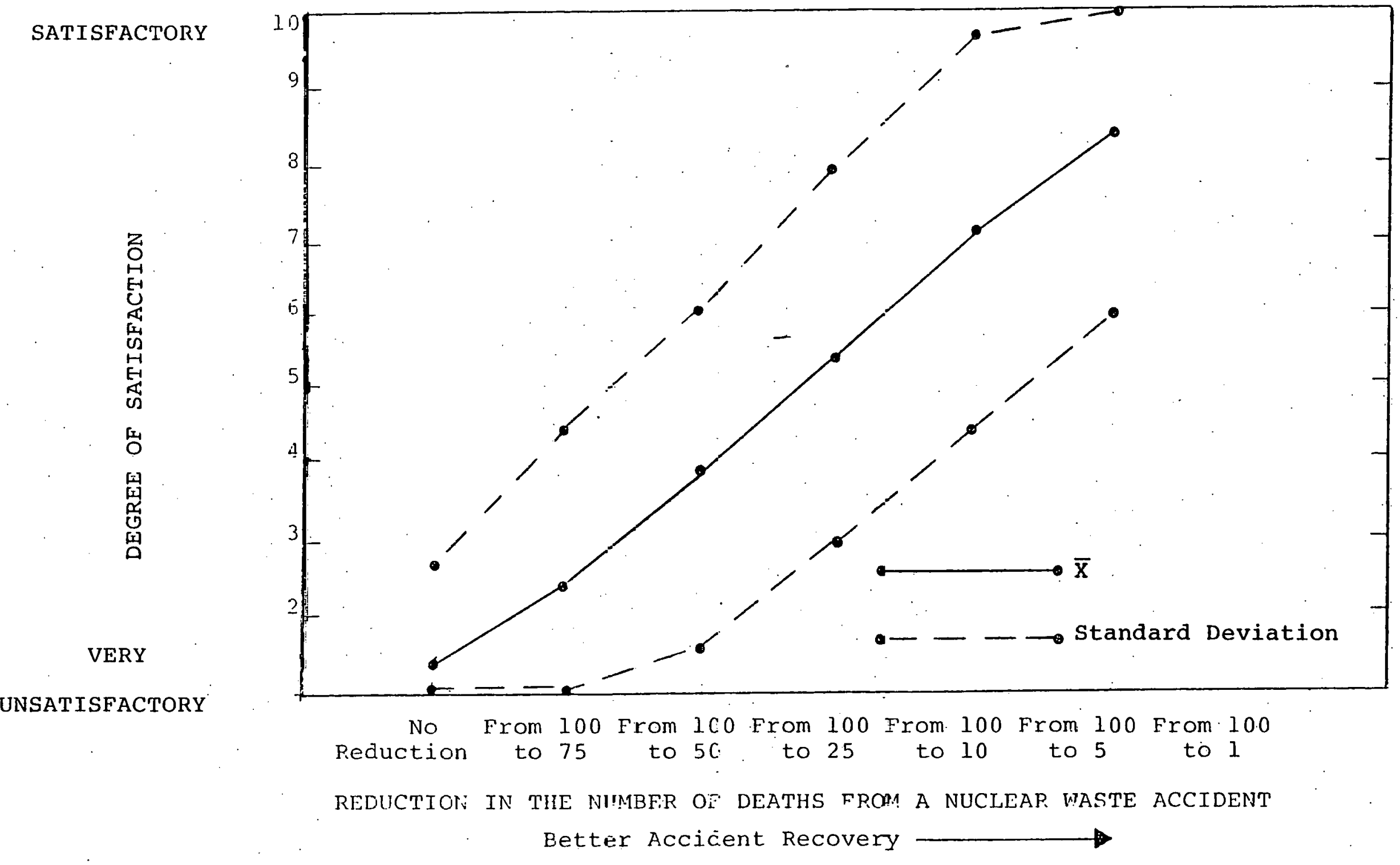


"standard deviation", an index of the variability of judgments about the average. The standard deviation "band" on both sides of the average, roughly speaking, shows the range of judgments for approximately two-thirds of the respondents. For example, the risk level, "l death per year". received an average rating of 6.5 and the standard deviation band ranged from 3.5 to 9.4. A final note of explanation concerns the lowest level of risk, "1 death per 100 years". No values are shown for this risk level, and it will be noted that on the succeeding figures, values for the lowest level of risk and cost are not shown. In the questionnaire, these optimal or "best achievable" levels of risk and cost were arbitrarily assigned a value of "10", or "Satisfactory". These assignments of "10" to the lowest level of risk and cost were made in order to fulfill some mathematical requirements of computer modeling analyses reported elsewhere (Litchfield and Hansen, 1975). Since these latter values were fixed rather than the result of respondent judgments (and were given a value of "10" for all respondents), they are not shown in the figures.

The results shown in Figure 15 for Short-Term Safety indicate that, for the total sample, increases in risk level tended to be matched by decreases in rated Satisfaction. Short-Term fatality rates of one death per 50 years, one death per 10 years, and one death per year received average judgments above the midpoint (" 5 ") of the Satisfaction scale. Fatality rates in excess of one death per year received average judgments which were closer to the "Very Unsatisfactory" end of the scale.

Average ratings and variability bands by the entire sample for Long-Term Safety are shown in Figure 16. As in the case of Short-Term Safety, increases in Long-Term Safety were accompanied by increased ratings of Satisfaction. Five of the risk levels associated with Long-Term Safety were also used in the 
Short-Term Safety scale: 100 deaths per year; 10 deaths per year; one death per year; one death per 10 years; and one death per 100 years. Comparisons of Satisfaction ratings for these risk levels common to both Long-Term Safety and Short-Term Safety indicate that these risk levels were rated more satisfactory as Short-Term risks than as Long-Term risks. For example, as a LongTerm risk, "one death per year" received an average rating of 5.03 . When considered as a Short-Term risk, "one death per year" received a rating of 6.48 .

Average ratings for cost are shown in Figure 17. Increases in the cost of electricity were, not surprisingly, accompanied by decreases in rated Satisfaction. The results show that approximately 75 percent of the sample rated an increase of $\$ 3.00$ in the monthly cost of electricity above the midpoint of the Satisfaction scale.

Ratings of Satisfaction for Accident Detection and Recovery are displayed in Figure 18. This profile indicates that death reduction factors of less than 50 percent ("from 100 to 50 ") were rated below the midpoint of the Satisfaction scale by approximately half of those surveyed.

Comparisons of the average profiles for the four factors shown in Figures 15 through 18 should be made cautiously since variation in the way respondent groups and individual respondents evaluated levels of the factors nust af so be considered.

A few observations can, however, be made about the results shown in Figures 15 to 18. First, the average values suggest that respondents tended to use a broad range of values for the 10-point Satisfaction scales. The mean values for STS and LTS ranged from approximately "2" to "9", for Cost, from "3" to "9", and for ADR, from 1.5 to 8.5. Second, there was considerable variation in the way respondents evaluated different levels of each factor. Results which are 
presented next focus somewhat on this variation by showing the average ratings for each of the six respondent clusters and also by presenting some examples of response patterns for individual respondents.

For each factor, discriminant analysis was used to assess the significance of differences among the respondent clusters with respect to 211 levels of the factor. Average response profiles for the six clusters of respondents to the different levels of the four factors are shown in Figures 19 to 22 . Figure 19 presents the profiles for Short-Term Safety. The most noticeable difference among the groups is the higher average Satisfaction ratings given to all levels of Short-Term Safety by the Nuclear Technologists. Least tolerant of Short-Term risk levels are the Environmentalists. Discriminant analysis revealed that the differences between the Nuclear Technologists and the Environmentalists were statistically significant. The Jr. High/High School Students and the University Students were also significantly different from one another in a statistical sense. This latter difference can be traced to the relatively large sample sizes of these two groups and hence, this difference is probably not significant in a practical sense. Profiles for the remaining four groups are quite close together (and close to the profile for the Environmentalists). Not surprisingly, the pattern and location of these four groups are quite similar to the average profile for the total sample, shown in Figure 15. By way of illustration of the group differences in evaluating risks, the Nuclear Technologists rated a risk level of 10 deaths per year as about "7" on the Satisfaction scale; Public Utility Employees rated one death per year at the same level of Satisfaction, while Environmentalists gave a rating of "7" to one death in 10 years. Thus the Environmentalists and 
SHORT-TERM SAFETY

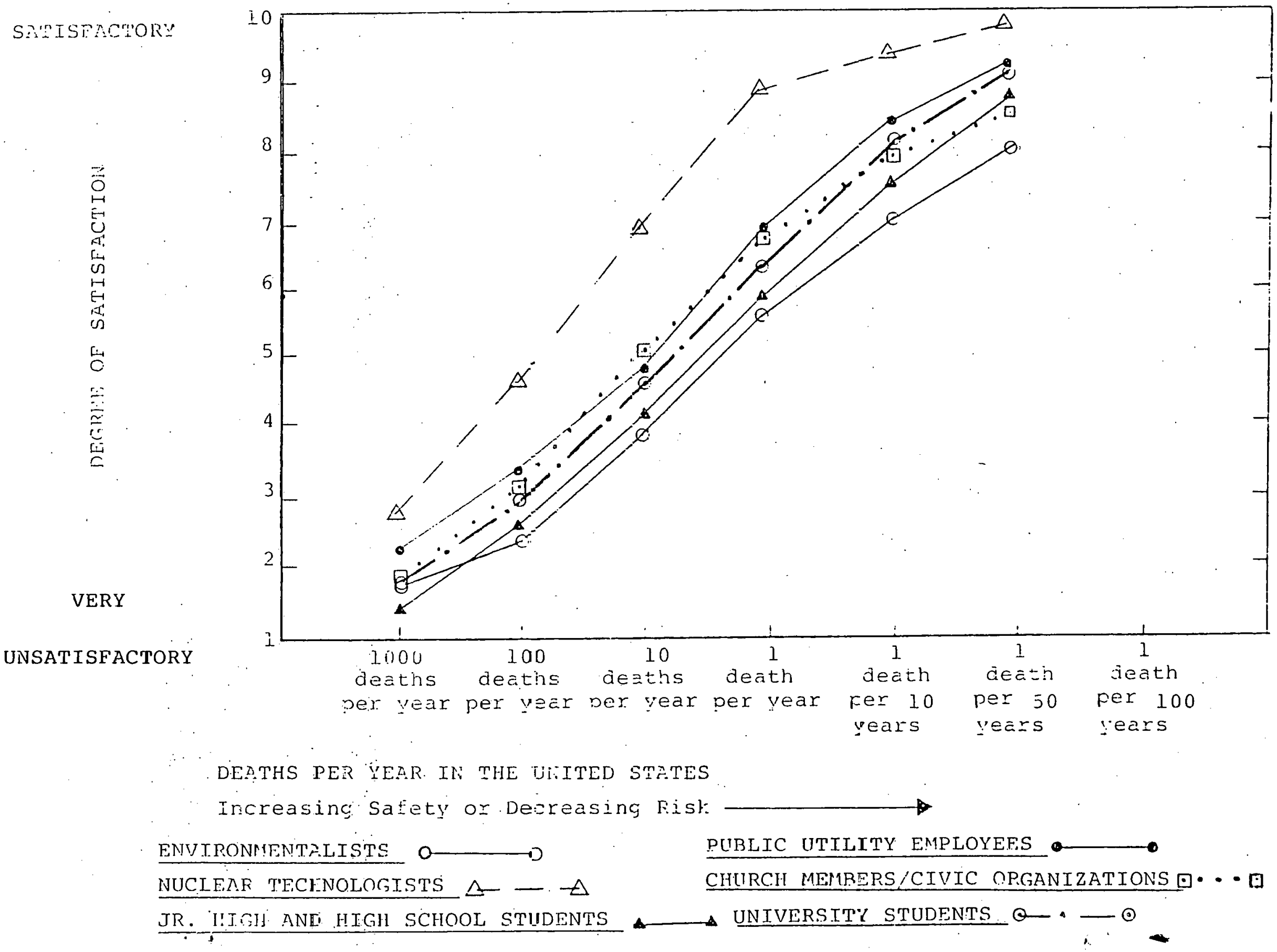


FIGURE . 20

\section{LONG-TERM SAFETY}

\section{SATISFACTORY}

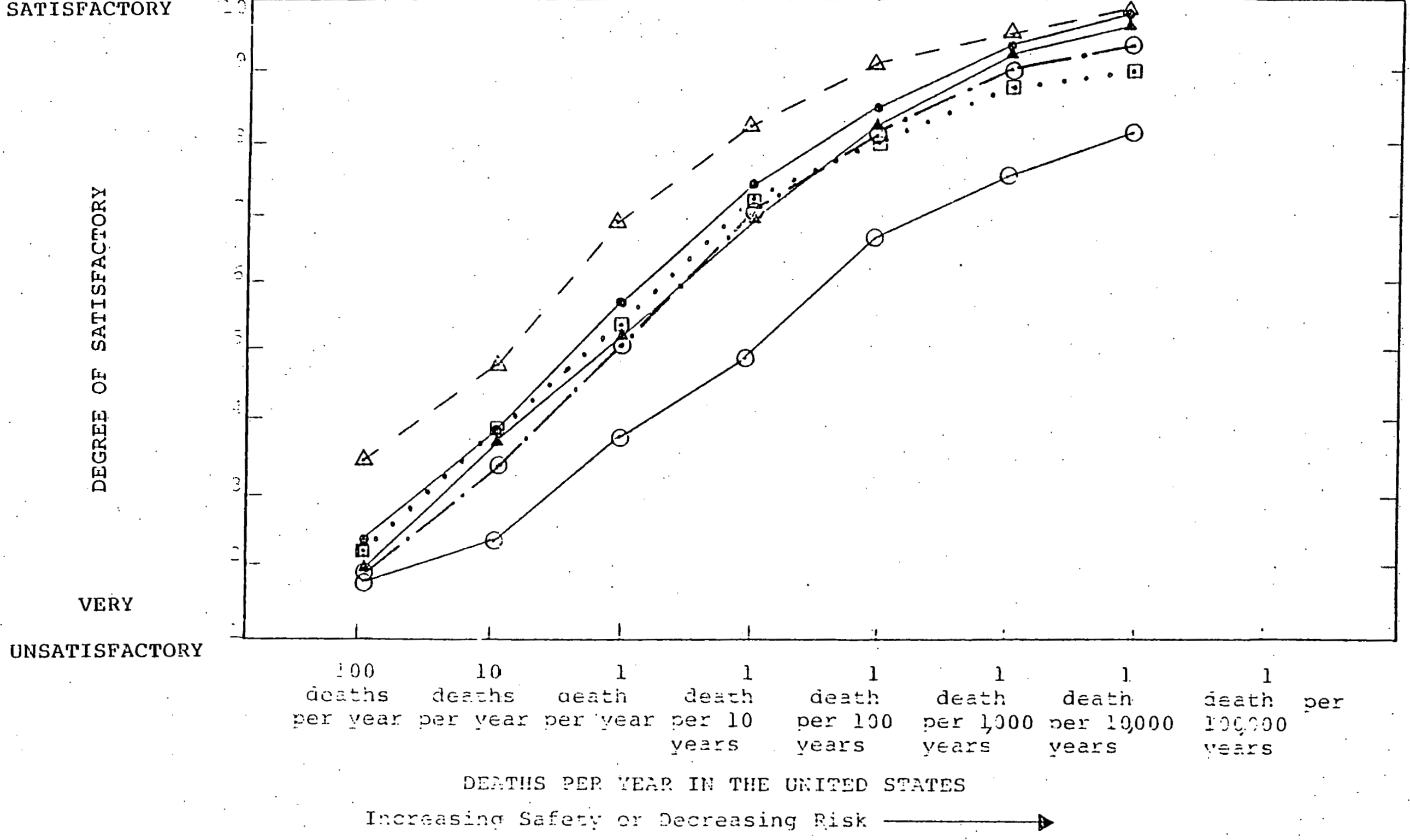

EMVTRONATENTELTSTS O-C

PUBLIC IITILITY EMPLOYEES -

MUCLEER TECHYOTORISTS A- - $\triangle$

CIIIRCH IEMARES/CIUIC OPGANIZATIONS 曰-・日

JR. UIGH AMT: UTGH SCHONL STUDENTS

$\triangle$ INTVEPSTTY STUDENTS 
FIGURE 21

$\cos \mathrm{T}$

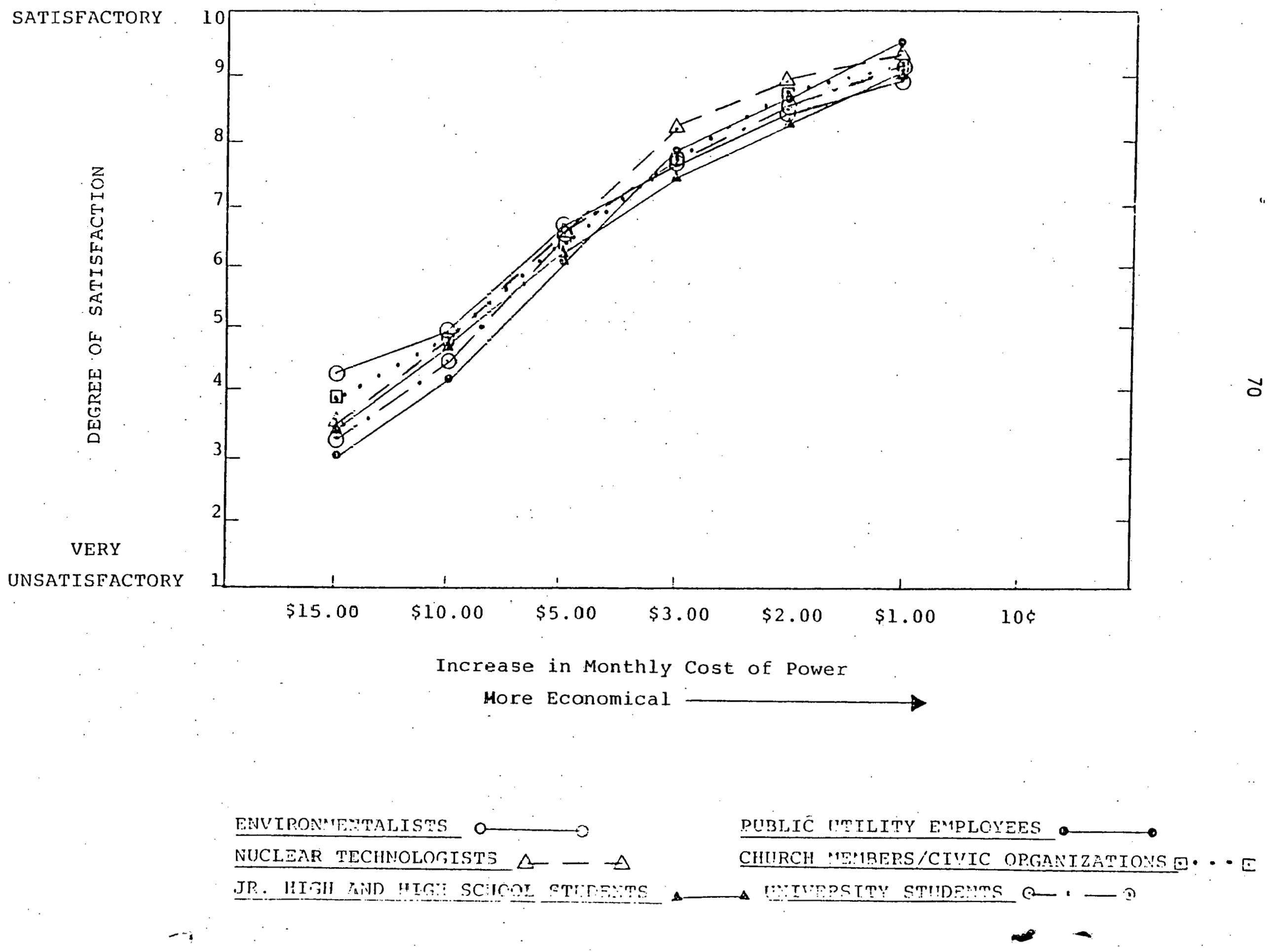


ACCIDENT DFTECTION AND RECOVERY

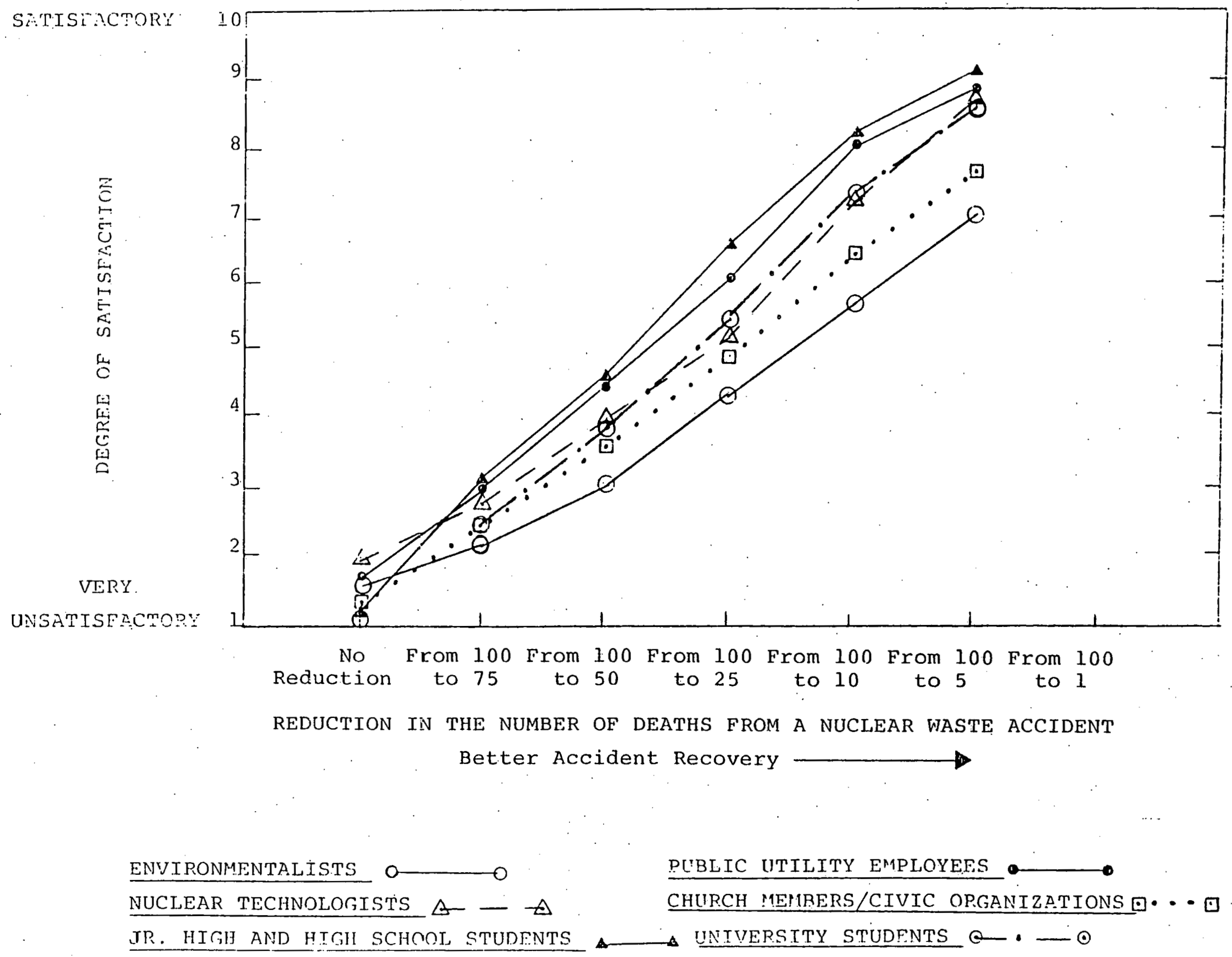


Nuclear Technologists gave equal Satisfaction ratings to risks that differed by the ratio of 100 to 1. Similar comparisons are possible for the other factors.

Figure 20 shows the average profiles for the six groups for various levels of Long-Term Safety. The most obvious differences among respondent clusters are between the Nuclear Technologists and Environmentalists, and between these two groups and the other four respondent groups. As in ShortTerm Safety, these latter four groups have very similar profiles and approximate very closely the total sample average for Long-Term safety shown in Figure 20. Results of discriminant analysis indicated the statistically significant differences existed between the Environmentalists and Nuclear Technologists and between the Environmentalists and the Jr. High/High School Students. Also of interest is the finding that the Nuclear Technologists are most different from the rest of the sample at the lower risk levels.

Profiles of the groups on Cost are shown in Figure 21 . A1l six groups are very similar in their satisfaction with various levels of increase in monthly cost of electricity. There were no statistically significant differences among the groups for this factor.

Figure 22 presents Accident Detection and Recovery profiles for the six clusters. At the lowest levels of accident reduction ("No reduction", "From 100 to $\left.75^{\prime \prime}\right)$, the average ratings of satisfaction for the six groups are quite similar. All groups judge these low levels of accident detection as unsatisfactory. However, differences among the groups do emerge at the 50 percent reduction level ("From 100 to 50"). Over all levels of accident reduction, the Envirónmentalists judged reductions of less than 100 percent as less satisfactory than did the other five groups. For this factor, the Nuclear Tech- 
nologists did not emerge as more tolerant of risk levels as they did with Short- and Long-Term Safety. Instead, the Jr. High/High School Students' average satisfaction ratings were the highest for most levels of this factor. The difference between the Jr. High/High School Students and the Environmentalists was statistically significant. This difference may reflect the relatively large sample size of the student group, but probably reflects real differences as well.

Earlier the point was made that the expression of results in the form of average profiles tended to mask some of the variability in individual respondents' profiles. Generally, most respondent profiles were rather similar in both elevation and slope to the average profiles which have been presented above. Although pronounced "non-linear" profiles were relatively rare in the total sample, there was equite a variety of profile shapes. Figure 23 displays three profiles which reflect this diversity. Levels of Short-Term Safety are used for illustrative purposes. The profile for "Respondent $A$ il suggests that he or she judged the lowest two risk levels to be "Satisfactory", but then shifted rather dramatically to the "Very Unsatisfactory" end of the scale in judging the three highest levels of risk.

The profile for "Respondent $B$ " is similar to the average profile for the total sample and for the six respondent clusters, i:e., successive increases in risk level were accompanied by successive decreases in judged satisfactoriness. The profile for "Respondent $C$ " appears to reflect the attitude that "any level of risk. is unsatisfactory and unacceptable."

To summarize the results presented in this section, differences among the six respondent groups will be addressed, followed by a discussion of the possible interpretations which may be made of the evaluations for each 
FIGURE 23

SHORT -TERY. SAFETY

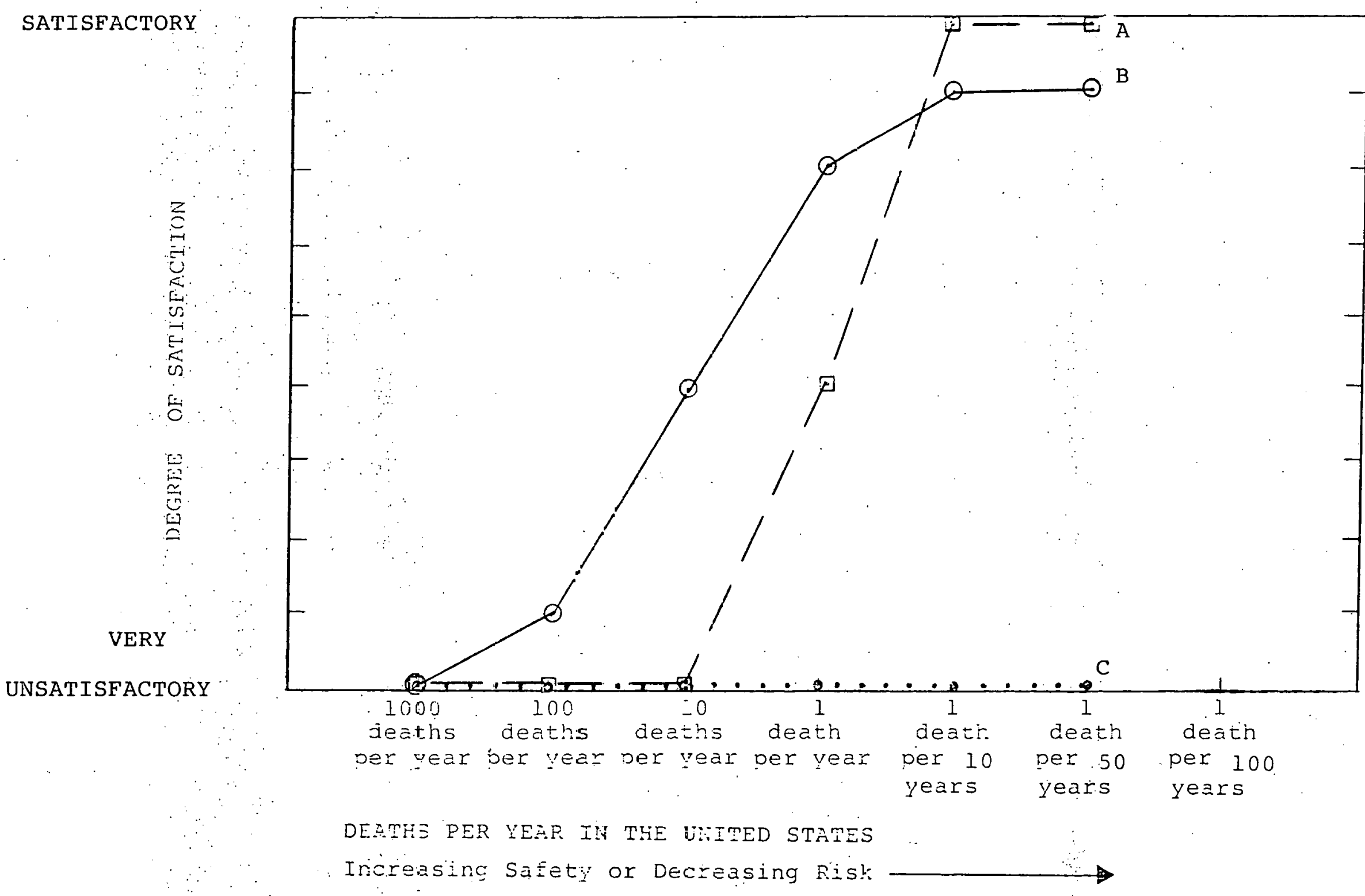


factor. The Nuclear Technologists were most tolerant of risk, both Short-Term and Long-Term. Least tolerant of risk were the Environmentalists. The other four groups tended to occupy "middle ground" in their evaluations of these factors. There was a fairly close agreement among the six groups with respect to Cost. For Accident Detection and Recovery, there was near-consensus that "No Reduction" in fatality level was very unsatisfactory, but at higher levels of accident reduction, the groups diverged somewhat with the Environmentalists being the least tolerant of anything less than near-perfect recovery systems.

The final consideration concerns the meaning to be attached to these results and the potential implications which may flow from them. In the first two chapters of this report, the stated rationale for obtaining evaluations of various levels of each factor was to help answer such questions as, "How safe is 'safe enough'?" It is clear from the above discussion that the answers to these questions vary among groups and among individual respondents. It is not obvious that average scores should be taken to reflect a: group or population consensus about risk/benefit and cost/benefit issues. However, it may be reasonable to consider aggregated scores and profiles as "best estimates" of perceived acceptable levels of risk and cost.

Applying the decision rule that the "satisfactory" level of risk or cost is that level for which the majority of the respondent sample is above the midpoint of the 1-10 satisfaction scale. the following results are suggested: a satisfactory level of Short-Term Safety probably lies between one death in 10 years and one death in 50 years; a satisfactory level of Long-Term Safety probably lies between one death in 100 years and one death per 1,000 years; increases in monthly electricity costs of approximately $\$ 3.00$ are satisfactory; 
and a satisfactory level of Accident Detection and Recovery is near the 95 percent reduction level in fatality rates from a nuclear waste accident. 


\section{E. Supporting Results: Attitude and Bel ief Measurement}

Part $V$ of the questionnaire consisted of 30 attitude statements with which respondents were asked to express their agreement or disagreement. Some of these statements focused directly upon the topic of nuclear waste disposal, but the majority dealt with broader contextual issues within which nuclear waste disposal may be considered. Respondents indicated their extent of agreement or disagreement by circling one of five answers: Strongly Agree, Agree, Neither Agree Nor Disagree, Disagree, and Strongly Disagree.

Appendix $C$ presents the attitude statements and the results for the total sample of respondents. Beside each statement, the number and precentage of respondents circling each of the response categories are shown. These results give a goneral impression of respondent attitudes for the total sample, but they do not adequately depict the differences in attitudes and beliefs among the respondent groups. Needed is a reduction and synthesis of this information for better understanding.

Factor analysis (Cooley and Lohnes, 1971) was performed on the resporses to the 30 questions by the total respondent sample. Factor analysis is a statistical technique for determining the underlying dimensions or "factors" underlying a set of questionnaire items. A second purpose for factor analyzing the responses to a set of items is to determine whether the researcher's $\underline{a}$ priori expectations of the questionnaire's content is a meaningful way to conceptualize the items: Recall from Chapter II that the items were written to assess attitudes about nine content catcgories. 
Results of a seven-factor solution (varimax rotation) are presented in Table 4. The factors are defined by examining the relative contributions made to the 30 items in each factor. The "loadings" indicate the importance of each item in the factor. For example, Attitude Statement Number 7 had a loading of .62 on the first factor, indicating that it was one of the main "definers" of Factor 1. Tentative "definitions" of the factors are as follows:

Factor 1 Need for and efficacy of nuclear power and the need for power in general

Factor 2 Emphasis upon safe power

Factor 3 Pollution and safcty

Factor 4 Importance of Short-Term Safety versus Long-Term Safety

Factor 5 Accident Detection and Recovery

Factor 6 Perceived severity of the nuclear waste problem

Factor 7. Respondents' self-ratings of knowledge about nuclear waste disposal.

The factors and the items which serve as "markers" or definers of each factor are presented as Appendix $D$. Several points need to be made about these results. First, single item factors (such as 5 and 6 ) are not likely to be reliable upon repeated administration of the questionnaire items.

In general, factors based on a very few items will not be as reliable as those based on many items. Second, the labeling of the factors is based on inspection of the content of the items which load highly on the factors and tends to be somewhat subjective. Thus the definitions shown above represent inferences by the authors and should be treated as such. Third, some items such as Number 13, have high loadings on more than one factor. 
FACTOR LOADINGS FOR ATTITUDE STATEMENTS

\section{FACTORS}

ATTITUDE

STATEMENTS

$$
\begin{aligned}
& 1 \\
& 2 \\
& 3 \\
& 4 \\
& 5 \\
& 6 \\
& 7 \\
& 8
\end{aligned}
$$

10

11

12

13

15

16

17

18

19

20

21

23

24

25

26

27

28

29

30

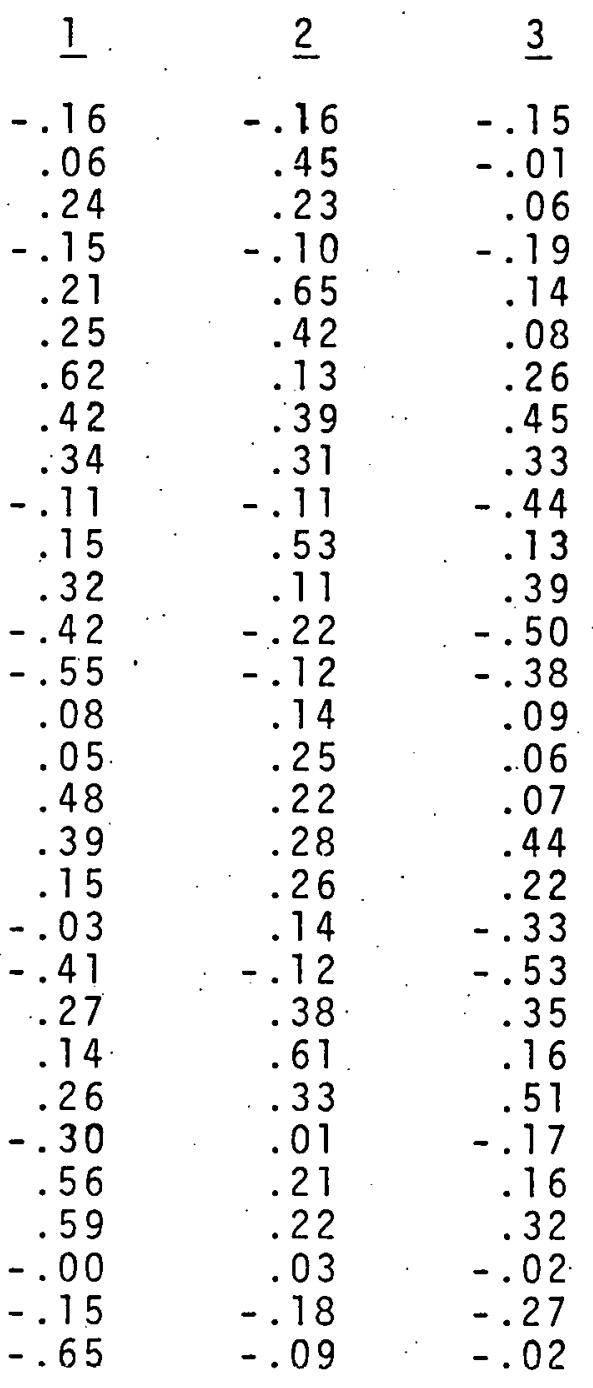

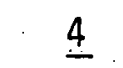

.27
.07
-.02

.00
-.00

$-.07$

.06

$-.03$

$-.03$

$-.03$

.32

$-.16$

$-.17$

.25

.24

$-.12$

.12

$-.06$

.01

.02

.15

.12

.15

$-.10$

$-.04$

.28

.08

.05

.41

.45

.15

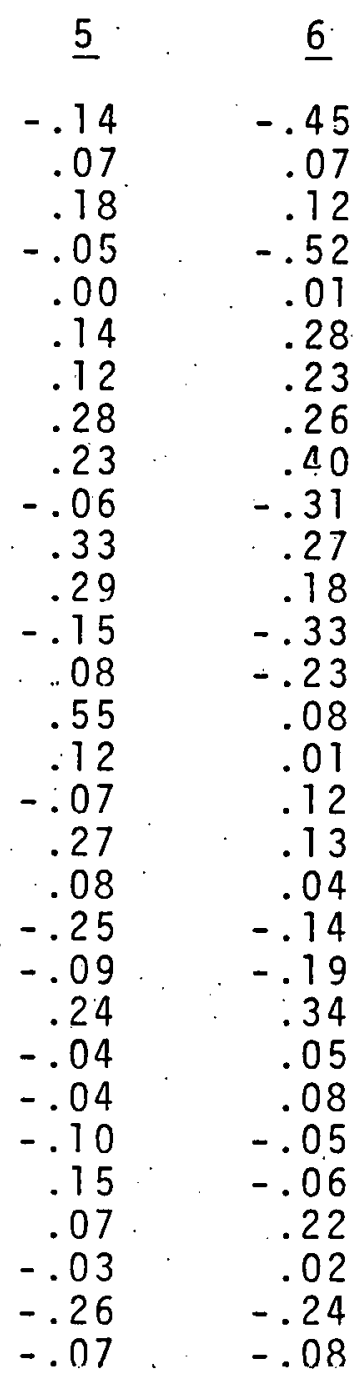

6

.

$-.20$

.05

$-.19$

.10

.08

.00

$-.11$

.02

.03

$-.14$

$-.05$

$-.20$

$-.02$ .12 .12

.57

.13

.18

$-.21$

.12

$-.05$

.28

.20

.10

$-.05$

$-.05$

$-.03$

.14

$-.20$

. .20
-.13 
Beneath each column in Table 4, the loadings also provide information about the relationships among the items. Loadings of opposite sign indicate a tendency on the part of respondents to respond in an opposite manner to the items. In Factor 1 , for example, the Statement Number 7 and 14 express somewhat different sentiments, 7 urging that nuclear power is not needed, and 14 promoting it as the most promising. The factor loadings for these two items are both large, but opposite in sign.

The interpretation given to Factors 2 and 3 as separate factors may seem puzzling since both stress safety. The items loading high on Factor 2 appear to focus upon the relative safety of nuclear power versus solar or geothermal power. Factor 3 appears to be a coal versus nuclear power dimension in terms of pollution and safety. The remaining factors are easily interpreted because of the few items loading on them. Again, there is no guarantee that these factors would emerge upon subsequent administrations of this questionnaire.

The results of factor analysis suggest partial confirmation of prior expectations about the relationships among the attitude statements. It was expected that nuclear waste disposal would be a salient issue (Factor 6) and that risk and safety issues would be important (Factors 2 and 3 ). Finally it was anticipated that there would be concern about the necessity for nuclear power in general (Factor 1). Such partial confirmations of a priori expectations are frequent in exploratory attitude research directed toward previously unexplored content areas.

The seven-factor solution, however, does not lend itself to a clear presentation of results among the six respondent clusters. Consequently, the results are organized and displayed according to five content categories. 
These categories bear some similarity to the factors described above.

The attitude statements are arranged to allow for the results to be integrated with those from previous sections of this chapter. The five categories are:

1. Attitude toward nuclear waste disposal factors

2. Perceived severity of nuclear waste problem

3. Perceived safety of nuclear power

4. Perceived need for nuclear power and need for power in general

5. Perceived efficacy of alternatives to nuclear power

Figure 24 displays the results for the six respondent cluster to statements related to the four waste disposal factors. The average responses for the respondent groups are plotted beside each of the statements. The response categories, e.g., "Strongly Agree," are abbreviated beneath the plots. Average responses to the far left indicate strong disagreement with the statement while those on the far right indicate strong agreement. "The midpoint of the plot, abbreviated "AD" represents the response "Neither Agree nor Disagree". Three general types of information are contained in this figure and in succeeding ones: the direction of response (i.e., agreement or disagreement) to each statement, the intensity of response (e.g., agree vs. strongly agree), and differences among the average responses of the respondent groups. In comparing the average responses for two respondent groups to a given statement, a difference of a half-scale unit is statistically significant in most instances. For example, on item 19, a significant difference exists between Environmentalists and Nuclear Technologists. 
19. The generation that uses nuclear power should take all the risks for waste disposal.

28. The main concern of nuclear waste planners should be a safe system for the short term.

\section{Long-Term Safety}

11. Future generations must be totally safe from our nuclear waste.

29. Compared to other problems that future generations will face, nuclear waste monitoring is insignificant.

\section{Cost}

3. In dealing with nuclear wastes, cost should be of. no concern.

25. To satisfy critics, the U.S. nuclear waste system will' probably cost far more than is necessary.

\section{Accident Detection and Recovery}

2. Nuelear wastes should be disposed of in such a way that no one will ever be able to disturb or recover them.

15. Whatever disposal system is devised, there must be a way to detect leaks and recover the waste.

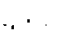

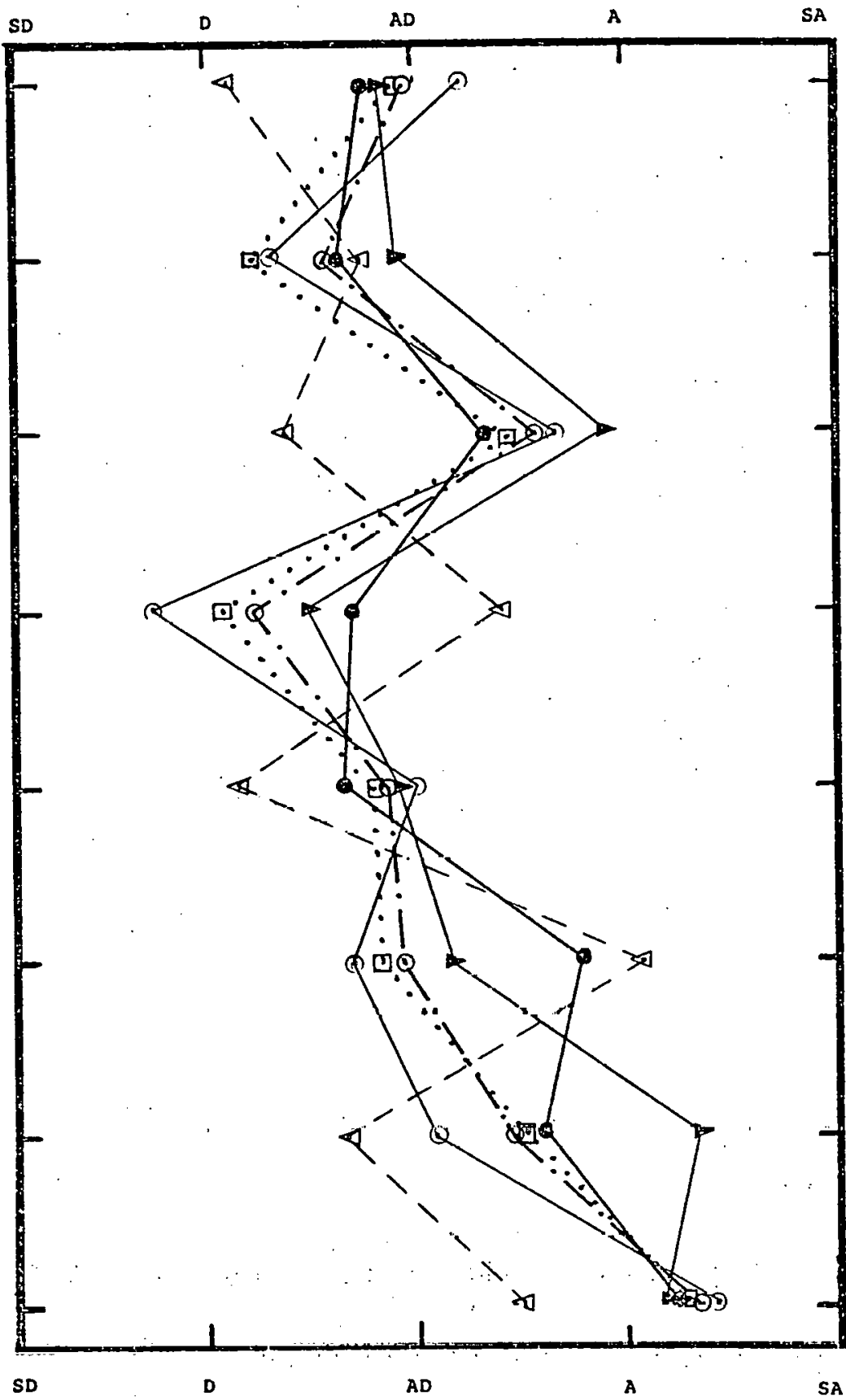

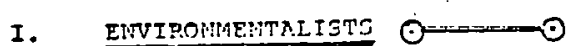

II. MUCLTAR TECHOTOGISTS $7-7$

III. JR. HIGil MOD UIGH SC OOL STUDENTSA
IV. PURLIC UTJLETE EMPLOYEES

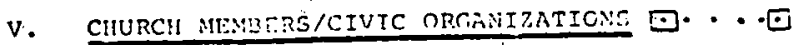

vi. UnJVersity students $G \cdot-0$ 
Several points can be made about the results shown in Figure 24 . One general observation is that few of the statements elicited a consensus among the respondent groups. Another general finding is that the Nuclear Technologists and Environmentalists are frequently on opposite sides of many issues. More specific results are described below.

With respect to Short-Term Safety, Nuclear Technologists disagree that the present generation should bear all of the risks for nuclear waste disposal (\#19), while the average responses for the other five groups are closer to the neutral midpoint on this issue. Regarding Long-Term Safety, all groups except the Nuclear Technologists express some support for the statement that future generations must be absolutely safe from present-day wastes (\#11); the Nuclear Technologists are in moderate disagreement with this statement. On item 19, the Environmentalists disagree that nuclear waste will be an insignificant problem for future generations; the Nuclear Technologists are in moderate agreement with this statement, and the other four groups' average scores are in the direction of disagreement with the statement. Nuclear Technologists indicate that cost is of some importance, while the other groups are clustered about the neutral midpoint. On item 25, the Nuclear Technologists and Public Utility Employees indicate that critics will have the effect of boosting the cost for nuclear waste disposal. The other four groups are on or near the midpoint on this item. Response patterns for the two items dealing with Accident Detection and Recovery tend to point up the logical/engineering problems of retrievable storage versus permanent disposal. All groups except the Nuclear Technologists agree that detection and recovery systems are important in disposal systems (item 15), but the groups vary considerably in response to item 2, which is concerned with permanent, non-retrievable disposal. 
Figure 25 presents the results for five attitude statements which deal with the perceived severity of nuclear waste disposal. Nuclear Technologists and Public Utility Employees, to a lesser degree view the problem of nuclear waste disposal as less severe than other conditions facing humanity (items 1 and 9). The Environmentalists tend to differ most from the Nuclear Technologists on these five items, but the intensity of their average response is less pronounced.

The six statements shown in Figure 26 address the issues of the perceived safety and pollution associated with nuclear and coal-fired power plants. These statements produced the greatest ditterences among the respondent yruups. On every item, there are significant differences between the responses of the Nuclear Technologists and the Environmentalists. Item 13, relating to the benefits versus risks of nuclear power, is a good example. Environmentalists clearly disagree that the benefits outweigh the risks, while the Nuclear lechnologists and Utflity Empluyees agree. Average responses for the other three respondent groups are again in the midrange between the polarized groups. The profile in Figure 26 states the current controversy surrounding nuclear power rather eloquently.

Items displayed in Figure 27 focus on respondents attitudes and beliefs concerning the need for additional nuclear power as well as non-nuclear power. For these items, there is general consensus that more power will be needed in the future (items 17 and 30), and with the exception of the Environmentalists, nuclear power is viewed as an acceptable source of electrical power.

The three statements comprising Figure 28 are concerned with respondent perceptions about three alternatives to nuclear power: solar, geothermal, 
PERCEIVED SEVERITY OF PUCLEAR WASTE PROBLEM

se

1. Overpopulation and economic conditions are more serious threats to our way of life than the problem of nuclear waste disposal.

4. Based on the information I got from this study, the hazards of nuclear wastes are less serious than I thought.

6. The loss of even one life from nuclear waste is unacceptable.

9. Nuclear waste is one of the most serious threats facing the world:

22. Participating in this study makes me realize just how frightening nuclear waste is.

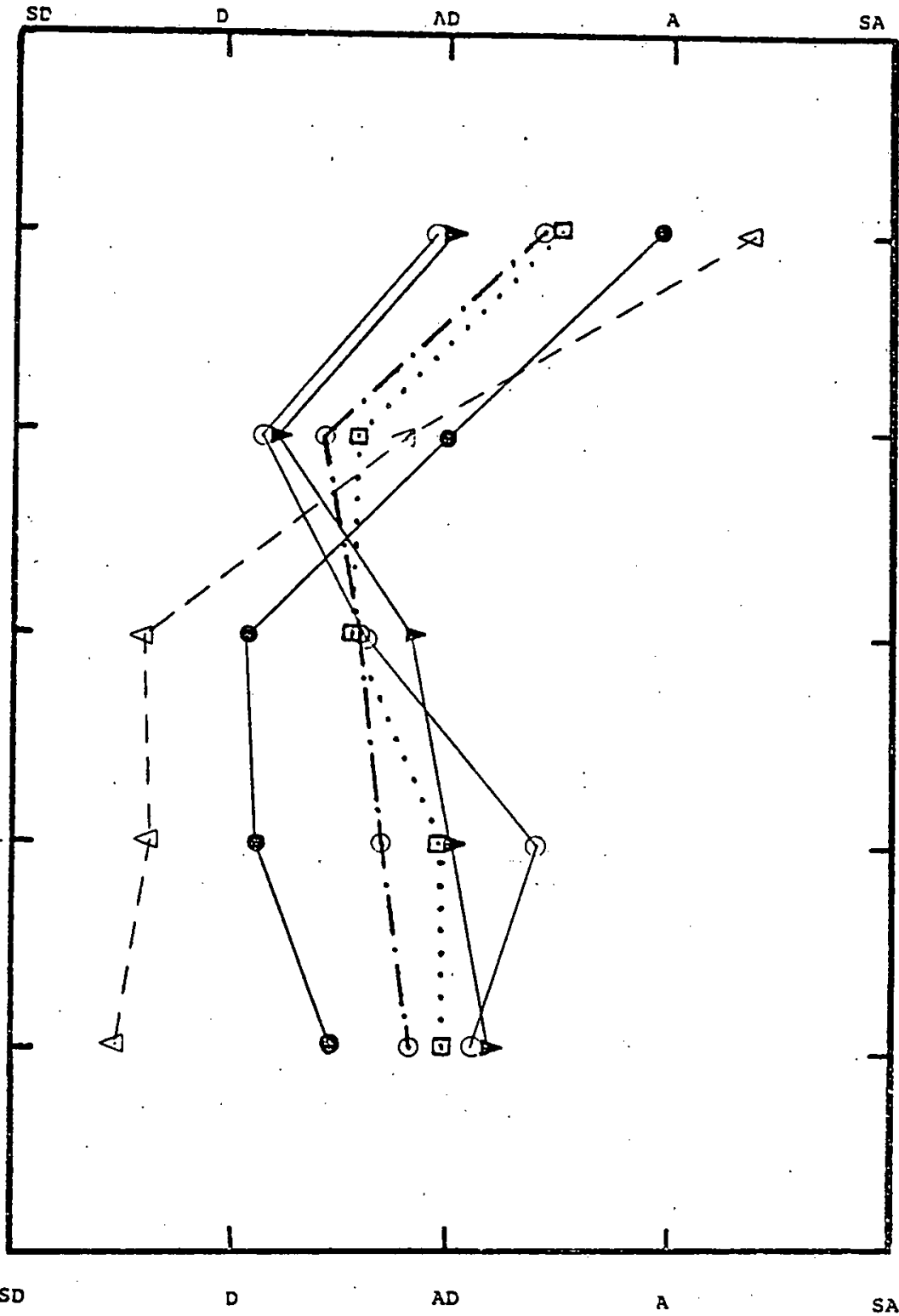

I. EnvTzomentaists $\odot$ -

II. Nicizer techococists $F-7$

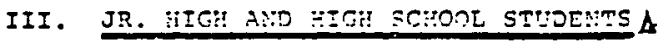

IV. PUBIIC UTIIEY? EMPLOYEES

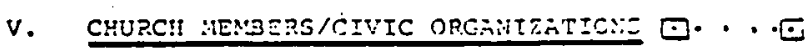

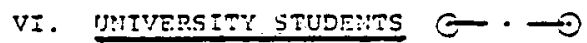


8. The constructicn of nuclear power plants should be slowed until an absolutely safe waste disposal system has been developed and thoroughly evaluated.

10. The radiosctive hazards in nuclear power are no greater than the environmental hazards from coal burning power plants.

13. The benefits of nuclear power more than outweigh the hazards in nuclear waste storage and disposal.

18. I would not want to have nuclear wastes disposed of in my region of the country.

21. Based on past operaing experience, nuclear energy has been demonstrated to be a clean and safe source of electrical power.

24. Using more coel is far less harmful to man than ising nuclear power.

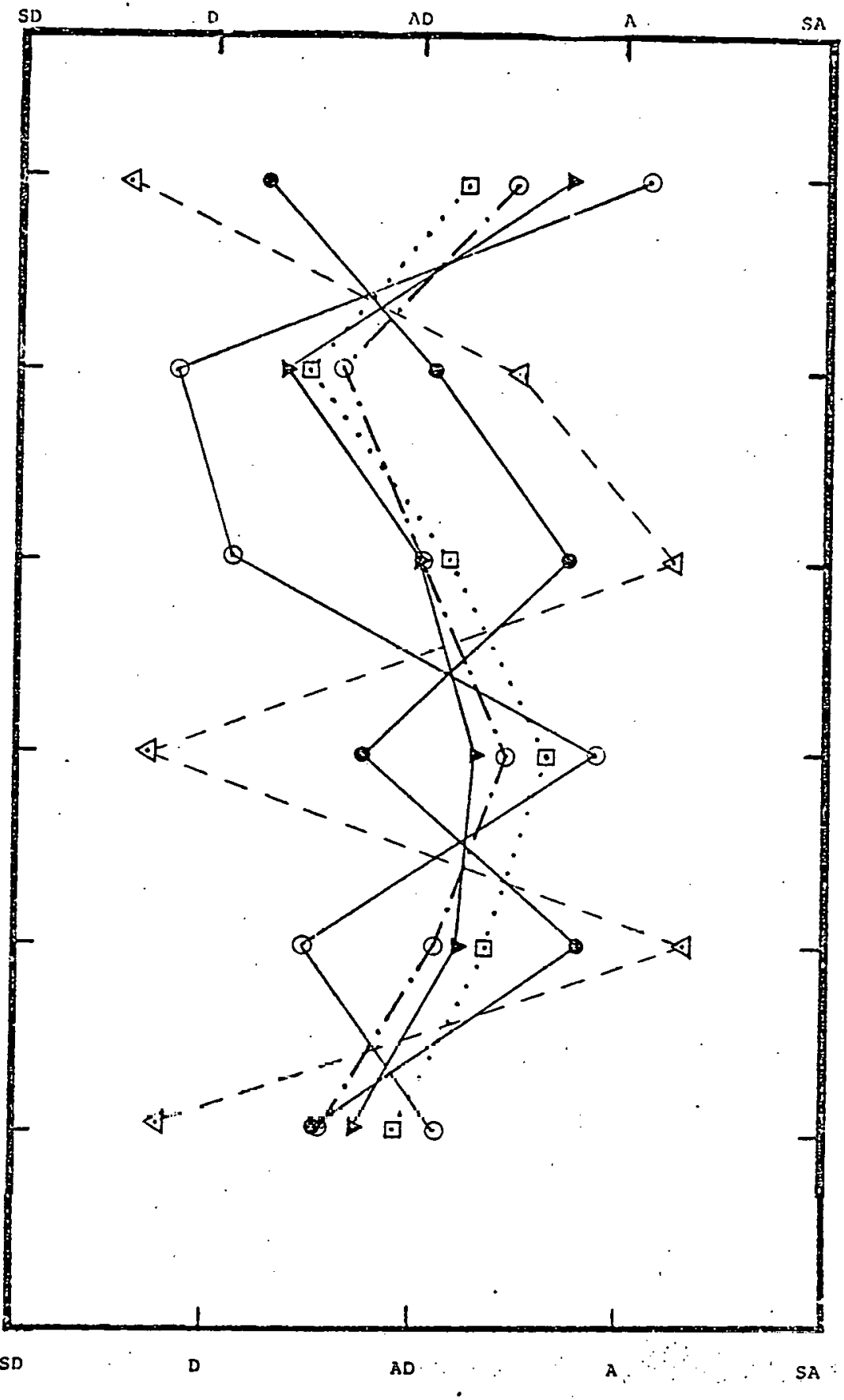

IV. PUBLIC UTII:T: EYPLOVEES

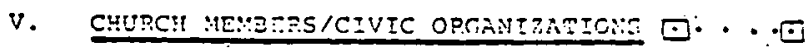

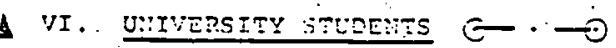

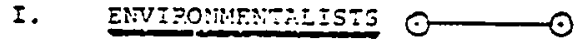

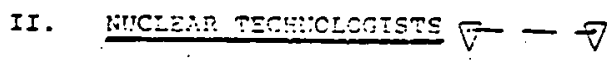

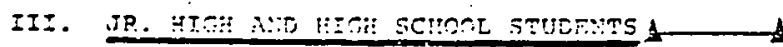




\section{FIGURE 27}

PERCEIVED NEED FOR NUCLEAR POHER AND NEED FOR POMER IN GENERAL

D

7. The U.S. can maintain a strong cconomy without having nuclear power.

14. Nuclear power is the most promising source of electrical power for the next 30 years.

17. The construction of additional electrical power plants will not be necessary for the U.S. to maintain its present standard of liying.

27. We should immediately stop developing nuclear technology as an energy source.

30. If the United States does not increase the production of electricity, our economy will decline.

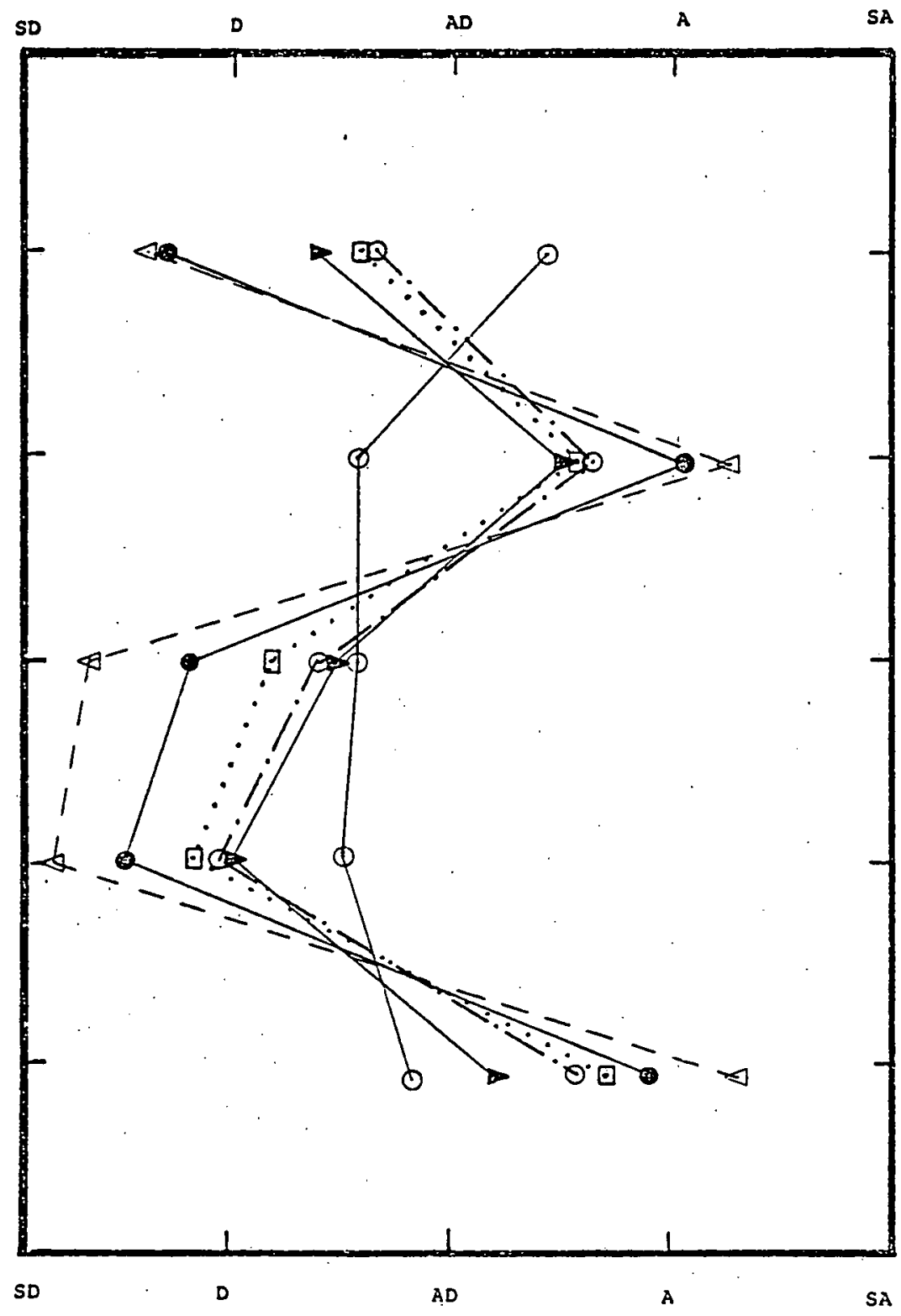

IV. PUBLIC UTIL:TY EMPIOYEES

v. CHURCH MEMUERS/CIVIC ORCRMIZATIONE $\square \cdot \cdots$

VI. Untversiti sTudente 
PERCEIVED EFFICACY OF ALTERNATIVES TO NUCLEAR POMER

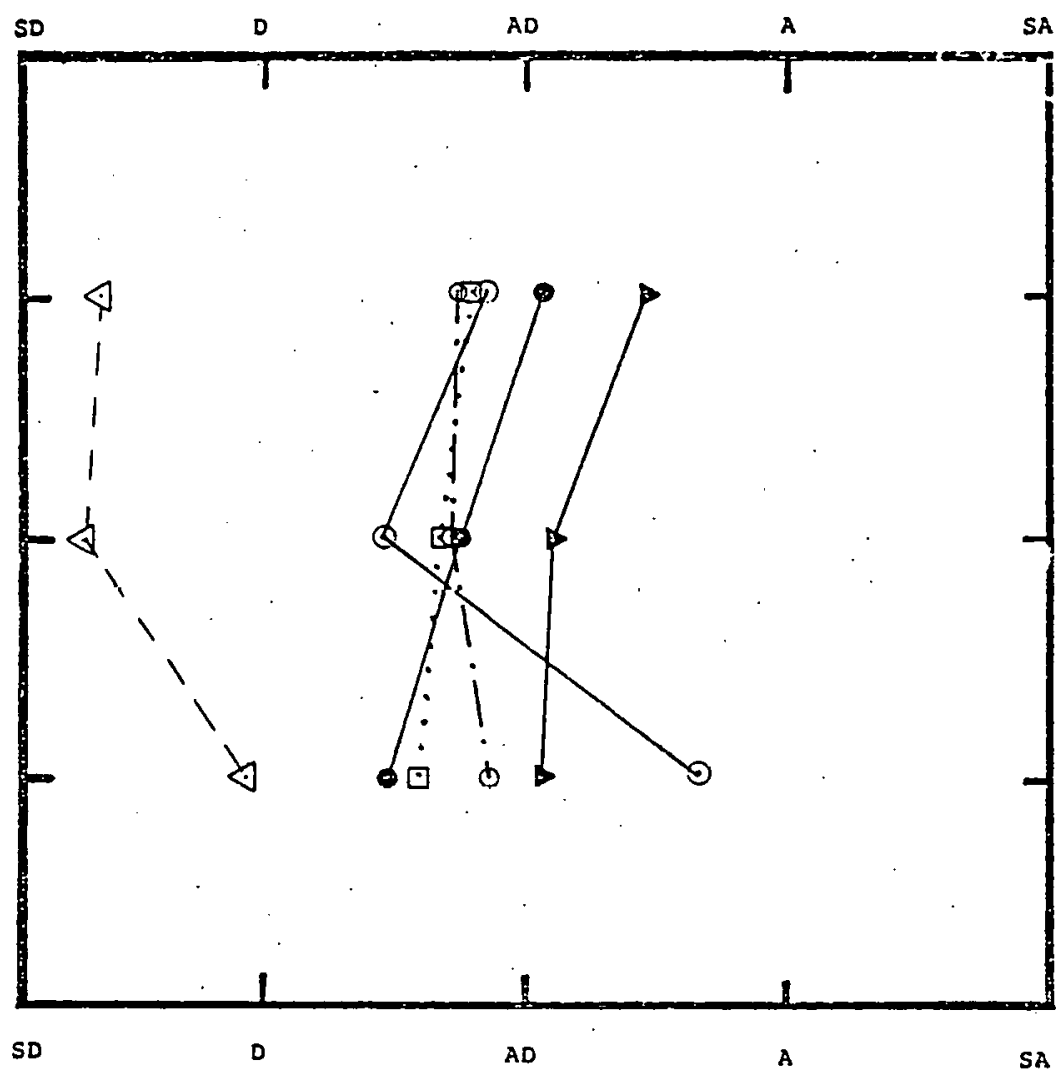

I. ENVIZOMENTMEISTS $\odot$ -

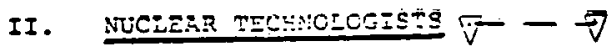

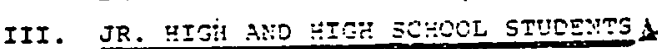

IV. PUBLIC UTILITY EMPLOYEES -

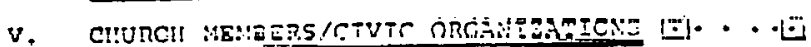

vI. UNIVESSTT: OUUUETS 
and conservation. The Nuclear Technologists strongly disagree that solar or geothermal power could solve "the problem" in the next 10 years. The other five groups are clustered near the midpoint on these two items. Average responses to item 26 show that conservation is held out as an important element in coping with energy problems, while the Nuclear Technologists give conservation little emphasis.

In summary, the results presented in this section suggest that there are few practical differences among the respondent groups with respect to the four. factors emphasized in the study. In spite of some statistically significant differences, means for the six respondent clusters tended to fall on the same agreement side, or to be in close agreement. The only exception was Long-Term Safety (item 29) for which the Environmentalists and Nuclear Technologists differed considerably. The most dramatic differences were found in the polar opposition of Environmentalists and Nuclear Technologists with respect to the following issues: perceived seriousness of the nuclear waste problem; the pollution and safety aspects of nuclear versus coal-fired power plants; perceived need for additional nuclear power; and the perceived efficacy of non-nuclear solutions to energy problems. 


\section{F. Supporting Results: Respondents' Evaluation of Survey}

In the final section of the questionnaire, respondents were asked to evaluate and comment upon the rationale behind this study and the methods and procedures employed. Most of the questions in the evaluation section were written so that the answers could be statistically summarized, but respondents were encouraged to add their own personal comments about the study. It was anticipatcd that information from this evaluation wnild he. helpful in answering some of the following questions: Were respondents favorably or unfavorably disposed to the approach? What impact did their overall reaction to the study have on their questionnaire answers? Were the film and questionnaire perceived to contain bias with respect to the topic under consideration? Did respondents feel the film had the effect of predetermining their answers? For whom was this approach appropriate and for what respondent groups would it be inappropriate as a vehicle for gathering public input? What specific changes or refinements in the methodology would respondents suggest be made in subsequent research studies which use a similar methodological approach?

Presentation of results is organized around each of the questions posed in Part VI of the questionnaire, beginning with general issues and proceeding to more specific aspects of the study.

Question 1:

Do you think it is wise to consult the general public in the United States about decision making on nuclear waste disposal? Yes _ No Why or why not? 
An assumption guiding this study was that some form of public input to technological decision making about nuclear waste was desirable. The question above was posed to test this assumption. For the total sample of respondents, 369, or 82 percent, responded "Yes". Figure 29 presents the percentage of each cluster of respondents who answered "Yes". The percentages varied between approximately 70 percent and 90 percent. The Environmentalists, Public Utility Employees, and Jr. High/High School Students had the highest percentage of "Yes" responses, while the Nuclear Technologists had the lowest percentage, although nearly 70 percent of the latter group agreed with the statement.

Approximately 80 percent of the respondents added their own comments concerning this question. The majority of the comments could be classified under one of four general categories:

1) The public should be consulted since it will bear the consequences of these decisions.

2). The public should be consulted because participation embodies the democratic ideal of the U.S. form of government.

3) The public should be consulted because consultation, broadly defined, includes informing followed by the obtaining of input concerning the information. The process of informing the public is desirable in itself.

4) The public should not be consulted because it is too uninformed and incapable of dealing with complex issues such as the disposal of nuclear wastes.

A sample of comments representative of these four categories is contained in Appendix E. Comments to Question 1 and to the remaining questions in this section were specifically chosen to cover the range from the very positive to those which were very negative and highly critical of the study. 
PCRCENT AHSHERIHG YeS

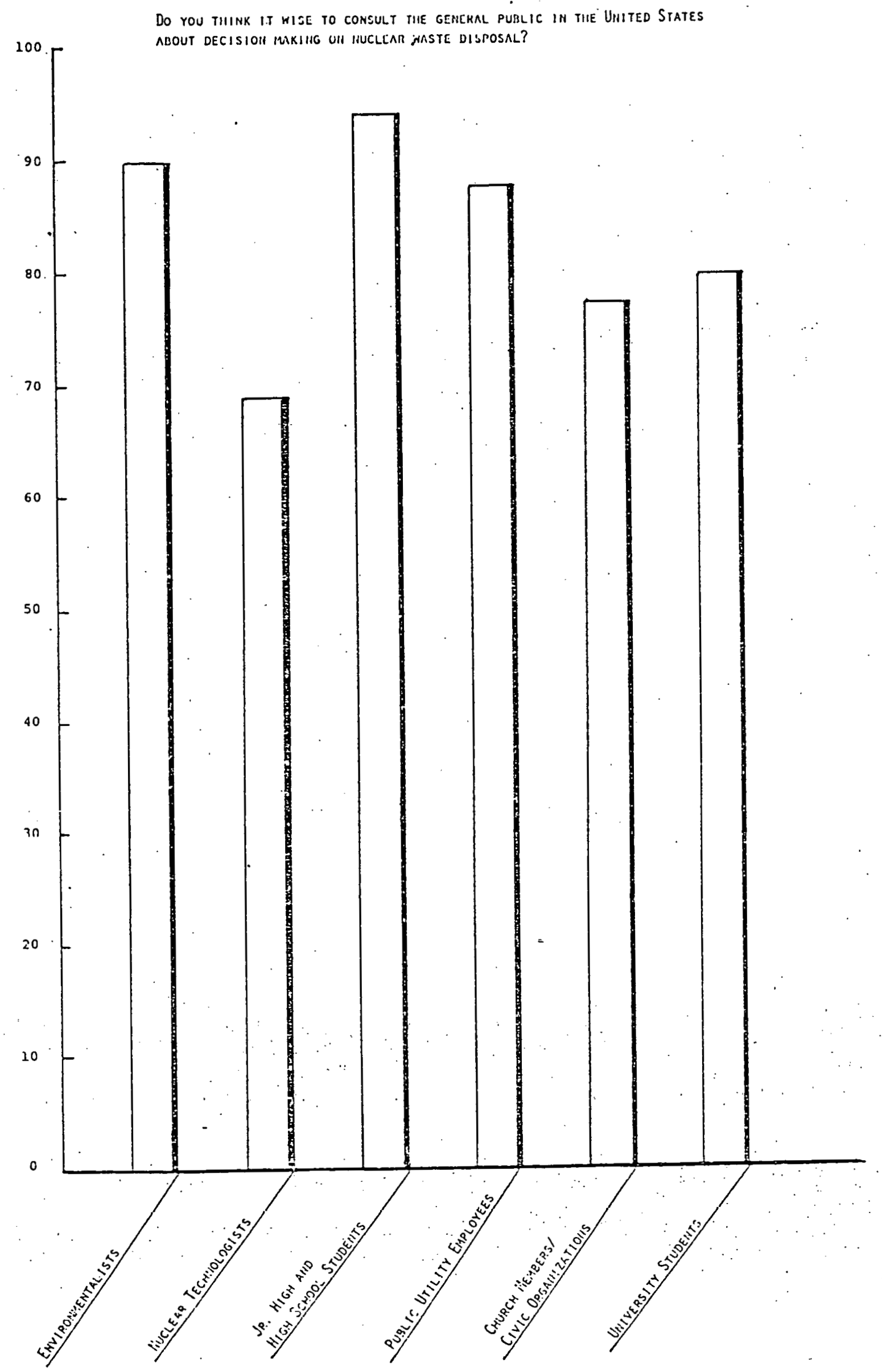

Do you tilink $1 . t$ klee to consult the genehal public in the United States ABOUT DECISIOH MKIHG UII IUCLLCAR MASTE DISPOSAL? 
Question 2:

What suggestions or comments do you have concerning pubiic involvement in technical problems such as the disposal of nuclear wastes?

A total of 257 respondents, or 57 percent, made comments in response to this question. Major categories of comments were:

1) The public needs more information and education about such issues.

2) A reaffirmation from the previous question that the public should be involved.

3) A reaffirmation that the public should not be involved.

A major theme in many of the comments was the need for more information. More than 60 percent of the responses specifically mentioned "information", "publicity", "education", "knowledge", "communication", etc. Appendix F contains representative examples of responses to this question.

An effort was made to assess respondent knowledge levels concerning nuclear waste disposal by having respondents rate themselves on the two questions shown below.

Questions 3 and 4 :

Before you participated in this study, how well informed were you about the subject of nuclear wasste disposal?

and

After participating in this study, how well informed do you feel you are on the subject of nuclear waste disposal? 
Ratings were made using a 7-point scale where " 1 " represented "Very well-informed" and "7" represented "Not at all informed". Results for these two questions are shown in Figure 30 . Note that the scale shown on the vertical axis was reversed so that higher numbers would depict greater levels of knowledge or information. Average ratings for each cluster of respondents and for the total sample are shown by the columns beginning at the horizontal axis. The first column for each group indicates the average rating for the "before" question and.the column beside it on the right shows the average rating for the "after" question.

With the exception of the Nuclear Technologists, all groups showed an increase in self-rated knowledge level after taking part in the study. The Nuclear Technologists rated themselves highest on both the "before" and "after" question. The reason for this group's slight "drop" in knowledge level after participation was due to a few respondents who marked "Not at all informed" on the "after" question in order to protest some aspect of the film or questionnafre.

Average "before" knowledge levels for the other five respondent groups varied considerably with the Jr. High/High School Students group registering the largest gains. The average "after" scores were quite similar across groups. This finding suggests that the film and questionnaire had the effects of both boosting the level of knowledge and of equalizing the information levels across these groups.

Two cautionary notes are in order before leaving these questions. First, it should be remembered that these results are based on respondent self-report and hence, were personal and subjective interpretations of information level. Somewhat related to the question of subjectivity, the two questions did not 
FIGURE 30

RESPONDENTS' LEVEL OF KNOWLEDGE CONCERNING NUCLEAR WASTE DISPOSAL (SELF-REPORTED)

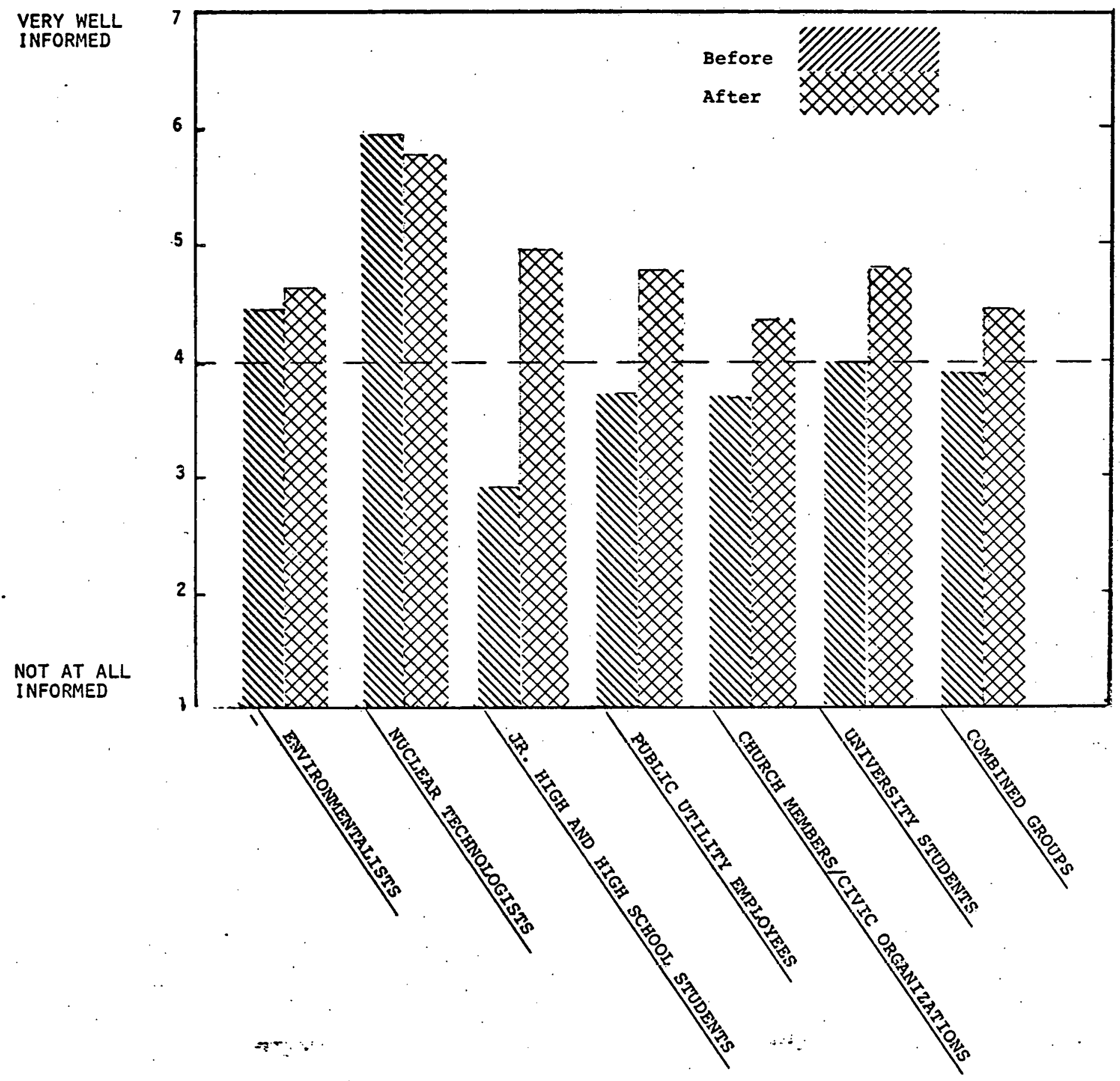


furnish an external referent for comparison, e.g., "compared to a nuclear physicist working on the problem", or "compared to the average person on the street".

The remaining three questions in the evaluation section were directed toward respondent evaluations of the methodology employed in the study. Question 5:

Is the approach used in this study (movie and questionnaire) an effective way to gather public input about nuclear waste disposal? Yes No _ Why or why not?

For the total sample, 338 respondents, or roughly 75 percent, answered "Yes" to this question. Figure 31 shows the percentage of "Yes" responses for each of the respondent groups. The Public Utility Employees were the strongest advocates of the approach, followed by the Jr. High/High School Students and Environmentalists. The Nuclear Technologists as a group were least supportive; however, nearly two-thirds felt that the film/questionnaire procedure was an effective method for eliciting public input.

Sixty-five percent of the respondents added their own comments below this question. Comments fell into the following categories:

1) The approach depends upon an adequately informed public..

2) Methodological comments.

3) Qualifications of "Yes" answers to the original question.

More than half of the comments were directed toward the necessity for an adequately informed public. Some respondents felt the approach was effective because it did provide an information base with which to respond 
to questions, others felt the approach was inadequate because it did not furnish enough information. Many respondents commented that the film was too short and simplistic and that the questionnaire was too long and complex. Methodological comments focused upon the following issues: sampling considerations (who is the 'public' and how should respondents be selected?); complexity of the procedure, particularly some parts of the questionnaire; and the need for refinements in the film and questionnaire. Qualified "Yes" answers included: Yes, the approach is effective if you improve the film and questionnaire; Yes, if you poll an informed population; Yes, if you can truly educate before getting public opinion. Representative comments are presented in Appendix G.

Respondents were asked to rate both the information presented in the film and the issues addressed in the questionnaire. Three aspects of the film and questionnaire were evaluated. The film was rated on Understandability, Completeness of Topic Coverage, and Extent of Bias. The questionnaire was rated according to Understandability, Quantity of Questionnaire Items, and Relevance to Problem of Nuclear Waste Disposal. Seven-point rating scales were used to gather respondent evaluations of the film and questionnaire.

Average ratings of the film for each respondent group are shown in Figure 32. Al1 groups except the Jr. High/High School Students felt that the film was fairly easy to understand. Most respondent groups indicated that the film did not provide adequate coverage of the topic; exceptions were the Jr. High/High School Students and Public Utility Employees who rated the film somewhat higher with respect to coverage. All groups indicated that the film was relatively unbiased and balanced in its treatment of the topic. 
Very casy to underatand

Very complete in its coverage of the topic. very biased and one-sided in coverage

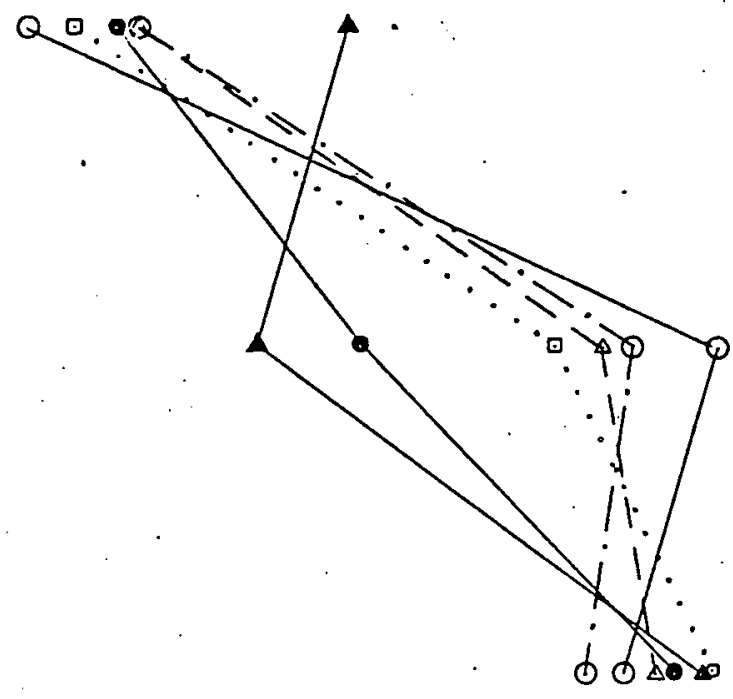

Very cifflcult

to understand

Very incomplete in its coverage

very unbiesed and balanced in coverage

\section{ENVIRONMENTALISTS O-}

NUCLEAR TECHNOLIGSTS $\triangle-\triangle$

JR. HIGH AND HIGH SCHOOL STUDENTS

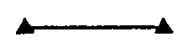

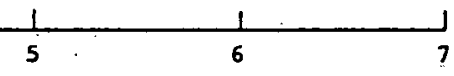

PUBLIC UTILITY EMPLOYEES UNIVERSITY STUDENTS $Q \cdot-\odot$

\section{FIGURE 33}

THE QUESTIONS AND ISSUES RAISED IN THE QUESTIONNAIRE WERE:

Very easy.

to understand
Too few in number kelevane to the problem of waste disposal

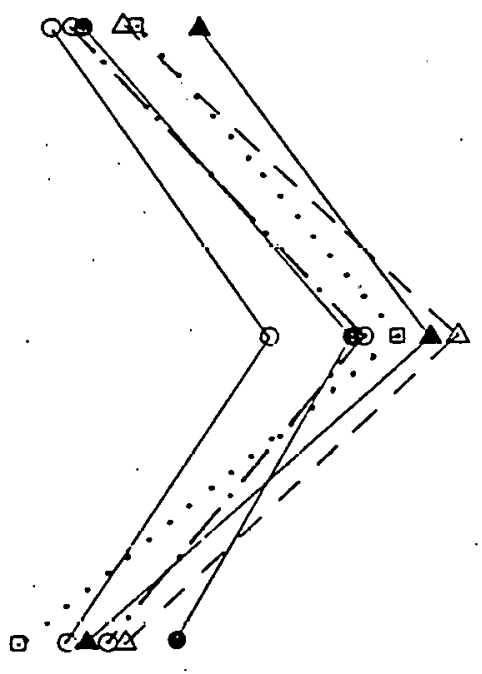

Very difficult to understand

Too many in number
Irfeleyant to the problem of waste disposal

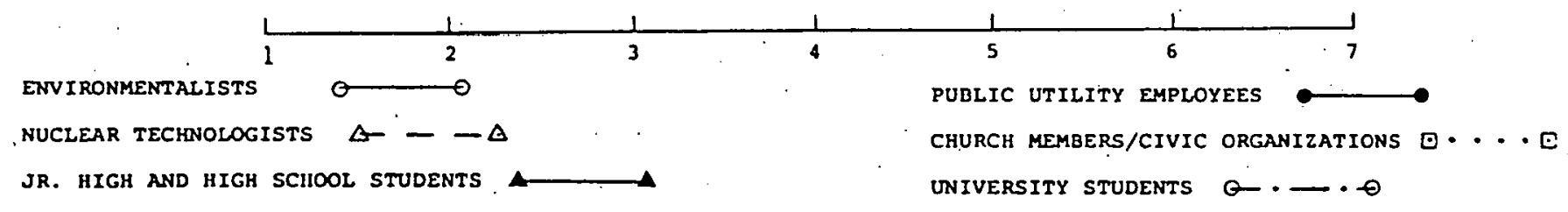


The message which has recurred once again is that insufficient information about the topic was provided in the methodology.

Figure 33 shows the average group ratings for the three questionnaire dimensions. The questionnaire was perceived as moderately easy to understand. All group averages fell near the midpoint of the scale which dealt with the perceived number of questions in the survey instrument. All respondent groups indicated that the questions and issues raised in the questionnaire were fairly relevant to the topic of nuclear waste disposal.

Question 6:

What suggestions do you have which would improve the quality of the film or questionnaire?

A total of 293 respondents, or roughly 65 percent of the sample, offered comments to this question. Responses fell into three general categories:

1) Coverage of the topic.

2) Criticism of film quality.

3) Complexity of the questionnaire.

The majority of the comments dealt with some aspect of the information presented about nuclear waste disposal. General comments emphasized the need for more information. A considerable number of respondents wanted more information about the proposed methods for nuclear waste disposal. (The film emphasized the four factors, Short-Term Safety, Long-Term Safety, Cost, and Accident Detection and Recovery, and used two disposal options, geologic disposal and seabed disposal, primarily as a way of illustrating the four factors.) Many respondents wished to have more specific and technical information about these and other disposal methods being considered. 
Another aspect of topic coverage was the treatment given to the potential risks involved in disposal. Some respondents for example, questioned the way in which risk was expressed, and others expressed the need for additional comparative data concerning risk.

Comments directed to improvements in the film included: the need for better graphics, fewer cartoon characters, interviews with experts, etc. Representative comments are presented in Appendix $H$.

Question 7:

Were the four factors emphasized in this study a satisfactory way to think about nuclear waste disposal? Yes No If no, what factors should have been emphasized?

For the total sample, 387 , or 86 percent of the respondents, answered "Yes" to this question. Figure 34 shows the percentage of each respondent group who answered "Yes". The Environmentalists and University Students had the lowest percentage of affirmative answers (75-80\%) and the Jr. High/High School Students and Public Utility Employees had the highest percentage of "Yes" responses (over 90\%).

Ninety-one respondents, or 20 percent, added comments following this question. Most of the comments were made by respondents who answered "No" to the original question. Two major categories of comments were identified:

1) Need for better definitions and clarification of the factors.

2) The factors did not adequately deal with important hazards. Suggestions for additional factors. 
WERE THE FOUR FACTORS EMPHASIZED III THIS STUDY A SATISFALTORY WAY TO TIIINK ABOUT IUUCLEAR WASTE UISPOSAL?

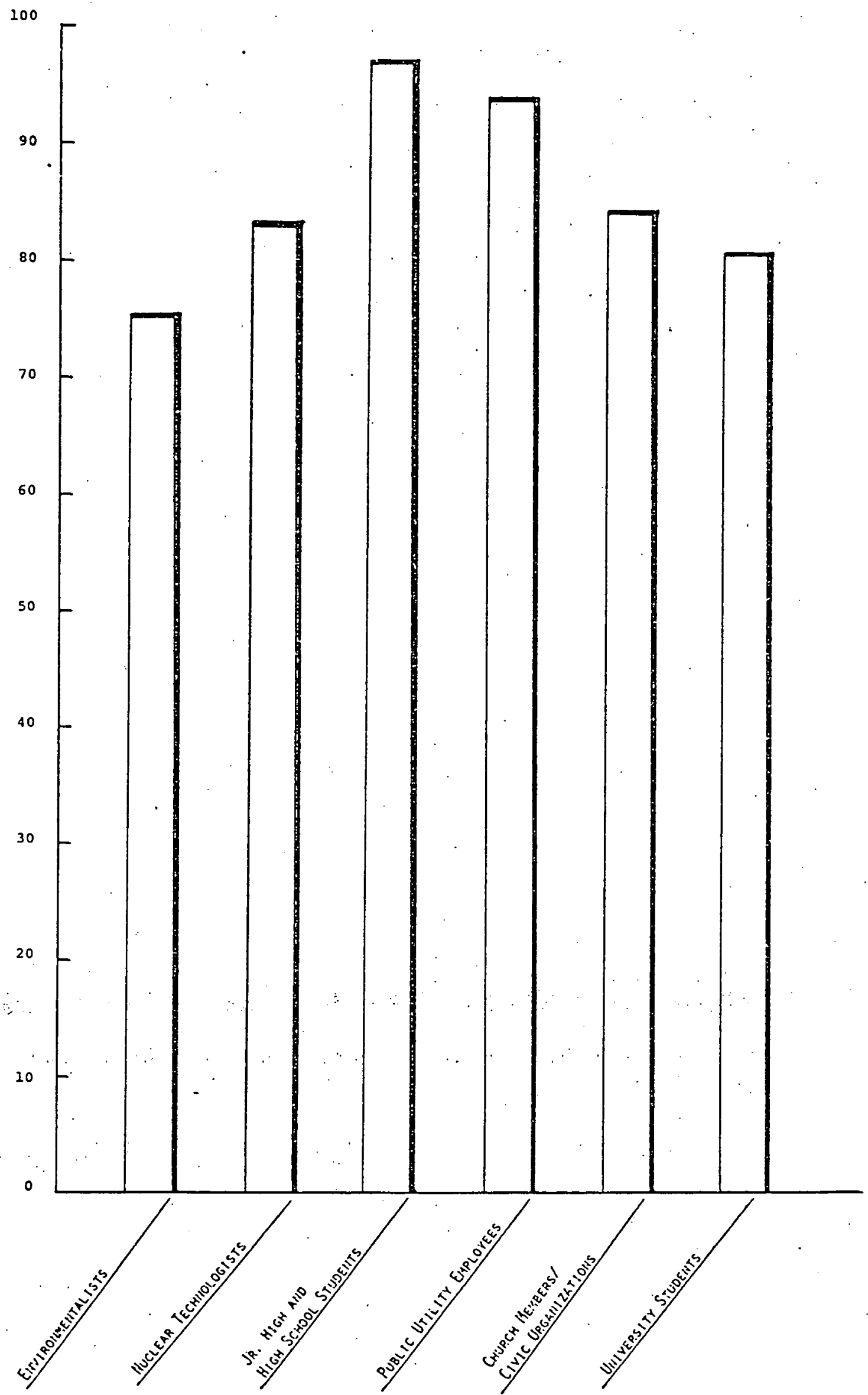

t) 
Some respondents felt that the distinction between Long-Term Safety and Accident Detection and Recovery should be sharpened. Others disagreed with the scaling of risks solely in terms of mortality rates per unit of time.

Suggestions for additional factors included consideration of long-term genetic damage or mutation, risks from sabotage, and consideration of nonnuclear sources of energy. Representative comments are presented in Appendix I. Appendix I also contains a sampling of comments which were written in the margins or on the back of the questionnaire. Many of these latter remarks also dealt with the proper selection and definition of relevant factors to consider. 


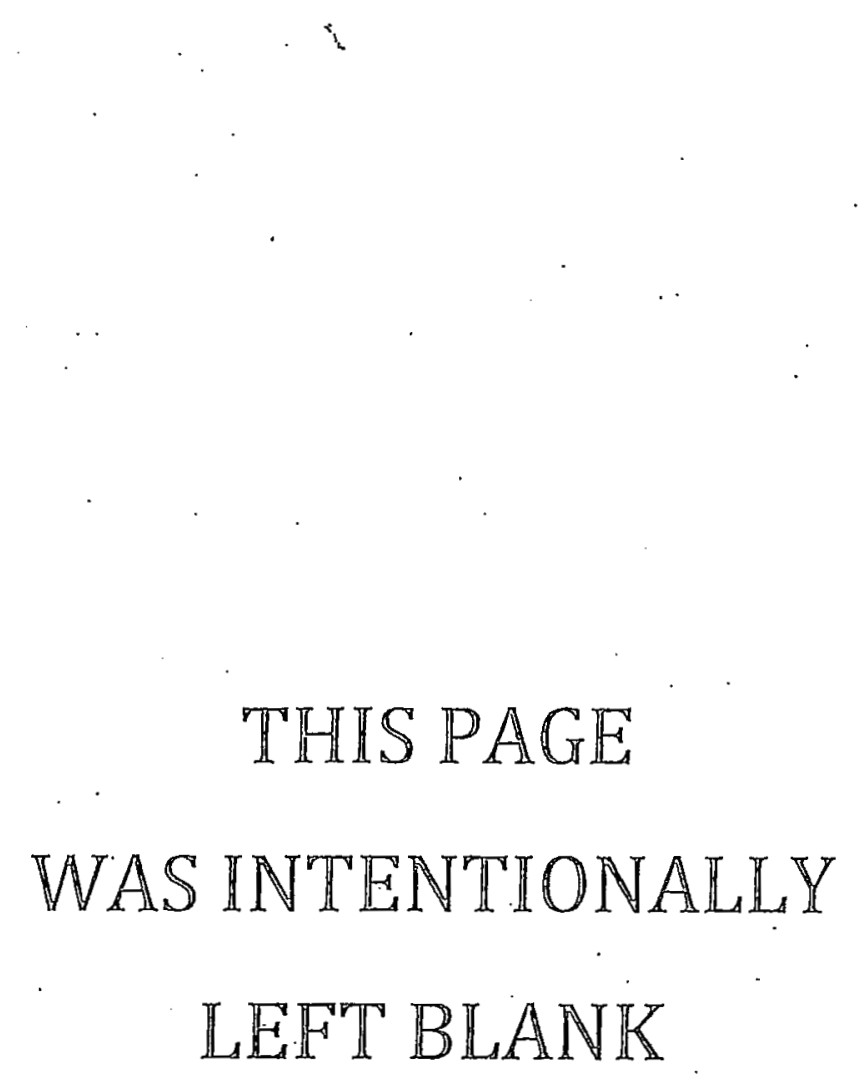




\section{SUMMARY OF RESULTS}

This chapter will present some of the highlights and major findings from each section of the previous chapter.

Sampling. Results are based upon the questionnaire responses from 465 study participants. The sample included 22 groups comprised of: junior high, high school, and university students; members of church, civic, service, and recreationist groups; members of environmental interest groups; public utility employees; public officials and nuclear engineers and scientists. Discriminant analyses, based on the questionnaire responses to a set of attitude-belief statements and questions concerning respondents' reactions to the study, produced six major "clusters". of respondents. Survey results were presented using average responses by the total sample and by the six respondent clusters.

Priorities Among Nuclear Waste Disposal Issues. Three different measurement methods (ranking, ratio estimation, and policy capturing/regression analysis) were used to assess the relative importance which respondents attached to four factors or issues associated with the design of nuclear waste disposal systems: Short-Term Safety, Long-Term Safety, Cost, and Accident Detection and Recovery. Although there were some subtle differences in the results produced by the three measurement methods; there was generally strong agreement among the three sets of results. For the total respondent sample, Long-Term Safety received the highest priority or weight, followed closely by Short-Term Safety and Accident Detection and Recovery. Cost received the lowest priority across the three measurement methods. Comparisons among the respondent clusters indicated that Environmentalists clearly attached the greatest importance to Long-Term Safety, while Nuclear Technologists tended to place the greatest emphasis on Short-Term Safety considerations. 
Evaluations of Levels of Risk and Cost. Respondents were asked to judge the satisfactoriness of several levels of risk and cost which might be associated with nuclear waste disposal systems. For Short-Term Safety, fatality rates in excess of one death per year were generally seen as unsatisfactory by the total respondent sample. For Long-Term Safety, fatality rates exceeding one death in 10 years were judged unsatisfactory.

An increase of $\$ 3.00$ in the monthly household cost for electricity were generally judged as satisfactory. For Accident Detection and Recovery, reductions in fatality rates of less than $50 \%$ were judged unsatisfactory. Comparisons among clusters of respondents indicated the following. Nuclear Technologists rated all levels of Short-Term and Long-Term risks as more satisfactory than did the other six respondent clusters. Environmentalists gave the lowest satisfaction ratings to levels of Short-Term and Long-Term risks. There were no significant differences among the clusters with respect to levels of cost. All groups rated the lower levels of fatality reduction rates as unsatisfactury. Environmentalists were least satisfied with higher levels of fatality reduction and Junior High/High School. Students gave the highest satisfaction ratings to these higher levels.

Attitude-Belief Measurement. The six respondent clusters were compared according to their agreement or disagreement with five sets of attitudinal statements which addressed the following areas: the four nuclear waste disposal factors; severity of the nuclear waste problem; safety of nuclear power; need for nuclear power as well as other sources of power; and efficiacy of alternatives to nuclear power. For all five areas, the Nuclear Technologists and the Environmentalists were the most dissimilar in their attitudes and beliefs. Average responses for the other six clusters of respondents tended to fall 
between these two respondent groups. The attitude statements which evoked the greatest degree of consensus among respondents were those dealing with the four nuclear waste disposal factors. However, the Nuclear Technologists and Environmentalists differed considerably in their attitudes about the salience of Long-Term Safety.

Nuclear Technologists and Public Utility Employees, to a lesser degree, felt the problem of nuclear waste was less serious than did the other respondent groups. The Nuclear Technologists and Environmentalists were most dissimilar in their attitudes about the safety of nuclear power; average responses for the other groups tended to fall midway between the first two groups. There was general consensus among groups that more power will be needed in the future, and, with the exception of the Environmentalists, nuclear power was perceived as a promising source of power. The Nuclear Technologists strongly disagreed that solar or geothermal power could solve the problem of additional power in the near-term, while the other respondent groups were less certain in their beliefs about these sources of power. Nuclear Technologists disagreed that conservation would remedy the need for more power, while Environmentalists were more optimistic about conservation.

Respondent Evaluation of Survey. The majority of the respondents in the study agreed: that the public should be consulted on issues such as nuclear waste disposal; that the method used in this study ( $f i l \mathrm{~m} / q u e s t i o n n a i r e)$ was an effective tool for obtaining input; and that the four factors used in the study were an effective way to conceptualize the problem. A majority of the respondents added their own comments about the study. Comments ranged from generally positive and supportive to very negative and critical of the study. Many respondents emphasized that the public needed more information in order to make informed judgements about nuclear waste disposal. 
THIS PAGE

WAS INTENTIONALLY

LEFT BLANK 
V. CONCLUSIONS

The discussion of the results of this study and their implications will be structured around three questions:

1. What do the data tell us about social values associated with nuclear waste disposal and with related issues?

2. What are the potential policy implications of the results?

3. What is the methodological relevance of this research? What work remains to be done?

What do the data tell us about social values associated with nuclear waste disposal and with related issues?

With respect to the four waste disposal factors which were stressed in this study, perhaps one of the most salient findings was the relatively high importance which many of the respondents felt should be placed on LongTerm Safety. The majority of the study participants felt that much attention should be placed upon the protection of future generations from the wastes being generated today.

One of the objectives in sample selection was to survey public officials and nuclear scientists who were currently involved in nuclear technology research and planning, and to compare their perceptinns and values with - those of public groups whom they serve. The results of the importance measurements suggested that the Nuclear Technologist groups placed somewhat less relative weight on Long-Term Safety than they did on Short-Term Safety. The Nuclear Technologists did not downgrade the importance of Long-Term considerations by any means, but they placed somewhat less priority upon this issue than did those respondents who were representative of the general public, as well as respondents who were more critical of the nuclear industry. 
The Environmentalist cluster clearly attached the greatest importance to Long-Term Safety issues. These groups did not downgrade the significance of Short-Term Safety but tended to relegate it to a slightly less important role when it was contrasted with Long-Term Safety. Indeed a dominant theme running through the results from several parts of the survey was the high priority placed on the Long-Term consideration by the Environmentalists. A major tenet in the environmentalist philosophy is the notion of man as a temporary steward of the environment, responsible for conserving and preserving it for the future. In this study, Long-Term Safety was defined within the context of nuclear waste disposal; the result's suggest that this factor was perceived as a component in the environmental ethic.

Another theme which emerges from the data is the polarization of values and attitudes among the various respondent groups. The Nuclear Technologists and The Environmentalists, in particular, differed greatly on a number of key issues. Descriptions of the results in Chapter III repeatedly contrasted and commented upon these two groups' responses, sometimes to the relative exclusion of the other groups of respondents. In many instances the results showed Nuclear Technologists to be on one side of an issue, the Environmentalists clearly on the other side, with the remaining groups somewhere "in the middle." The sampling strategy was designed to incorporate groups whose views toward nuclear power differed greatly as well as groups whose orientations were less pronounced. The results from the measurement instruments used in the study suggest that this sampling objective was reasonably well met.

The finding that cost was a relatively unimportant factor in the minds of most respondents also warrants mention. Care was taken in the way the four factors were operationally defined so that the expected values for the 
factors would be within the range of risks and costs for disposal systems. Given these best estimates of risk and cost, cost was judged to be of relatively little concern. While the data do not indicate that "cost is no object", they do reveal that economic considerations pale when compared to fatality risks for the present generation or for future generations.

One section of the questionnaire was devoted to measuring the perceived satisfactoriness or acceptability of several levels of risk and cost. The levels which respondents were asked to judge bracketed the range of risks and costs expected to be associated with waste disposal systems. The data indicate that the respondent groups varied considerably in their tolerance for risk, but agreed fairly well with respect to the acceptability of different levels of cost. Nuclear Technologists and Environmental ists differed by as much as two or three orders of magnitude in the judged satisfactoriness of Short- and Long-Term risk levels. These two groups set the risk boundaries within which the average responses for the other respondent groups fell. For the factor, Accident Detection and Recovery, there was close agreement among the respondent groups that low levels-or no reduction in fatality levels were unsatisfactory. At the higher levels of risk reduction (e.g., 90-95\%), there was a divergence among the average responses. Although all groups judged these higher levels to be more satisfactory than the lower levels, the Environmentalist cluster was the least tolerant of less-than-100\% reduction levels.

Clearly, the data suggest that the answer to the question, "How safe is 'safe enough'?" varies considerably among individuals and among groups of the public. Using the aggregated responses for the total sample of respondents, some tentative "best estimates" were derived for what appear to be 
satisfactory levels of risk and cost for nuclear waste disposal systems. For Short-Term Safety, a satisfactory level of risk probably lies in the area of one death in 10 years and one death in 50 years. A satisfactory level of Long-Term Safety probably Ties between one death in 100 years and one death per 1,000 years. For Cost, a satisfactory level of increase in monthly household electricity is approximately $\$ 3.00$. Satisfactory levels of Accident Detection and Recovery were those approximating a 95 percent reduction in fatality rates.

While the respondent groups varied somewhat in their assessment of the relative importance of nuclear waste disposal factors, the points of greatest polarization and variation in respondent values were on sets of issues of which nuclear waste disposal is one component. Nuclear Technologists and Environmentalists differed greatly in their perceptions of the severity of the nuclear waste problem and on their beliefs about the risks associated with nuclear power in general. These two groups also differed in the extent to which nuclear power was seen as an acceptable source of additional energy. There was some consensus that more power will be needed in the future, but much disagreement as to how these needs should be met. Respondents frequently mentioned that while nuclear waste disposal was a critical problem, the overriding question in their minds was whether the development of nuclear power should be continued at its present rate.

Results from the final part of the questionnaire indicated that the majority of respondents felt it was a good idea to consult the public on technological problems such as nuclear waste disposal and generally agreed that the approach used in this study was a reasonable way to obtain public input 
It is interesting to note that those groups who differed most from one another on value-attitude issues tended to be least supportive of the methodology, al though the majority of the Nuclear Technologists and Environmentalists tended to support the film/questionnaire methodology. Frequent criticisms of the method were that it "failed to address the 'real' issues" or that it was overly simplistic in its treatment of the subject matter. The self-report data from respondents tends to indicate that the film/questionnaire method had some informational/educational value for most of the respondents. However, a frequent comment was that more information would be needed in order for them to deal adequately with value issues in the area of nuclear waste disposal.

What are the potential policy implications of the results?

This study was designed to obtain public value information concerning nuclear waste disposal at a relatively early stage of overall planning and assessment activities. A number of specific findings presented may be of relevance to planners and decision makers in making early assessments of potential disposal options. First, Long-Term Safety was a high priority item in the minds of a large number of respondents. Second, respondents judged Cost to be of very minor importance when contrasted with risk considerations. Third, some tentative estimates of acceptable levels of risk were identified. To the extent that different disposal options being considered vary in Shortand Long-Term Risk, Cost, and Accident Detection and Recovery, some of these findings may be useful in assessing these options from the standpoint of public acceptance.

Some of the more general findings also appear to be highly relevant from a policy perspective. For example, there were pronounced differences among respondent groups in their appraisal of acceptable risk levels, 
in the priorities they attached to the disposal factors, and in their values and attitudes toward broader issues surrounding the topic of nuclear waste disposal. There is fairly consistent evidence that respondents who were representative of planners and decision makers differed considerably on many key issues from respondents who were more representative of the general public (and particularly from respondents with strong reservations about the efficacy of nuclear power).

The data-based results and impressionistic information gathered by the survey administrators indicate that most respondents were willing to grapple with hard questions about risk and to make considered judgments about acceptable and unacceptable risk levels. Policy making about cost/benefit and risk/benefit questions has traditionally been based on expert judgment; much of the public involvement in these policies has traditionally been reactive in nature, as evidenced by the consumerism movement, for example. In short, broad-based public input into risk/benefit decision making has been relatively lacking. Results presented in this report suggest that. it is possible to obtain information about perceived risk from a broad range of the public.

Finally, the results which point up the variation (and clashes) of values and beliefs among respondent groups can be examined from a "conflict resolution" frame of reference. A first stage in conflict resolution calls for the identification and explication of points of agreement and disagreement among affected partfes. In addition, the weights or values which parties attach to given issues are identified and made known to all participants. Armed with this information, it is assumed that the affected parties will be in a better position to work toward some level of consensus or compromise. 
Decision making on an issue such as nuclear waste disposal may or may not be amenable to widely agreed-upon choices. The points of polarization among the population may be so great as to preclude a choice which is satisfactory to all concerned parties. The orientation of the authors, nevertheless, is that while more information of the type presented in this report may not simplify the decision maker's taks, better decisions and more acceptable decisions are likely when it is available.

What is the methodological relevance of this research? What work remains to be done?

The purpose of this research was to assess public values and attitudes about a complex technological topic. This was a difficult task since 1) the general level of awareness of the problem by the public was relatively low, and 2) there was no history of pretested methodologies for obtaining this type of information. The approach taken was to communicate a small body of information to respondents about the topic and to then elicit their judgments and attitudes about the topic via a survey questionnaire. Most respondents in the study voiced approval of the approach and the rationale used, al though many pointed out areas where refinements in the approach were needed. Public input on other complex issues, if it is to be obtained early in the planning process, may require a variation of the methodology developed for this study. Providing respondents with scenarios which depict anticipated future alternatives and then obtaining their assessments of these alternatives may prove to be useful mechanisms for getting public input to crucial decisions. The research reported here constitutes an initial, exploratory effort using such an approach. Many of the results presented also suggest needed improvements and refinements in the method, 
Another objective of this research was to test the utility and applicability of several measurement methods. For example, three measurement techniques for assessing relative importance were incorporated in the questionnaire. All three methods tended to produce fairly comparable and consistent results, and the answer to 'which method is best?' may depend on the researcher's objectives. Many respondents expressed irritation with the policy capturing method in Part III of the questionnaire. This method may be a simulation, however, of the actual demands required in multi-attributed decision making, e.g., situations requiring several factors to be weighed and assessed simultaneously in deciding among alternatives. In other instances where the overriding question is one of relative priorities, a method similar to the ratio estimation procedure may be most useful.

This study focused on a set of value dimensions (i.e., Short-Term and Long-Term Safety, Cost, and Accident Detection and Recovery) which could be used to characterize all nuclear waste disposal options. Relatively little emphasis was placed upon the dispoșal options in the $f i 1 \mathrm{~m}$, and respondents were not asked to judge the acceptability of disposal options in the questionnaire. Respondents commented about this point and many expressed an interest in the actual disposal methods being considered. A useful area for future research might be directed toward furnishing public groups with information about specific methods, followed by an assessment of their attitudes and opinions of various methods. As the technical assessments and evaluations of disposal methods begin to narrow the range of options, public input regarding their acceptability could serve as vital information for decision makers. 
Finally, the relevance for decision-making purposes of the information presented in this report should be assessed in a systematic fashion. Current follow-up activities call for the feedback of survey results to key groups such as planners, decision makers, and critics. The results from this feedback process will be vitally important in suggesting new directions for subsequent research on public values. 
THIS PAGE

WAS INTENTIONALLY

LEFT BLANK 
REFERENCES

Arnstein, S., "A Ladder of Citizen Participation," American Institute of Planners, July, 1968.

Cooley, W. W. and Lohnes, P. R., Multivariate Data Analysis, New York: Wiley, 1971.

DuBois, P. H., Psychological Statistics, New York: Harper and Row, 1965 .

Kerlinger, F. N. and Pedhazur, E. J., Multiple Regression in Behavioral Research, New York: Holt, Rinehart, and Winston, 1973.

Litchfield, J. W. and Hansen, J. V., Multi-Attributed Decision Analysis Incorporating Social Values Using Utility Theory, Battelle Northwest Laboratories, BNWL SA-5410, 1975.

Naylor, J. C. and Wherry, R. J., Sr., "The Use of Simulated Stimuli and the 'JAN' Technique to Capture and Cluster the Policies of Raters:" Educational and Psychological Measurement, $1965,25,969-988$.

Runkel, P. J. and McGrath, J. E., Research on Human Behavior, New York: Holt, Rinehart, and Winston, 1973 .

Slovic, P. and Lichtenstein, S., "A Comparison of Bayesian and Regression Approaches to the Study of Information Processing in Judgement," Organizational Behavior and Human Performance, 1971, 6, 649-744.

Starr, C., "Social Benefit Versus Technological Risk," Science, 165, $1232,1969$.

Stevens, S. S., "Ratio Scales of Opinion," in D. K. Whitla (Ed.), Handbook of Measurement and Assessment in Behavioral Sciences, Reading, Mass.: Addison-Wesley Publishing Company, 1967. 


\section{THIS PAGE}

\section{WAS INTENTIONALLY}

LEFT BLANK 
This survey contains questions about several aspects of nuclear waste disposal. Much of the material, however, concerns your opinions about radiation-related risks involved in the disposal of nuclear wastes.

There are several parts in the questionnaire, and it takes about thirty to forty-five minutes to complete the entire survey. Specific instructions are given for each part and you will find that some of these instructions contain rather detailed examples and illustrations to better explain the questions which follow. Since the survey deals with opinions and attitudes, there are no "right" or "wrong" answers to the questions, so answer the questions in the way that best describes how you think or feel about each issue.

Please read all the directions carefully and answer all of the questions. Feel free to add your own comments in the margins or on the last page.

We appreciate your participation in this study and hope that you in turn will have been stimulated by the film and questionnaire. 
PART I

In this section the task is to rank the four waste disposal factors to show the order of importance you attach to them. These four waste disposal factors are listed below. Please read them over and decide how important each one is to you.

\section{Waste Disposal Factors}

1. Short-Term Safety - Those risks involved in the temporary storage, transportation, and emplacement of nuclear waste materials. These risks are largely borne by the people who used the electrical power which created the wastes. These risks would occur during a few years following the creation of the wastes.

2. Long-Term Safety - That portion of total risks which would begin after the wastes uere finally emplaced or disposed and which would continue for the next 250,000 years. These risks would be due to geologic changes and other "Acts of God," and possibly to negligence by man.

3. Cost - The dollar cost required for a given waste disposal method.

4. Accident Detection and Recovery - Steps that could be taken to reduce the consequences of an accident if it does occur after final disposal.

To help you think about the importance of these factors as you rank them, consider a hypothetical waste disposal system with the following characteristics:

Short-Term Safety: Probable risk to the U. S. population of about one death per year for the short-term period.

Long-Term Safety: Probable risk to the U. S. population of about one death in ten years over the long-term period.

Cost: Average increase in a family's cost of all electrical power, both direct and as a portion of goods and services, of: about $\$ 3$ per month.

Accident Detection and Recovery: Probable reduction in the consequences of an accident after disposal of about 75 percent.

Keeping this information about each factor in mind; please rank the four factors according to their importance to. you. 
DIRECTIONS:

There are four lines below. On the top line, write the name of the waste disposal factor which you feel is most important when compared to the others. On the second line write the factor which is next in importance. Continue until you have ranked all four waste disposal factors. The factor you feel is least important should be on the bottom line.

(Most important) 1 .

2.

3 .

(Least important) 4 . 
PART II

The objective of this section is to get more exact about how important you feel each waste disposal factor is when compared to the others. To do this you will be asked to compare the waste disposal factors two at a time and give them numbers to show their relative importance. The example below may help to explain.

Example: Let's say someone asked you to compare various public bus systems. Three factors for consideration might be frequency of service, cost of fares and time to get to destiniatiun. Let's say you ranked these as follows:

$\begin{array}{cll}\text { (most important) } & \text { 1. } & \text { Time } \\ & \text { 2. } & \text { Fares } \\ \text { (least important) } & \text { 3. Frequency }\end{array}$

A more exact ranking involves giving the two factors in each pair numbers to show how much more important one is than the other. For example, the first pair, time and fares, is written below with numbers in the boxes to show how important each might be. The first number of each pair is alvays assigned the value of 100 . By making the second number 95, it shows that fares were seen as almost as important as time.

$$
\begin{aligned}
& \text { 1. Time } 100 \text { Example? } \\
& \text { 2. Fares } 95
\end{aligned}
$$

If fares were seen as much less important than time, a smaller number, like 30 or $10 \mathrm{might}$ he given to fares. The point is, you choose a number for the second factor in the pair to show how important 1t is when cumparred to the first factor in the-pair.:

Example 2 below shows how the second pair of factors: fares and frequency, might be rated to show that frequency was considered about half as important as fares.
1. Fares 100 Example 2
2. Frequency 50 


\section{DIRECTIONS :}

There are three pairs of lines below. On the top line, copy the name of the factor you ranked as most important back in part I. Then on the next two lines, both marked "2." copy the name of the factor you ranked as second in importance. On the two lines marked "3.", write the name of the factor you ranked as third in importance in Part I. Finally on the last line, marked "4.", write the name of the factor you ranked as least important.

The box beside the first factor of each pair already has the number 100 written in it. For the second factor of each pair, write a number to show how important you think the second factor is when compared to the first factor, of that pair.

1.

2.

2.

3.<smiles>C1C2CC12</smiles>

3.

4. 


\section{PART III}

In the first two sections of the survey, you compared the four factors with one another and ranked them according to the importance you attached to each. In this section, we ask you to examine each factor separately and make several judgments about each factor. The reason for doing this is that the importance you attach to a factor may really depend on the value or size of that factor.

To illustrate this point, recall the example in Part II which considered Iime, Fare, and Frequency in a mass transit system. If you assumed that the Fare would be perhaps 25\% or 50k, you may have seen Fares to be relatively unimportant when compared with the convenience associated with faster Time or more Frequent service. However, if you assumed or learned that the Fare would be $\$ 10$ or $\$ 20$ per trip, then it's quite possible you would place more importance on Fares when compared with Time and Frequency!

In the exercise which follows, we want you to look at each of the four factors and indicate how satisfactory you think various levels of risk, cost, and accident recovery would be in the case of nuclear waste disposal. The risks of interest in this study are those due to the special nature of nuclear power, i.e., risks due to radiation rather than general industrial risks.

As you judge each of the factors, we would like for you to think about risk and cost (1) from the standpoint of society at large rather than from an individual point of view and (2) in terms of the benefits which are associated with these risks and costs. For example, we as individuals would all agree that the national death rate from automobile accidents is highly undesirable. On a societal basis, however, most members of our society apparently have been willing to accept these risks in order to receive the benefits of automobile transportation.

In reviewing the risks and costs of àisposing of núlieàr wastes, the benefits come from the electricity generated by nuclear power plants. Most energy planners believe that coal and nuclear resources will have to provide the bulk of our electrical energy for the rest of this century. If present trends continue, it has been estimated that approximately 50\% of our electrical energy will come from nuclear power by the year 2000. The issue of interest in this section of the survey is, "What risk levels and costs are satisfactory and justifiable to society and which are unsatisfactory to society in relation to the benefits"?

Your responses on the following pages will give an indication of how satisfactory you feel various levels of risk and various levels of cost are for each of the four factors. 


\section{SHORT-TERM RISKS}

Statistics from the National Safety Council are shown below to provide a framework for thinking about risk and to illustrate the expected range of risks for the Short-Term Risk factor. We have marked the section of this range of risks which can reasonably be associated with nuclear waste disposal for the short-term. On the following page, you are asked to make judgments about how satisfactory these levels of Short-Term risk are.

Accidental \& Disease Caused

Deaths in the U.S. During 1970

(Source: National Safety Council)

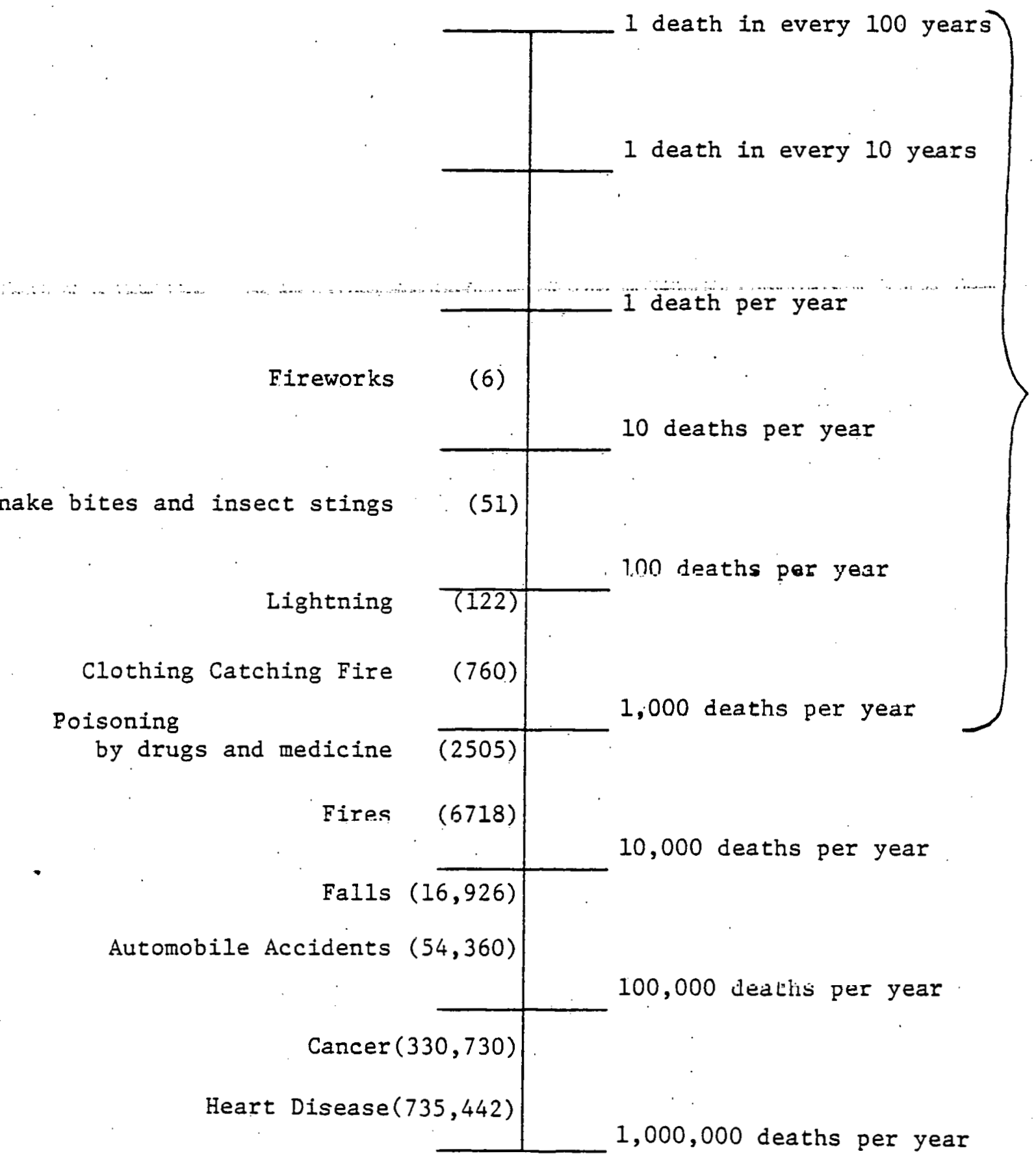

Range of shortterm risks that can reasonably be associated with proposed methods. 
Proposed methods for disposing of nuclear wastes will differ some what from one another in the extent to which they are safe for the short-term. It is estimated, however, that the range of risks shown below covers all proposed methods. On the scale below, please consider each risk level and indicate how satisfactory or unsatisfactory you think it would be for our society to bear that level of risk.

By "Satisfactory" we mean that the benefits justify the risks. In other words, "Satisfactory" lives up to our expectations as a good system. At the other end of the scale, a very unsatisfactory risk is one that falls far short of our expectations. The risks are greater than the benefits. Clearly, a Very Unsatisfactory system would need improvement before implementation.

DIRECTIONe: Flace an "X" on each line below at the point which best describes how you evaluate each risk level. (You will note that we have taken the lowest level of short-term risk that appears possible, "I death in 100 years", and arbitrarily given it a score of 10. This was necessary to provide a common starting point for everyone.) Starting on the second line below, place an " $X$ " at the place which best describes your evaluation of that level of risk. Then continue on through the rest of the lines.

Deaths Per Year in U.S.

(Assumes a population

of 220 milition)

\section{Very \\ Unsatisfactory Satisfactory}

1 death in 100 years

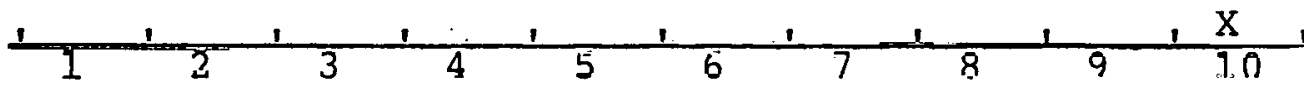

1 death in 50 years

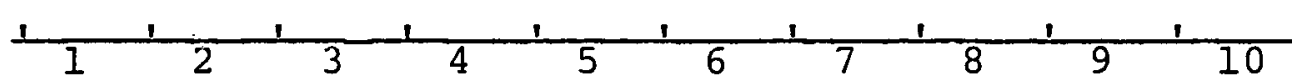

1 death in 10 years

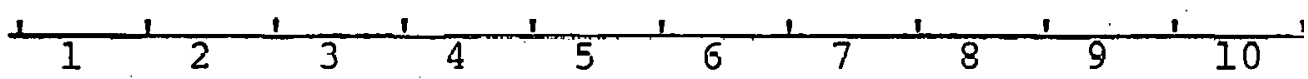

1 death per year

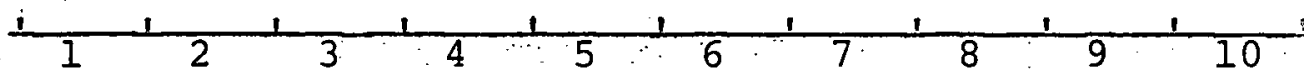

10 deaths per year

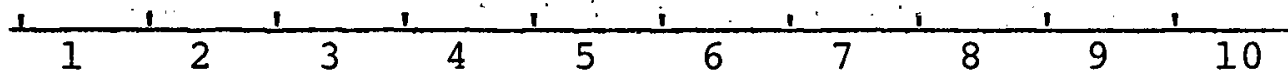

100 deaths per year

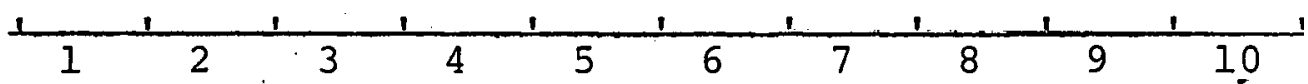

1,000 deaths per year

$\begin{array}{lllllllllll}1 & 1 & & & 1 & & & & & & \\ 1 & 2 & 3 & 4 & 5 & 6 & 7 & 8 & 9 & 10\end{array}$




\section{LONG-TERM RISKS IN NUCLEAR WASTE DISPOSAL}

It is anticipated that once nuclear wastes have been transported and put in their final disposal location (all features of shortterm risks), the long-term risks will be quite small. On a yearly basis, these risks will likely be far less than the chance of being struck by lightning. However, these risks will go on for thousands of years, and even small risk levels, if carried out over a long period of time, have the potential for causing a substantial number of deaths.

DIRECTIONS: As you did in the case of Short-Term Risks, examine the information below and place an " $X$ " at the place on each line which best describes your judgment. Again, the lowest level of Long-Term Risk has been assigned a value of 10 , or "Satisfactory."

Deaths Per Year in U.S.

(Assumes a Constant

Population of 220 million)

Very

Unsatisfactory

Satisfactory

1 death per 100,000 years

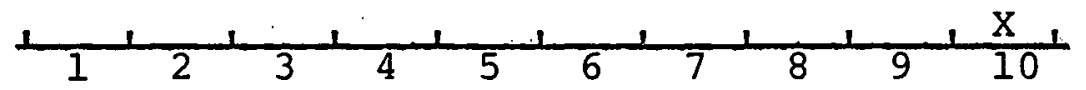

1 death per 10,000 years

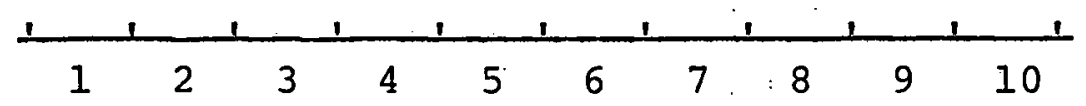

1 death per 1,000 years

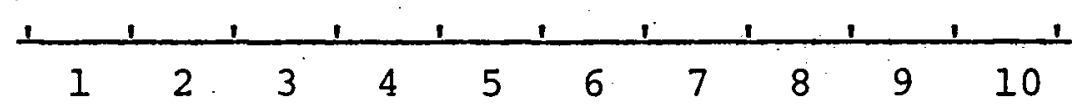

1 death per 100 years

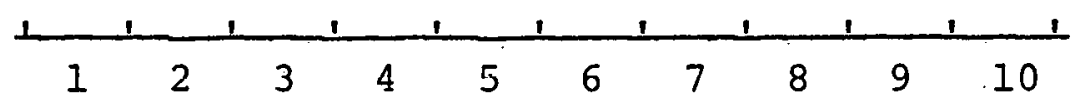

1 death per 10 years

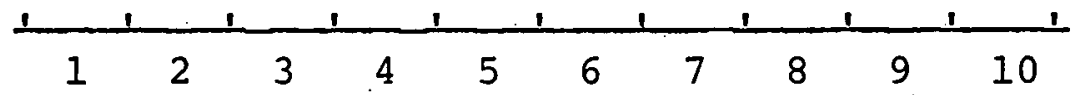

1 death per year

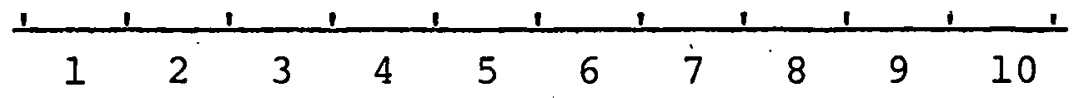

10 deaths per year

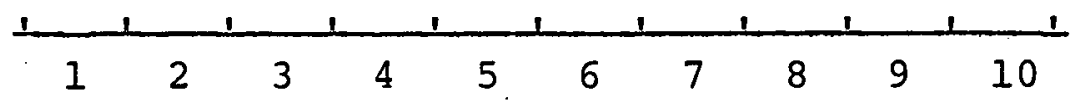

100 deaths per year

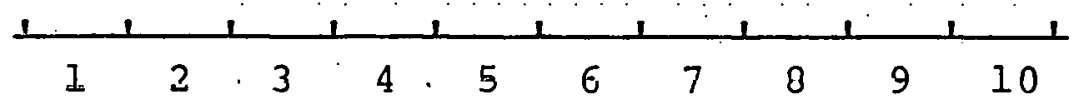


COST OF NUCLEAR WASTE DISPOSAL

Disposal of nuclear wastes using any of the methods now under consideration will involve substantial dollar costs running into many millions of dollars. Some nethods, such as launching the wastes into outer space, would be more expensive than other methods, such as placing them in a mined cavity beneath the earth's surface.

The scales below reflect the costs of nuclear waste disposal as increases in the monthly costs you pay for electrical power. These figures represent average increase in a family's cost of all electrical power, both direct and as a portion of the increased price of goods and services.

DIRECTION: Examine the information below and place an " $\mathrm{X}$ " at the place on each line which best describes your evaluation. An increase of 10 \& per month has been assigned a value of 10 or "Satisfactory."

Increase in Monthly Cost of Power

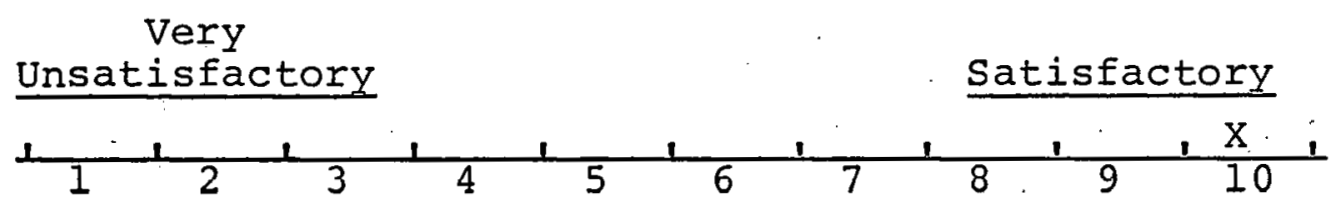

$$
\begin{aligned}
& \$ 1.00 \\
& \$ 2.00 \\
& \$ 3.00
\end{aligned}
$$
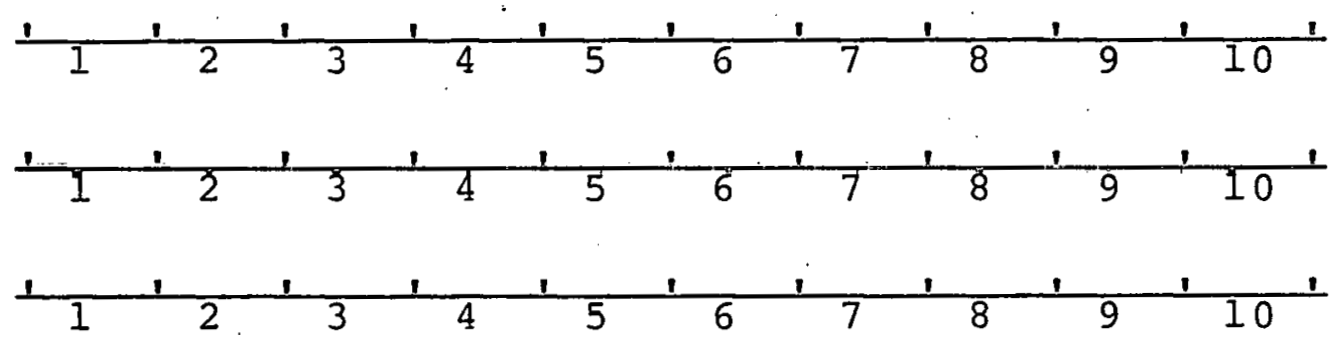

$\$ 5.00$

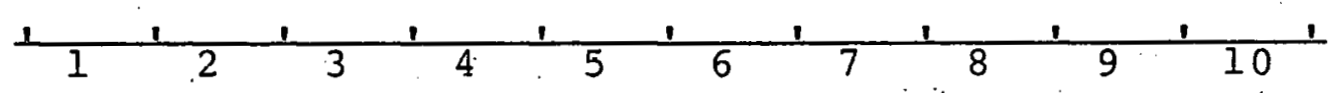

$\$ 10.00$

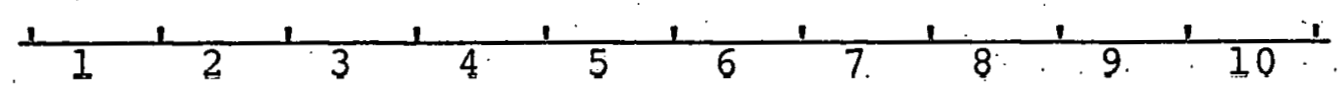

$\$ 15.00$

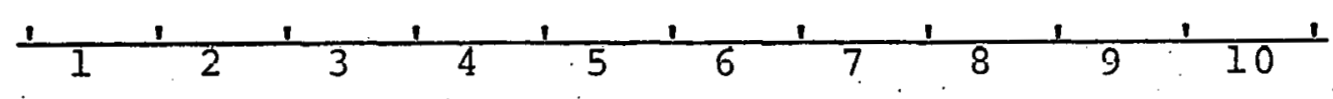




\section{ACCIDENT DETECTION AND RECOVERY}

As pointed out in the film and in the beginning of the questionnaire, accident detection and recovery involves the extent to which a waste disposal method allows for: the early detection of leaks; the ability to take protective reaction measures if wastes were to escape into man's environment; and the ability to retrieve the wastes if necessary. Thus, this factor deals with the potential reduction in the consequences of a waste leak if it occurred. To the extent that various proposed disposal methods have Accident Detection and Recovery mechanisms built in, the effects of waste leaks could be minimized.

To illustrate the concept of Accident Detection and Recovery, consider two fairly familiar examples: automobile safety and hurricanes. Although automobiles kill over 50,000 people in the U.S. each year, over the past 50 years the number of deaths per million miles driven by U.S. citizens has gradually decreased. This decrease has occurred even though there have been increases in the total num-. ber of automobiles on the highways. Part of this decrease in deaths per mile can be explained by the development of measures which reduce the potential for injuries after an accident occurs. Such measures include: safety belts, padded dashboards, energy-absorbing steering wheels, and also better, more efficient emergency health care procedures.

As a second example, the number of hurricanes that strike the Atlantic and Gulf coasts has not decreased over the years, but the death toll from hurricanes has been reduced over the years. This reduction in deaths can be explained, in part, by such factors as: better detection and early warning devices like radar and weather satellites, better evacuation procedures, better emergency medical care, and better disease control procedures in the hurricane's aftermath.

Similarly, the effects of potential leakage of nuclear waste materials into man's environment could be minimized. Designing into the disposal method various mechanisms for reacting to leaks of nuclear wastes could reduce the number of deaths in ways similar to those described for automobiles and hurricanes. 


\section{ACCIDENT DETECTION AND RECOVERY}

The scales below contain examples of reductions in the number of deaths in an incident involving nuclear wastes. All of the examples use a waste accident which would take 100 lives as a starting point. Each example involves a reduction from a larger number to a smaller number of deaths which represents the reduction in risk which might be achieved if various accident recovery measures were present.

DIRECTIONS: Examine the information below and place an " $\mathrm{X}$ " at the place on each line which best describes your evaluation. $A$ reduction in deaths from 100 to 1 has been assigned a value of 10 or "Satisfactory".

Reduction in The Number of Deaths From A Nuclear Waste Accident

From 100 to 1

From 100 to 5

From 100 to 10

From 100 to 25

From 100 to 50

From 100 to 75

No Reduction

\section{Very \\ Unsatisfactory}

Satisfactory

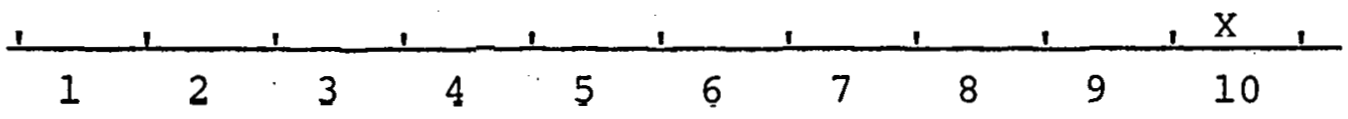

$\begin{array}{llllllllllll}1 & 1 & & & & & & & 1 & 1 & 1 & 1\end{array}$
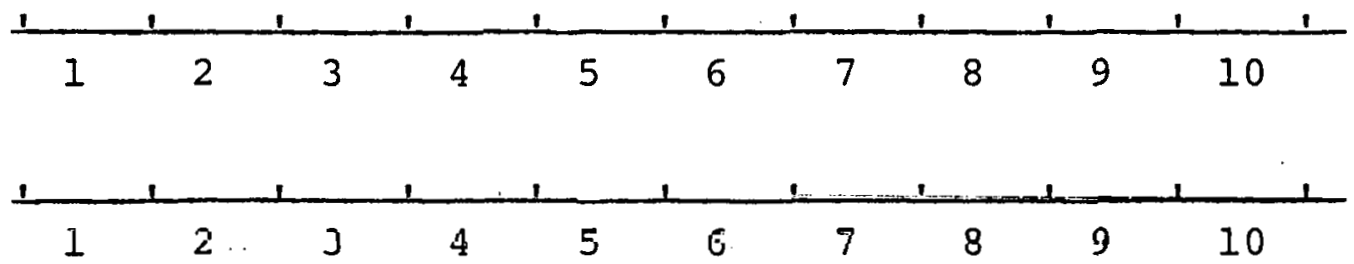

$\begin{array}{llllllllllll}1 & 1 & & & 1 & & & & 1 & 1 & 1 & 1\end{array}$

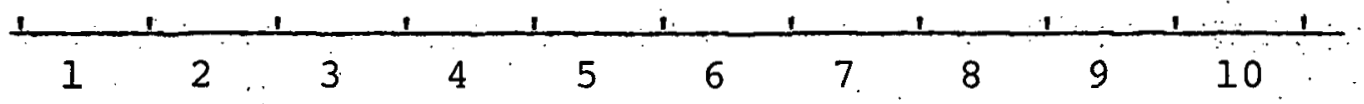

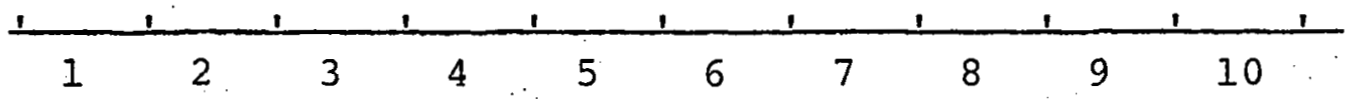


In this section, the four waste disposal factors will be used to "construct" several hypothetical waste disposal systems. These disposal systems will be described by the way they stand on the four waste diṣposal factors taken together.

The waste disposal system described in Example 1 below has high "scores" for short-term safety and economy; in other words it would be very safe for the short-term and very economical. Example 1 also has a moderately high score for long-term safety and a low score for accident detection and recovery; in other words it would be moderately safe for the long-term but lacks provision for good accident recovery.

Example 1

\begin{tabular}{|l|l|}
\hline \multicolumn{1}{|c|}{ Factors } & Scores \\
\hline Safe for the Short-Term & \\
Safe for the Long-Term & \\
Economical & \\
Accident Detection and Recovery & \\
\hline
\end{tabular}

By contrast, Example 2 would be quite different from Example 1. The second example would be low in safety for the short-term, very high in safety for the long-term, quite uneconomical, and very high in provision for accident detection and recovery. Longer lines indicate greater amounts of each factor and shorter lines represent lesser amounts of each factor.

Example 2

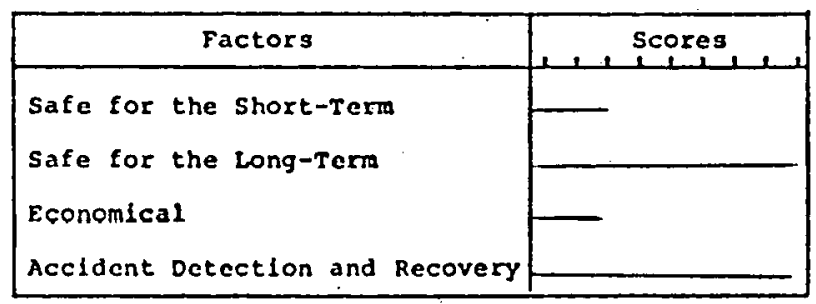

On the pages that follow, a number of hypothetical waste disposal methods are described by combining various amounts of the four waste disposal factors. The objective of this part is to find out how acceptable each of these hypothetical waste disposal methods is to you. 
DIRECTIONS: Below each hypothetical method is a line with ten numbers representing a range from "very unacceptable" to "very acceptable." Please place an " $X$ " at the place on the line to show how you feel about that method. For instance, if you feel that the first example shown is "very unacceptable," place an " $X$ " on the line above "1." If you think it is "very acceptable," place an " $X$ " on the line above "10." If you think it is "neither acceptable nor unacceptable," you might place an " $X$ " above "5."

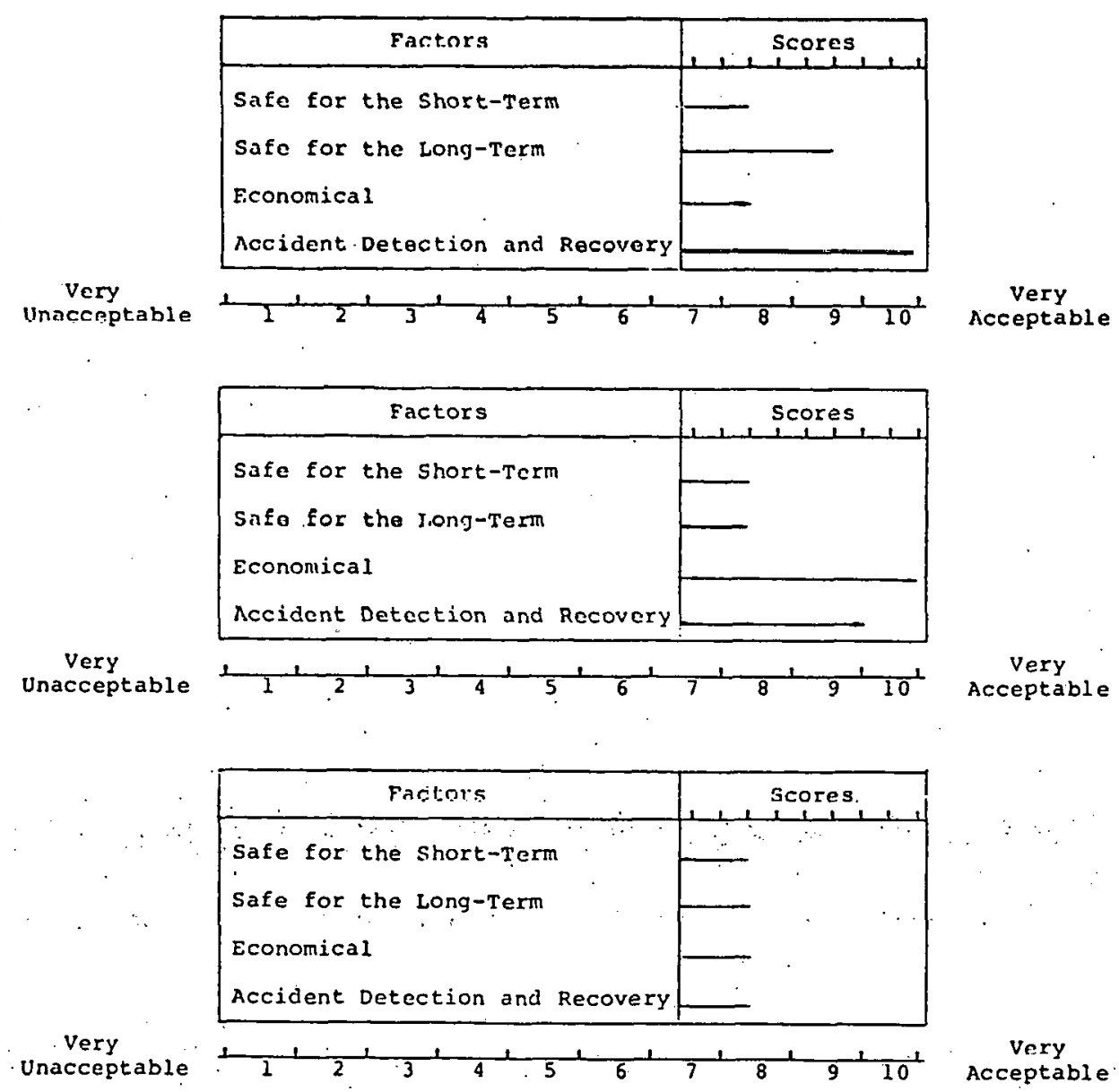




\begin{tabular}{|l|l|}
\hline \multicolumn{1}{|c|}{ Factors } & Scores \\
\hline Safo for the Short-Term & \\
Safe for tho Long-Term & \\
Economical & \\
Accident Detection and Recovery & \\
\hline
\end{tabular}
Very
Unacceptable

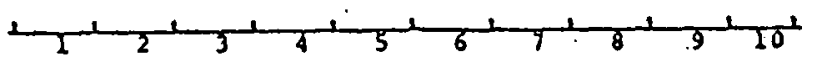
Acceptablo very.

\begin{tabular}{|l|l|}
\hline \multicolumn{1}{|c|}{ Factors } & Scores \\
\hline Safe for the Short-Term & \\
Safe for the Iong-Term & \\
Economical & \\
Accident Detection and Recovery & \\
\hline
\end{tabular}
Unacceptable

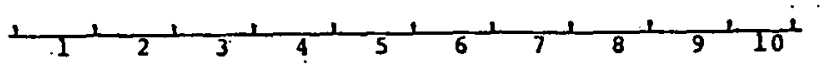

very Acceptable

\begin{tabular}{|l|l|}
\hline \multicolumn{1}{|c|}{ Factors } & Scorcs \\
\hline Safe for the Short-Term & \\
Safe for the Long-Term & \\
Economical & \\
Accident Detection and Recovery & \\
\hline
\end{tabular}

very Unacceptable

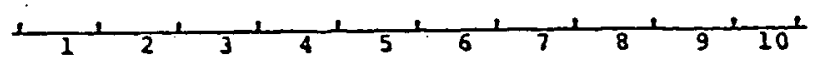
Acceptable

\begin{tabular}{|l|l|}
\hline \multicolumn{1}{|c|}{ Eactors } & Scores \\
\hline Safe for the Short-Term & \\
Safe for the Long-Term & \\
Economical & \\
Accident Detection and Recovery & \\
\hline
\end{tabular}
Very
Unacceptable

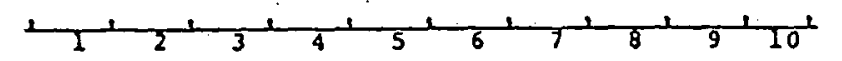
ncceptable

\begin{tabular}{|l|l|}
\hline \multicolumn{1}{|c|}{ Factors } & Scores, \\
\hline Safe for the Short-Term & \\
Safe for the Iong-Term & \\
Economical & \\
Accldent vetection and Recovery & \\
\hline
\end{tabular}

Very Unaccoptablo

$$
\begin{aligned}
& 1
\end{aligned}
$$

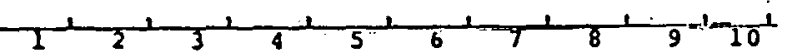

\begin{tabular}{|l|l|}
\hline \multicolumn{1}{|c|}{ Factors } & Scorea \\
\hline Safe for the Short-Term & \\
Safe for the Long-Term & \\
Economical & \\
Accident Detcction and Recovery & \\
\hline
\end{tabular}

Very Unacceptablo 


\begin{tabular}{|l|l|}
\hline \multicolumn{1}{|c|}{ Factors } & Scorca \\
\hline Safo for the Short-Term & \\
Safo for tho Long-Term & \\
Economical & \\
Accident Detection and Recovery & \\
\hline
\end{tabular}

Very Unacceptablo

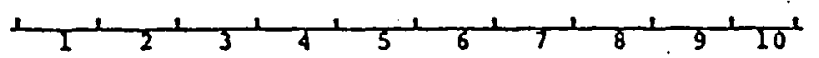

\begin{tabular}{|l|l|l|}
\hline \multicolumn{1}{|c|}{ Factors } & \multicolumn{1}{|c|}{ Scorcs } \\
\hline Safe for the Short-Term & \\
Safe for the Iong-Term & \\
Economical & \\
Accident Detection and Recovery & \\
\hline
\end{tabular}

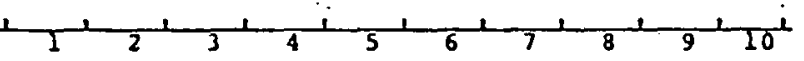

very Acceptable

\begin{tabular}{|l|l|}
\hline \multicolumn{1}{|c|}{ Pactors } & \multicolumn{1}{|c|}{ Scoies } \\
\hline Safe for the Short-Term & \\
Safe for the Long-Term & \\
Economical & \\
Accident Detection and Recovery & \\
\hline
\end{tabular}

very Unacceptable

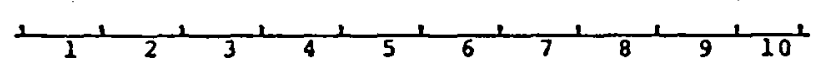

Very Acceptable

Very Unacceptable

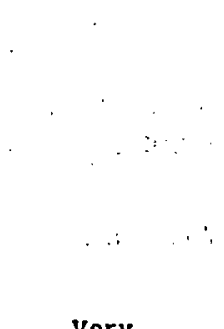
Unacceptable

\begin{tabular}{|l|l|}
\hline \multicolumn{1}{|c|}{ Pactors } & Scores \\
\hline Safe for the Short-Term & \\
Safo for the Long-Term & \\
Esononlcal & \\
Accident Detection and Recovery & \\
\hline
\end{tabular}

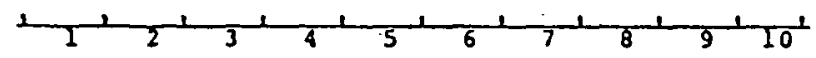
Acceptable

\begin{tabular}{|l|c|}
\hline \multicolumn{1}{|c|}{ Factors } & Scores \\
\hline Safe for the Short-Term & \\
Safe for the Iong-Term & \\
Fconomical \\
Accident Detection and Recovery
\end{tabular}

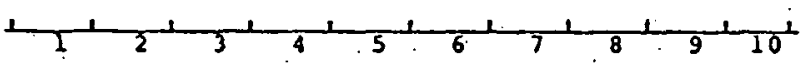

\begin{tabular}{|l|l|}
\hline \multicolumn{1}{|c|}{ Factors } & Scores \\
\hline Safe for the Short-Term & \\
Safe for the Long-Term & \\
Economical & \\
Accldent Detcction and Recovery & \\
\hline
\end{tabular}

Very Unacceptable

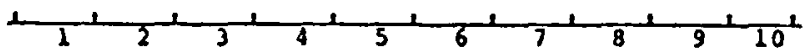




\begin{tabular}{|l|l|}
\hline \multicolumn{1}{|c|}{ Eactors } & Scores \\
\hline Safo for the Short-Term \\
Safe for tho Long-Term \\
Economlcal \\
Accident Detection and Recovery
\end{tabular}

Very Unacceptable

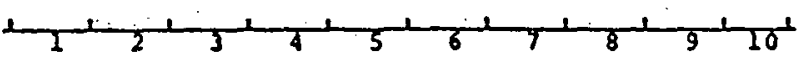

\begin{tabular}{|l|l|}
\hline \multicolumn{1}{|c|}{ Factors } & Scores \\
\hline Safe for the Short-Term & \\
Safe for the Iong-Term & \\
Economical & \\
Accident Detection and Recovery & \\
\hline
\end{tabular}

Very Unacecptable

very Unacceptable

Very Unacceptable

Very Unacceptable le

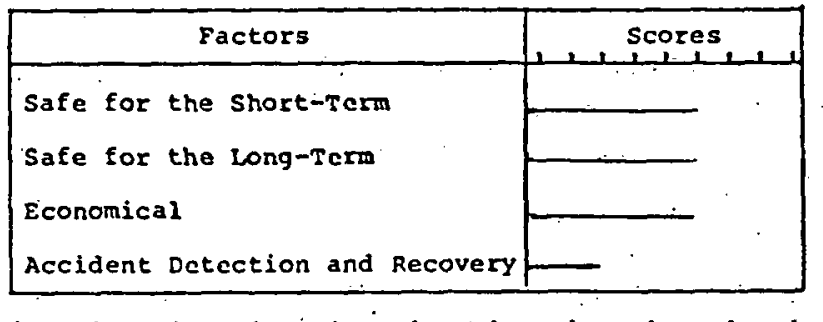

$$
1
$$

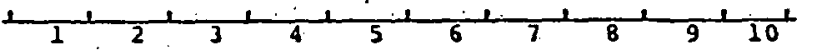

\begin{tabular}{|l|l|}
\hline \multicolumn{1}{|c|}{ Factors } & Scores \\
\hline Safe for the Short-Term & \\
Safe for the Long-Term & \\
Economical \\
Accident Detection and Recovery
\end{tabular}$$
\text { e }
$$

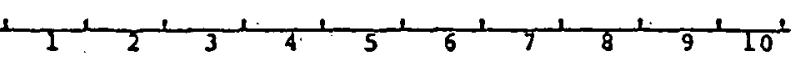

\begin{tabular}{|l|l|}
\hline \multicolumn{1}{|c|}{ Factors } \\
\hline Safe for the Short-Term \\
Safe for the Iong-Term \\
Economical \\
Arcident Detection astd Recovery
\end{tabular}

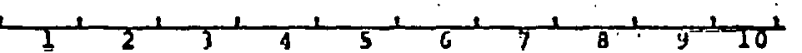

$$
\text { . }
$$

\begin{tabular}{|l|l|}
\hline \multicolumn{1}{|c|}{ Factors } \\
\hline Safe for the Short-Terim \\
Safe for the Long-Terma \\
Economical \\
Accldent Detection and Recovery
\end{tabular}

Very Unacceptable

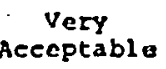

Very

Very Acceptable Acceptable Acecptable 


\begin{tabular}{|l|l|}
\hline \multicolumn{1}{|c|}{ Sactors } & Scorcs, \\
\hline Safo for the Short-Term & \\
Safo for the Long-Term & \\
Economical & \\
Accident Detection and Recovery & \\
\hline
\end{tabular}
Very
Unacceptable

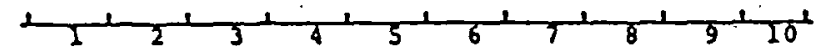
Acceptabla

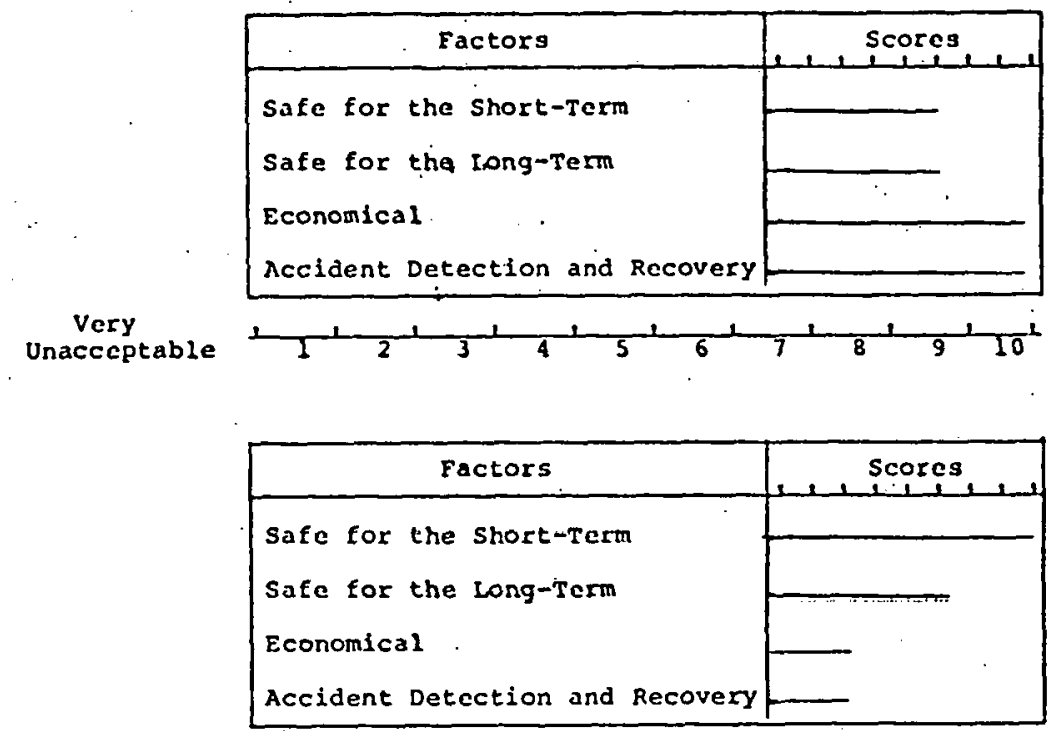

Very Unacceptable

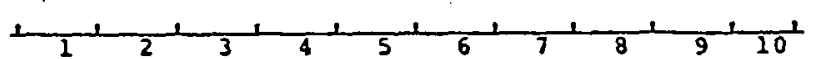

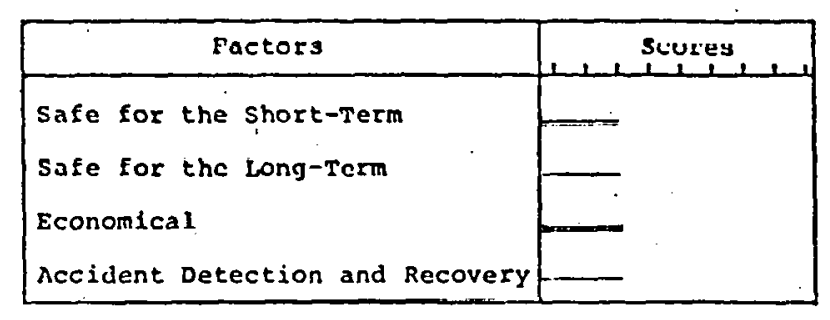

Very Unacceptable

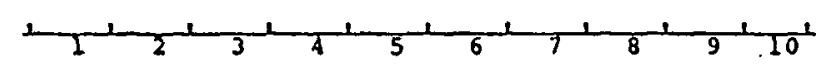

Very Acceptable

\begin{tabular}{|l|l|}
\hline Factors & Scores \\
\hline Safe for the short-Term \\
Safe for the rong-Term \\
Economical \\
nccident Detection and Recovery
\end{tabular}

Very
Unacceptable

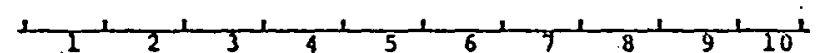

Acceptabla

\begin{tabular}{|l|l|}
\hline \multicolumn{1}{|c|}{ Factors } & \multicolumn{1}{|c|}{ Scores } \\
\hline Safe for the Short-Term & \\
Safe for the Long-Term & \\
Economical & \\
Accident Detection and Recovery & \\
\hline
\end{tabular}

Very 
The three hypothetical waste disposal methods shown on this page do not have lines drawn beside the factors. For these three we want you to draw in the lines to describe three methods.

For the first method, draw lines beside each of the four factors to describe what you think the best or the ideal waste disposal system would look like.

1. Best or Most Ideal Method

\begin{tabular}{|l|l|}
\hline \multicolumn{1}{|c|}{ Factors } & Scores \\
\hline Safe for the Short-Term & \\
Safe for the Long-Term & \\
Economical & \\
Accident Detection and Recovery & \\
\hline
\end{tabular}

In the second method, draw lines beside each of the four factors to describe a waste disposal system which would just meet your minimum standards for an acceptable system.

2. Minimum Acceptable Method

\begin{tabular}{|l|l|}
\hline \multicolumn{1}{|c|}{ Factors } & Scores \\
\hline Safe for the Short-Term & \\
Safe for the Long-Term \\
Economical \\
Accident Detection and Recovery
\end{tabular}

Finally, for the third method, draw lines to describe the waste disposal method which is most like the method that you think will actually be put into practice in the United States.

3. 'Most Likely Method

\begin{tabular}{|l|l|}
\hline \multicolumn{1}{|c|}{ Factors } & Scores \\
\hline Safe for the Short-Term & \\
Safe for the Long-Term & \\
Economical & \\
Accident Detection and Recovery & \\
\hline
\end{tabular}


PART V

In this part of the questionnaire we would like to have your opinions about a wide variety of issues involved with nuclear waste disposal. Some are broader and some are more specific than the issues already considered in the first four sections of this questionnaire.

DIRECTIONS: READ EACH STATEMENT AND INDICATE HOW MUCH YOU AGREE OR DISAGREE WITH IT BY CIRCLING ONE OF THE FIVE ANSWER CHOICES. BESIDE EACH STATEMENT.

1. Overpopulation and economic conditions are more serious threats to our way of life than the problem of nuclear waste disposal.

2. Nuclear wastes should be disposed of in such a way that no vile will ever be able to a1sturb or recouver them.

3. In dealing with nuclear wastes, cost should be of no concern.

4. Based on the information I got from this study, the hazards of nuclear wastes are less serious than I thought.

5. In the next 10 years, solar power could solve the problem of electrical power in the U.S.

6. The loss of even one life from nuclear waste is unacceptable.

7. The U.S. can maintain a strong economy without having nuclear power.

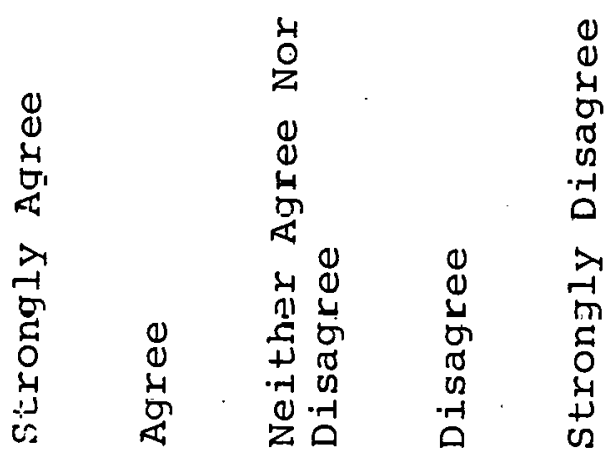

SA $\quad A \quad A D \quad$ D $\quad$ SD

$\begin{array}{lllll}S A & A & A D & D & S D\end{array}$

SA A $\quad A D \quad$ D $\quad S D$

SA $\quad$ A $\quad A D \quad$ D $\quad$ SD

SA $A \quad A D \quad$ D $\quad$ SD

SA. A AD $\quad$ D $\quad$ SD

$\begin{array}{lllll}S A & A & A D & D & S D\end{array}$ 
8. The construction of nuclear power plants should be slowed until an absolutely safe waste disposal system has been developed and thoroughly evaluated.

9. Nuclear waste is one of the most serious threats facing the world.

10. The radioactive hazards in nuclear power are no greater than the environmental hazards from coal burning power plants.

11. Future generations must be totally safe from our nuclear waste.

12. In my opinion, the information contained in this study seriously underestimates the real risks of nuclear wastes.

13. The benefits of nuclear power more than outweigh the hazards in nuclear waste storage and disposal.

D

$S D$

SA $\quad A \cdot A D$

D SD

SA A AD

D SD

SA A. AD

D SD

14. Nuclear power is the most promising source of electrical power for the next 30 years.

15. Whatever disposal system is devised, there must be a way to detect leaks and recover the waste.

16. Before I got involved in this study, I knew very little about the problem SA $S A \cdot A \quad A D$ $S D$ of nuclear wastes.

SA

A $\quad A D$

D

SD

SA $\quad$ A $\quad A D \quad$ D $\quad$ SD 
17. The construction of additional electrical power plants will not be necessary for the U.S. to maintain its present standard of living.

18. I would not want to have nuclear wastes disposed of in my region of the country.

19. The generation that uses nuclear porver should take all the risks for waste disposal.

20. Government and industry have done a good job of keeping the public informed about the advantages and disadvantages of nuclear power.

21. Based on past operating experience, nuclear energy has been demonstrated to be a clean and safe source of electrical power.

22. Participating in this study makes me realize just how frightening nuclear waste is.

23. In the next 10 years, geothermal power could solve the problem of electrical power in the U.S.

24. Using more coal is far less harmful to man than using nuclear power.

SA A $\quad A D$

$S A$

A $\quad A D$

D

SD

SA A AD

D

SD

SA A AD

D

SD

SA A AD

D

SD

$S A \quad A \quad A D$

D

SD

25. To satisfy critics; the U.S. nuclear waste system will probably cost far more than is necessary.

SA A A A A D $\quad$ SD

$\mathrm{SA} \cdots \mathrm{A}, \mathrm{AD} \cdots \mathrm{D} \cdot \mathrm{SD}$


26. Paying a little more attention to conservation would make more electrical power unnecessary.

27. We should immediately stop developing nuclear technology as an energy source.

28. The main concern of nuclear waste planners should be a safe system for the short term.

29. Compared to other problems that future generations will face, nuclear waste monitoring is insignificant.

30. If the United States does not increase the production of electricity, our economy will decline.

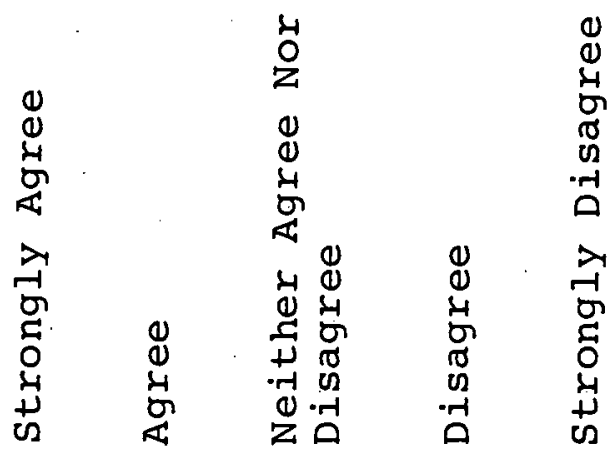

$\begin{array}{lllll}S A & A & A D & D & S D\end{array}$

SA $\quad$ A $\quad A D \quad$ D $\quad$ SD

$\begin{array}{lllll}S A & A & A D & D & S D\end{array}$

SA A $A D$ D $\quad$ SD

$\begin{array}{llllll}S A & A & A D & D & S D\end{array}$ 
PART VI

\section{Evaluation of Survey}

The questions below deal more with this particular study than with the subject of nuclear waste disposal. We are interested in getting your opinions about the effectiveness of the procedures used in this study for obtaining public input. Circle the number beside each question which best describes your opinion.

1. The information presented in the film was:
A. Very easy to understand
$\begin{array}{lllll}1 & 2 & 3 & 4 & 5\end{array}$
56
6
7 Very difficult to understand its coverage of
the topic
B. Very complete in

12

3
45
56
67 Very incomplete
C. Very biased and $1 \begin{array}{llllllll}2 & 3 & 4 & 5 & 6 & 7 & \text { Very unbiased }\end{array}$ one-sided in coverage and balanced in coverage

2. The questions and issues raised in the questionnaire were:
A. Very easy to understand
$1 \cdot 2$
34
56

$(7$
7 Very difficult to understand
B. Too few in num- ber

1 problem of vaste disposal
C. Relevant to the

$\begin{array}{llllll}1 & 2 & 3 & 4 & 5 & 6\end{array}$
7 Too many in number
7 Irrelevant to the problem of waste disposal

3. What suggestions do you have which would improve the quality of the film or questionnaire?

4. Before you participated in this study, how well-informed were you about the subject of nuclear waste disposal:

Very well-informed $\begin{array}{lllllllll}1 & 2 & 3 & 4 & 5 & 6 & 7 & \begin{array}{c}\text { Not at all } \\ \text { informed }\end{array}\end{array}$


5. After participating in this study, how well-informed do you feel you are on the subject of nuclear waste disposal?

Very well-informed $1 \quad \begin{array}{lllllllll} & 2 & 3 & 4 & 5 & 6 & 7 & \text { Not at all }\end{array}$ informed

6. Do you think it is wise to consult the general public in the United States about decision making on nuclear waste disposal? Yes No Why or why not?

7. Is the approach used in this study (movie and questionnaire) an effective way to gather public input about nuclear waste disposal? Yes No Why or why not?

8. What suggestions or comments do you have concerning public involvement in technical problems such as the disposal of nuclear wastes? (If you need more space or have other comments, feel free to use the back of this page.)

9. Were the four factors emphasized in this study a satisfactory way to think about nuclear waste disposal? Yes If no, what factors should have been emphasized?

Your answers to the following questions will be helpful in summarizing the results of this study.

Sex : $M \quad F$

Age:

Education (years of school or highest degree 
THIS PAGE

\section{WAS INTENTIONALLY \\ LEFT BLANK}




\section{APPENDIX B}

Nuclear Waste Disposal Film Script

This presentation is about values--your values. We want to know how you, personaliy, weigh such matters as immediate cost versus long-term safety; or, how you might judge risk against cost. There are no correct answers. These are judgments, and your opinions are important.

What we are trying to do is assess public views and values in an area of options. We have a situation that requires the input of public values to reflect real concerns over short and long-term safety, cost considerations, and the potential for corrective action in the distant future. Those four categories are similar to the questions that are asked before planning any major installation that is intended to have a long life: what will it cost, how long will it last, how safe is it, and how can we change our plan in the future?

The subject of our presentation is along these lines. We will discuss an issue, briefly illustrate some of the options, and then ask you to apply these four considerations.

Our subject is nuclear waste. Some of the material generated by nuclear power reactors will be radioactive for thousands of years. How would you assure that it is not hazardous to man? The wastes can be managed in different ways, and any decision must be made carefully. Your opinion is important to the people who will make those decisions.

We will describe some of the options and their main characteristics, and, after the presentation, ask some questions.

Here is the issue: Nuclear waste is composed of various kinds of radioactive substances. Some of them--plutonium is an example--give off particles 
which have poor ability to penetrate matter, but can injure living cells if directly exposed to them. Such elements are hazardous if they get into a person's body and are retained there; that might happen if they are present in the air you breathe or the food and water you eat.

Other waste materials such as cesium give off radiation that easily penetrates matter. Although in this case the radiation penetrates easily, it docs not damage living colls as readily as participes emitted hy ingested plutonium. Shielding can protect people from these penetrating radiations.

The fact that radiation is being emitted means that these materials are disappearing from existence. However, many of these radioactive materials will exist for long periods of time. In general, we are concerned with two groups of radioactive materials: those that last for about 1000 years, and those that exist, although at very low levels, for as much as a million years.

How much nuclear waste is there now and how much will there be, say, in the next 25 years? The answer depends on a lot of things, fncludiny liuw many nuclear power plants there are and how the waste is harided. Today there are about 40 nuclear power plants operating in the United States. A total of several hundred plants may be built during the next few decades. The waste from these reactors is expected to be handled by making it into a glass-like material and putting this material into steel cans about ten feet long and a foot in diameter. By the year 2000 we expect to have about 50,000 cans of this type. Sometime after the turn of the century the rate of accumulation of these wastes is expected to decrease.

What are the basic characteristics of good methods for managing these wastes? They should be aimed at isolating the waste from man during the disposal process. They should keep the wastes isolated for long periods 
of time without disruption by phenomena such as earthquakes, floods, or things men might do. If an accident does occur, there should be ways to reduce the consequences of such an event. And, there should be a reasonable cost for the disposal.

Now let's look briefly at some of the waste management methods that have been proposed for disposal. There are five basic kinds: placement in geologic formations such as salt; possibly in the seabed or by placement in polar ice; removal from earth by rocket; or converting it into other radioactive materials that would decay more quickly. There are ways to do all of these that are technically feasible. However, there are big differences in things such as costs and safety considerations. It's these differences that we want your opinion about.

Before describing some of these disposal methods in more detail, we want to distinguish between our terms "disposal" and "storage". Storage implies active control and maintenance by man. The waste in storage is accessible to man, and storage conditions are maintained by monitoring and other human activities.

In contrast, disposal means putting the waste somewhere so that man would have little or no control after it is put there. This is why the basic characteristics for disposal are isolation and stability. We don't expect ever to retrieve the waste after disposal.

At present, the U.S. government is planning to manage the wastes by storage until disposal methods are selected and put into practice. Storage will probably be used until about the turn of the century.

In this study we're concerned with the evaluation of alternatives for disposal. The activities involved in the various methods can differ 
substantially. Each alternative will be evaluated on the basis of the following four factors.

The four evaluation factors for you to consider are:

- Short-Term Safety

- Long-Term Safety

- Cost

- Accident Recovery

We will describe these four evaluation factors and then show how they apply to two of the disposal methods being considered.

1. Short-Term Safety

Short-term safety is concerned with the operations necessary to place the wastes in their disposal location. These include getting the waste into its disposal form, transportation to the disposal site, and putting the material in place. The safety considerations are short-term because they occur soon after the wastes are produced and they involve people who participated in the benefits and costs of the electricity production.

\section{Long-Term Safety}

Long-term safety is concerned with what happens to the waste after it is put into the disposal site. Since the objective of disposal is to isolate the waste from man, we need to ask about ways the waste might be released from isolation and the consequences of release. These are "long-term" safety issues because release, if it happened, would not occur until many years in the future.

\section{What About Costs?}

The various proposed methods will differ in how much it would cost to develop them and the costs to operate them. The proposed methods will probabiy 
affect the total price you pay for electricity by $\$ 1$ to $\$ 15$ per month.

4. Detection and Recovery from Accidents

After disposal, natural events such as earthquakes might release the waste from isolation. Places for disposal would be selected so that the possibilities for disruptive natural events or human activities is minimal. They would also be selected to provide natural barriers to help keep the waste from returning to man's environment. In spite of these precautions, if an accident did occur, the question is: "What could be done about it?" Accident recovery is therefore concerned with the steps that could be taken to minimize the consequences of an accident if it does occur.

Now let's examine these four evaluation factors in terms of two of the proposed methods for waste disposal. The methods we will consider are underground disposal in salt deposits and disposal to the seabed.

First, let's look at disposal into a salt deposit which we will assume is located somewhere in the continental U.S. With this method of disposal, the waste would be transported across land to the disposal site, transferred to a handling facility at the disposal site, and placed in holes drilled in the salt. The drilled holes would be in the floor of mined corridors deep underground.

In terms of our four evaluation factors, the characteristics of this disposal method that are important are the following:

1. Relatively few handling operations are needed, and those that would be needed are relatively simple. Engineering designs to assure short-term safety would not be difficult.

2. The fact that the salt deposit exists indicates the site has been free from water for many years in the past and probably will be far into 
the future. In general, salt deposits under the continental surfaces are known to be quite stable and free from phenomena such as earthquakes and water flow that might release waste. A question for longterm safety is the possibility that future populations might locate at the disposal site and engage in mining or other operations that could release the waste.

3. Operation and development of the salt disposal concept would be relatively inexpensive. Much of the development work has already been done.

4. If a long-term accident should occur, the waste could be located for recovery operations. People potentially affected by accident would be those in the vicinity of the disposal site. Alternate water supplies could be provided or, if necessary, the populace could be evacuated. Now let's look at disposal to the seabed. If this method is used, the waste would have to be transported to a port, placed on ships to carry it to the disposal site, taken off the ship, and placed in the seabed.

In terms of our four evaluation factors, the characteristics of this disposal method that are important are the following:

1. Handling operations involving loading and unloading ships would be necessary. Also, the ships and emplacement operations would be subject to storms at sea. Short-term safety would therefore involve more factors and uncertainties than disposal in the salt deposit.

2. Some portions of the seabed are among the most stable regions of the earth. These geologic regions also have very little water movement, and sedimentation processes in these areas would tend to add barriers between the disposed waste and man's environment. These are 
remote locations, unlikely ever to be the site of other activities by man.

3. Work is needed to develop the ships and systems needed for seabed disposal. Operating costs also would be higher for disposal in the seabed because of the addition of ship transport to the disposal operations.

4. A major earth shift could expose the wastes to water. Recovery of the wastes would be difficult. Although the wastes would be highly diluted, they would be spread through the oceans.

We hope these two examples illustrate the differences that are possible for the various disposal methods that have been proposed. We hope they show you that costs can differ and that the factors involved in safety and accident recovery will differ. In general, the major areas of uncertainty are associated with these four evaluation factors we have described.

What we want you to do now is express your opinions concerning these evaluation factors. Basically, what we are asking in the questionnaire that follows is for you to indicate the relative importance of these factors. Your npinions will help in selecting disposal methods. 
THIS PAGE

\section{WAS INTENTIONALLY LEFT BLANK}




\section{APPENDIX C}

Attitude Response Frequencies

for Total Sample

1. Overpopulation and economic conditions are more serious threats to our way of life than the problem of nuclear waste disposal.

2. Nuclear wastes should be disposed of in such a way that no one will ever be able to recover them.

3. In dealing with nuclear wastes, cost should be of no concern.

4. Based on information I got from this study, the hazards of nuclear wastes are less serious than I thought.

5. In the next 10 years, solar power could solve the problem of electrical power in the U.S.

6. The loss of even one life from nuclear waste is unacceptable.

7. The U.S. can maintain a strong economy wi thout having nuclear power.

8. The construction of nuclear power plants should be slowed until an absolutely safe waste disposal system has been developed and thoroughly evaluated.

9. Nuclear waste is one of the most serious threats facing the world.

10. The radioactive hazards in nuclear power are no greater than the environmental hazards from coal-burning power plants.

11. Future generations must be totally safe from our nuclear waste.

12. In my opinion, the information contained in this study seriously underestimates the real risks of nuclear wastes.

\begin{tabular}{|c|c|c|c|c|}
\hline$S A$ & $A$ & $A D$ & $D$ & $S D^{1}$ \\
\hline $\begin{array}{c}100 \\
22 \%\end{array}$ & $\begin{array}{c}151 \\
33 \%\end{array}$ & $\begin{array}{l}94 \\
21 \%\end{array}$ & $\begin{array}{l}94 \\
21 \%\end{array}$ & $\begin{array}{c}19 \\
4 \%\end{array}$ \\
\hline $\begin{array}{l}147 \\
32 \%\end{array}$ & $\begin{array}{c}124 \\
27 \%\end{array}$ & $\begin{array}{l}69 \\
15 \%\end{array}$ & $\begin{array}{l}94 \\
21 \%\end{array}$ & $\begin{array}{c}24 \\
5 \%\end{array}$ \\
\hline $\begin{array}{l}60 \\
13 \%\end{array}$ & $\begin{array}{l}96 \\
21 \%\end{array}$ & $\begin{array}{l}75 \\
16 \%\end{array}$ & $\begin{array}{r}182 \\
40 \%\end{array}$ & $\begin{array}{l}45 \\
10 \%\end{array}$ \\
\hline $\begin{array}{l}11 \\
2 \%\end{array}$ & $\begin{array}{l}73 \\
16 \%\end{array}$ & $\begin{array}{l}131 \\
29 \%\end{array}$ & $\begin{array}{l}146 \\
32 \%\end{array}$ & $\begin{array}{l}97 \\
21 \%\end{array}$ \\
\hline $\begin{array}{l}22 \\
5 \%\end{array}$ & $\begin{array}{l}101 \\
22 \%\end{array}$ & $\begin{array}{r}127 \\
28 \%\end{array}$ & $\begin{array}{c}145 \\
32 \%\end{array}$ & $\begin{array}{l}63 \\
14 \%\end{array}$ \\
\hline $\begin{array}{c}34 \\
7 \%\end{array}$ & $\begin{array}{l}71 \\
16 \%\end{array}$ & $\begin{array}{l}76 \\
17 \%\end{array}$ & $\begin{array}{c}178 \\
39 \%\end{array}$ & $\begin{array}{l}99 \\
22 \%\end{array}$ \\
\hline $\begin{array}{l}34 \\
7 \%\end{array}$ & $\begin{array}{l}58 \\
13 \%\end{array}$ & $\begin{array}{l}100 \\
22 \%\end{array}$ & $\begin{array}{l}157 \\
34 \%\end{array}$ & $\begin{array}{c}109 \\
24 \%\end{array}$ \\
\hline $\begin{array}{l}96 \\
21 \%\end{array}$ & $\begin{array}{l}147 \\
32 \%\end{array}$ & $\begin{array}{l}46 \\
10 \%\end{array}$ & $\begin{array}{l}118 \\
26 \%\end{array}$ & $\begin{array}{l}51 \\
11 \%\end{array}$ \\
\hline $\begin{array}{l}41 \\
9 \%\end{array}$ & $\begin{array}{c}102 \\
22 \%\end{array}$ & $\begin{array}{l}91 \\
20 \%\end{array}$ & $\begin{array}{l}153 \\
33 \%\end{array}$ & $\begin{array}{l}71 \\
16 \%\end{array}$ \\
\hline $\begin{array}{l}33 \\
7 \%\end{array}$ & $\begin{array}{l}75 \\
16 \%\end{array}$ & $\begin{array}{l}90 \\
20 \%\end{array}$ & $\begin{array}{l}176 \\
38 \%\end{array}$ & $\begin{array}{l}84 \\
18 \%\end{array}$ \\
\hline $\begin{array}{c}105 \\
23 \%\end{array}$ & $\begin{array}{c}170 \\
37 \%\end{array}$ & $\begin{array}{l}82 \\
18 \%\end{array}$ & $\begin{array}{l}78 \\
17 \%\end{array}$ & $\begin{array}{c}23 \\
5 \%\end{array}$ \\
\hline $\begin{array}{l}38 \\
8 \%\end{array}$ & $\begin{array}{l}80 \\
17 \%\end{array}$ & $\begin{array}{c}151 \\
33 \%\end{array}$ & $\begin{array}{c}163 \\
36 \%\end{array}$ & $\begin{array}{l}26 \\
6 \%\end{array}$ \\
\hline
\end{tabular}


13. The benefits of nuclear power more than outweigh the hazards in nuclear waste storage and disposal.

14. Nuclear power is the most promising source of electrical power for the next 30 years.

$\begin{array}{ccccc}\frac{S A}{3} & \text { A } & \text { AD } & \text { D } & \text { SD } \\ 56 & 148 & 92 & 109 & 53 \\ 12 \% & 32 \% & 20 \% & 24 \% & 12 \%\end{array}$

15. Whatever disposal system is devised, there must be a way to detect leaks and recover the waste.

16. Before I got involved in this study, I knew very little about the problem of nuclear wastes.

17. The construction of additional electrical power plants will not be necessary for the U.S. to maintain its present standard of living.

18. I would not want to have nuclear wastes disposed of in my region of the country.

19. The generation that uses nuclear power should take all the risks for waste disposal.

20. Government and industry have done a good job of keeping. the pubilc informed abuut the advantages and disadvantages of nuclear power.

21. Based on past operating experience, nuclear energy has been demonstrated to be a clean and safe source of electrical power.

22. Participating in this study makes me realize just how frightening nuclear waste is.

23. In the next 10 years, geothermal power could solve the problem of electrical power in the U.S.

24. Using more coal is far less harmful to man than using nuclear power.

$\begin{array}{lllll}79 & 184 & 106 & 53 & 36 \\ 17 \% & 40 \% & 23 \% & 12 \% & 8 \%\end{array}$

$\begin{array}{rrrrr}247 & 164 & 26 & 16 & 5 \\ 54 \% & 36 \% & 6 \% & 3 \% & 1 \%\end{array}$

$\begin{array}{lllll}55 & 115 & 56 & 165 & 67\end{array}$

$12 \% \quad 25 \% \quad 12 \% \quad 36 \% \quad 15 \%$

$\begin{array}{lllll}15 & 44 & 80 & 188 & 131\end{array}$

$3 \% \quad 10 \% \quad 17 \% \quad 41 \% \cdot \quad 29 \%$

$\begin{array}{lcccc}98 & 115 & 87 & 121 & 37 \\ 21 \% & 25 \% & 19 \% & 26 \% & 8 \% \\ 52 & 117 & 78 & 152 & 59 \\ 11 \% & 26 \% & 17 \% & 33 \% & 13 \% \\ & & & & \\ 12 & 42 & 48 & 194 & 162 \\ 3 \% & 9 \% & 10 \% & 42 \% & 35 \%\end{array}$

$\begin{array}{lllll}43 & 173 & 133 & 81 & 28\end{array}$

$\begin{array}{lllll}9 \% & 38 \% & 29 \% & 18 \% & 6 \%\end{array}$

31. $\quad 119 \quad 110 \quad 135 \quad 63$

$7 \% \quad 26 \% \quad 24 \% \quad 29 \% \quad 14 \%$

$\begin{array}{lllll}9 & 58 & 186 & 130 & 75\end{array}$

$2 \% \quad 13 \% \quad 41 \% \quad 28 \% \quad 16 \%$

$\begin{array}{llllll}11 & \cdots & 80 & 150 & 164 & 53\end{array}$

$2 \% \quad 17 \%, \quad 33 \% \quad 36 \% \quad 12 \%$

25. To satisfy critics, the U.S. nuclear waste $\begin{array}{llllll}48 & 178 & 89 & 100 & 43\end{array}$ system will probably cost far more than is $\quad 10 \% \quad 39 \% \quad 19 \% \quad 22 \% \quad 9 \%$ necessary. 
26. Paying a little more attention to conservation would make more electrical power unnecessary.

27. We should immediately stop developing nuclear technology as an energy source.

28. The main concern of nuclear waste planners should be a safe system for the short term.

29. Compared to other problems that future generations will face, nuclear waste monitoring is insignificant.

30. If the United States does not increase the production of electricity, our economy will decline.

$\begin{array}{lllll}\text { SA } & \text { A } & \text { AD } & \text { D } & \text { SD } \\ 47 & 97 & 98 & 169 & 47 \\ 10 \% & 21 \% & 21 \% & 37 \% & 10 \%\end{array}$

$\begin{array}{lllll}10 & 22 & 51 & 179 & 196\end{array}$ $2 \% \quad 5 \% \quad 11 \% \quad 39 \% \quad 43 \%$

$\begin{array}{lllll}25 & 95 & 68 & 212 & 58\end{array}$
$5 \% \quad 21 \% \quad 15 \% \quad 46 \% \quad 13 \%$

$\begin{array}{lllll}23 & 50 & 94 & 192 & 99\end{array}$ $5 \% \quad 11 \% \quad 21 \% \quad 42 \% \quad 22 \%$ $\begin{array}{lllll}66 & 194 & 116 & 66 & 16\end{array}$ $14 \% \quad 42 \% \quad 25 \% \quad 14 \% \quad 3 \%$ 
THIS PAGE

\section{WAS INTENTIONALLY \\ LEFT BLANK}


APPENDIX D:

\author{
Factor I - Need for and Efficacy of Nuclear Power; \\ Need for Power
}

\begin{tabular}{|c|c|c|}
\hline $\begin{array}{l}\text { Factor } \\
\text { Loading }\end{array}$ & $\begin{array}{l}\text { Question } \\
\text { Number }\end{array}$ & Question \\
\hline .62 & 7 & $\begin{array}{l}\text { The U.S. can maintain a strong economy without } \\
\text { having nuclear power. }\end{array}$ \\
\hline .42 & 8 & $\begin{array}{l}\text { The construction of nuclear power plants should } \\
\text { be slowed until an absolutely safe waste dis- } \\
\text { posal system has been developed and thoroughly } \\
\text { evaluated. }\end{array}$ \\
\hline-.42 & 13 & $\begin{array}{l}\text { The benefits of nuclear power more than outweigh } \\
\text { the hazards in nuclear waste storage and } \\
\text { disposal. }\end{array}$ \\
\hline-.55 & 14 & $\begin{array}{l}\text { Nuclear power is the most promising source of } \\
\text { electrical power for the next } 30 \text { years. }\end{array}$ \\
\hline .48 & 17 & $\begin{array}{l}\text { The construction of additional electrical power } \\
\text { plants will not be necessary for the U.s. to } \\
\text { maintain its present standard of living. }\end{array}$ \\
\hline-.41 & 21 & $\begin{array}{l}\text { Based on past operating experience, nuclear energy } \\
\text { has been demonstrated to be a clean, safe source } \\
\text { of electrical power. }\end{array}$ \\
\hline-.56 & 26 & $\begin{array}{l}\text { Paying a little more attention to conservation } \\
\text { would make more electrical power unnecessary. }\end{array}$ \\
\hline .59 & 27 & $\begin{array}{l}\text { We should immediately stop developing nuclear } \\
\text { technology as an energy source. }\end{array}$ \\
\hline-.65 & 30 & $\begin{array}{l}\text { If the United States does not increase the pro- } \\
\text { duction of electricity, our economy will decline. }\end{array}$ \\
\hline
\end{tabular}


Factor II - Emphasis on Safe Power

Factor Question Loading Number

.45

2

5

6

.42

.53

11

.61

23

\section{Question}

Nuclear wastes should be disposed of in such a way that no one will ever be able to disturb or recover them.

In the next 10 years, solar power could solve the problem of electrical power in the U.S.

The loss of even one life from nuclear waste is unacceptable.

Future generations must be totally safe from our nuclear. waste.

In the next 10 years, geothermal power could solve the problem of electrical power in the U.S. 
Factor III - Pollution (Safety)

Factor Question Loading Number .45 8 $-.44$ 10

$-.50$

$-.53$

21

.51 24
Question

The construction of nuclear power plants should be slowed until an absolutely safe waste disposal system has been developed and thoroughly evaluated.

The radioactive hazards in nuclear power are no greater than the environmental hazards from coal burning power plants.

The benefits of nuclear power more than outweigh the hazards in nuclear waste storage and disposal.

Based on past operating experience, nuclear energy has been demonstrated to be a clean, safe source of electrical power.

Using more coal is far less harmful to man than using nuclear power. 
Factor IV - Importance of Short Term

\begin{tabular}{ccc}
$\begin{array}{c}\text { Factor } \\
\text { Loading }\end{array}$ & $\begin{array}{c}\text { Question } \\
\text { Number }\end{array}$ & $\frac{1}{\text { Question }}$ \\
\hline 41 & 28 & $\begin{array}{l}\text { The main concern of nuclear waste planners } \\
\text { should be a safe system for the short term. }\end{array}$ \\
.46 & 29 & $\begin{array}{l}\text { Compared to other problems that future genera- } \\
\text { tions will face, nuclear waste monitoring is } \\
\text { insignificant. }\end{array}$
\end{tabular}

Factor V - Accident Detection and Recovery

.55

15

Whatever disposal system is devised, there must be a way to detect leaks and recover the waste.

Factor VI - Severity of Nuclear waste Problem

$-.45$

1

Overpopulation and ecullumic conditions are more serious threats to our way of life than the problem of nuclear waste disposal.

$-.52$

1

Dagen $n$ the information I got from this study, the hazards of nuclear wastes are less serıous than I thought.

$.40 \quad 9$

Nuclear waste is one of the most serious threats facing the world.

Factor VII - Knowledge

Before I got involved in this study, I knew very little about the problem of nuclear wastes. 


\section{APPENDIX E}

Representative comments to the question, "Do you think it is wise to consult the general public in the United States about decision making on nuclear waste disposal?"

No, this is an engineering problem, not public problem.

Yes, we may have good opinions.

Yes, we are educated enough to understand it.

No, they don't know enough about the problem.

No, problem is too technical and emotional for valid surveys--should be left to technical experts.

Yes, but the public must be educated first. The dangers of nuclear energy production and waste are not sufficiently known to the public. In fact, this study does a disservice by failing to address the more important--and prior --issue: would a public that is knowledgeable about these hazards (production as well as waste) support the development of nuclear energy plants the way an uninformed public is currently doing?

Yes, we and succeeding generations are the ones who have to live with whatever benefits or problems result from these decisions. In the United States the people are the government.

Yes, the general public has the right to know because their future is involved --and they're paying for it.

Yes, Americans have a right to be advised and informed. If the public is kept informed there will be less fear on the part of "John Q" as to nuclear power production.

Yes, I feel that the general public, if given the necessary data, is capable of making intelligent decisions. I am not too certain that appointed or elected officials would be able to weight all considerations without bias.

Yes, because it is the people who will be affected by any nuclear accidents. No industry has the right to endanger the environment without taking every step to protect it.

Yes, because a decision that has this long-term effect should be a public decision. All risks should be as publicized as the benefits. Unfortunately the general public does not have the funds to educate on nuclear power as do the utilities and government entities. 
Yes, about their fears and their feelings of cost-benefit because the issue has such immense ramifications for both contemporary and future generations that all should have value-oriented input. I don't, however, feel that surveys, etc., should be made about the techniques involved, because too many people are ignorant of salient issues.

Yes, it is possible the general public would wish to renounce risks involved, and concentrate on more available energy forms.

Yes, the public should be informed and allowed to voice an opinion. The problem is the source and quality of the information and to what extent public opinion affects a decision.

Yes, since my safety and that of.my progeny is at stake--it is vitally important that the public be informed in an accurate way, and consulted.

No, I think the general public is far more concerned about its own personal comfort and saving money than about hazards and consequences their actions may present to future generations.

Yes, in that the health and safety of the public are concerned they should be consulted. In that the public may be much more concerned with economics than safety, it is dangerous. On the whole, I think they should be consulted.

Yes, but open scientific study of the question should come first.

No, not unless they're educated. Public hearings are probably required for major decisions anywhere.

Yes, at least inform them with accurate and complete details.

Yes, public decision-making could not be any worse than governmental.

Yes, don't take them too seriously though.

Yes, this is one problem the government should not cover up.

Your people could provide an important service by using this approach of providing a balanced and informative film (or other means of education) and determining public reaction to the broader and more important issues regarding the alternatives we face in meeting energy needs. But then an important question becomes whether anyone in Washington, D.C. would listen--they appear so committed to nuclear energy. 


\section{APPENDIX $F$}

Representative comments to the question, "What suggestions or comments do you have concerning public involvement in technical problems such as the disposal of nuclear wastes?"

Public input is essential in our society. Obviously, some way must be found to deal with the nuclear waste we now have. The premise of this study is that the U.S. will go the nuclear energy route. The study should have concentrated more on alternatives. Conservation in many areas is possible. Reduction of consumer goods, advertising, packaging and other worthless $i$ tems are necessary. Two liter auto engines should be mandatory. I could go on for pages, but my point is that nuclear power is not inevitably necessary. I am married and have two children and live on $\$ 5000 / \mathrm{yr}$. I think many many Americans have way too high a standard of living which the planet cannot support.

It is time for an all-out effort to fairly compare all forms of power generation (e.g., if "worst case" is used to describe nuclear power then "normal conditions" for coal or gas cannot be used to describe and compare them!) and to make it a more available and more attractive (the info) (i.e., make it more enjoyable to learn, less dry, more able to compete with the yellow press).

I think we need more exposure to the problem of nuclear energy and nuclear waste. I dare say most people never think of the nuclear waste problem.

Extensive public information programs before citizen input.

Public television broadcasts informing citizenry of "pros and cons" would be helpful.

Feel strongly that public not able to deal competently with such an issue.

An informed public is capable of making prudent decisions. A system whereby the public is informed and then asked to make value judgments is a better method of determining what policy should be adopted on a given issue, is the best way to find the answer. I do not feel that our government or any of its agencies are doing the job properly at present, and see no improvement in the tmmediate or long-range future.

The general public does not have the competence to participate in a knowledgeable way.

More public awareness through groups whether they want to know or not. People tend to think scientific material is beyond their capabilities. This needs to be presented to groups that normally would not take time to listen. 
I believe public forums and debates provide most useful device. I would like to see a time limit placed on period of debate though and then get on with job.

Part of the problem today stems from a lack of communication. The general public may not be technically qualified to enter into the decision making process, but they should be informed of the options and how these decisions will affect them. They have an opportunity to review both the hazards and options for good waste management. Well designed programs will instill faith in the nuclear technical communities' ability to manage the business.

The age-0ld problem--nuclear power advocates use terms and assurances that the general public cannot relate to. The anli-nuclear forces usc gut-grabbing arguments that are readily grasped by the public.

Questionnaire too long.

If deaths cannot be totally eliminated, then the public should be involved in decision making.

The public should have final veto power on the use of any potentially hazardous method of energy supply, and should be made fully aware of all of the hazard involved. On the other hand, I don't think the public has the right, to saddle future generations with the safe maintenance and/or disposal of waste.

I feel the public should be given a final vote on whether large-scale constructions of breeder reactors (or conventional reactors) is to be undertaken by the power companies. This should occur after a large-scale discussion of the issues, not financed and put out by the power companies. The real problem is not nuclear waste disposal, but whether development of the systems that will produce the waste should proceed.

Educate the public in an unbiased way and then let them decide.

Technical problems should be solved by professionals; however, the specification should be set by public opinion.

The wider the discussion of technical topics the more understanding there will be so that no one agency or industry will be able to pull lhe wool ovel the public's eyes.

There needs to be more information dijsemination regarding nther energy sources --too much emphasis has been given to nuclear energy and little attention to other long-term sources.

The public should not only discuss how waste disposal takes place but make value judgment on nuclear power itself.

Really publicize in easy to understand terminology the dangers of this method of power production, the lack of specific knowledge, and the possible 1/2 1ife hazards. Public education is possible and highly desirable. 
APPENDIX G

Representative comments to the question, "Is the approach used in this study (movie and questionnaire) an effective way to gather public input about nuclear waste disposal?"

Yes, because study samples both and public knowledge and attitudes about nuclear waste, quality and value of life in general, and many analyses can be run with results.

No, since the questionnaire and survey was one-sided and biased and the movie was "cute", people would be inclined to not attach as much importance to the decisions as were needed.

Yes, but there should be more information.

Yes, the public should be made aware of the possible consequences of each system before it makes a decision.

Yes; however, you are dealing with a complex subject and probably will get a biased group who are even willing to consider approaches to it. Many people prefer to have their decisions made for them or know all the facts before even choosing a direction.

Yes, readily translatable to broad coverage via TV.

No, assumes we must have nuclear power--also minimized the dangers--e.g., the graphic of cleaning up a spill with a dust pan--come on! Also, its magnitude of the concept "long-term" was not given sufficient emphasis. The slick treatment used in the videotape was more appropriate in the question of soap flakes preference than an issue, the answer to which will affect mankind's very survival for 1000's of years.

No, the survey takes for granted the continued development and use of nuclear energy, and this is a much-debated, but prior question. The survey needs to be put in the higher context of energy development. Getting public input merely helps the proponents of nuclear energy solve their own problems.

No, the questionnaire is too complexed.

No, a highly informed person should also be included on the agenda to answer technical questions that people have on the subject.

No, you would never reach a decision and would simply stir up more individuals who are either ignorant or have nothing to do!

No, because this questionnaire is bugging me and the film was boring. 
No, interesting exercise, provokes thought; however, the sampling would have to be very careful to escape bias.

No, it can only measure pre-conceived opinions. It would be interesting to see if opinions change as a result of a much longer exposure to nuclear waste management information ( $1 / 2$ day to 1 week).

Yes, I'll say yes to the questionnaire, but the movie needs improvement by having real people involved.

No, I think a movie and questionnaire are o.k., but I don't think this short film and long questionnaire will do it.

Yes, but educating the public may be more important at this time.

Yes. Interesting, but I wouldn't have policy decisions tied to its outcomes.

Yes. It is a non-technical and simplistic approach to something that concerns all of us, i.e., it approaches the matter in a non-informational and purely value-oriented way.

Yes, but the movie was greatly simplified and the questionnaire is greatly complicated.

Yes, I don't know. This approach is clearly better than a "random" sampling, since much of the general public is uninformed on this issue. On the other hand, you're not gathering input from much of the public.

Yes, because the questions were so designed to check and cross-check individual viewpoints in a rather complete, easy to understand way. 


\section{APPENDIX H}

Representative comments to the question, "What suggestions do you have which would improve the quality of the film or questionnaire?"

I would like more information on risks involved in other types of energy production. It seems that the only real analysis that is worthwhile is a comparative one since it is assumed that some type of energy source is essential.

The movie was of poor quality, cartoon characters do not dramatize issues nearly enough. The questionnaire dwel 15 too much on the four factors at the expense of other facets of the issue.

Give more concrete knowledge. I really learned nothing about nuclear waste disposal methods.

The film could deal more explicitly with the hazards involved, particularly the environmental hazards of ocean disposal.

More information from opposing viewpoints and different interest groups, more empirical data and history of what has been done so far in nuclear power.

The major long term risks probably concern sudden major leaks and exposure of millions to radiation... a question which is avoided in this study.

Remove the prior assumption that there must be nuclear waste to dispose of.

Film should remain as is so as not to sway opinion of audience.

Consideration of risks in terms only of human death leaves out many of the most important possibilities, i.e., mutagenesis, carcinogenesis, and effects on the other plants and animals on the planet. Several questions do not allow one's opinion to be shown. For example, while I know perfectly well that solar energy cannot be developed in the next 10 years, it certainty can (and must) in the next 30-50.

In the film, present the public with more information about the actual hazards of nuclear wastes; perhaps outline several more (than two) alternatives to nuclear waste disposal.

Perhaps a little more on other effects of radiation besides death such as cancer, mutations. Also, the fact that a lot of nuclear waste has been generated by the U.S. bomb industry and over 20 years experience on this subject is available.

If your purpose is to inform, use all examples of possible disposal methods in film (not just salt and ocean floor). If your purpose is not to inform, use examples of decision making in other areas for the film. 
Information given too quickly and incompletely in film.

The film is too simple to go with the questionnaire--perhaps it was the cartooning I objected to most in the film--it was as if an explicit attempt was made to overly simplify the narrative--perhaps to the point of creating a mental (subliminal) credibility gap.

Some of the cartoons in the film are pretty simplistic and might be improved for mature audiences.

Supplement depth level for specific technical audiences who might be considered more "expert" than lie general public or audience responding to this particular film and questionnaire.

Have more pictures of various waste sites, and get into more detail of the containers and possible sites.

More detail to data available--actual number and cases of accident and leakage --deaths caused by N.W.

More information about the other two forms of disposal should be given.

Get to real case histories, show what can happen and what won't hurt us.

The film was well done. The questionnaire rather long.

Questionnaire i's too long dind tedious! Espesially Part IV.

The wording of the explanations takes as much time as the answering of the questions. More questions, less explanations.

The film should go into greater depth. The questionnaire could use more varied questions with more individual responses.

I think it's ridiculous to answer this type of survey without. more concrete facts.

Go into the other ways of waste dispusal. How scrious can it. get? With our present technology, how feasible are the different methods? 


\section{APPENDIX I}

Representative comments to the question, "Were the four factors emphasized in this study a satisfactory way to think about nuclear waste disposal? If no, what factors should have been emphasized?"

No, I was highly offended by the callous way in which the loss of human life was considered merely a factor or an acceptable hazard in the quest for more energy. This survey should contain accounts or pictures of people poisoned or burned by radioactivity so that your respondents will know what you are talking about.

Yes, the factors are reasonable, but you ask people to think about them in naive and misleading ways. For example, in Part III risks are posed in terms of " 1 death in $X$ number of years," etc. A serious accident will not influence one person, but hundreds or thousands of people. And the consequence may not be death in all cases, but numerous other serious consequences of exposure to radioactivity. The form of your questions underestimates the magnitude of the damage that could result. I'm concerned about how your results--from a public largely unaware of these dangers--may be at least misleading, at worst misused!

No, the subjects all were brushed over too lightly. More emphasis on each point was needed.

No, the potential hazards of human (and plant and animal!) exposure to radiation should have been emphasized more. Also, the distinction between long-term risk and accident detection and recovery are not clear--i.e., if accident detection and recovery systems are excellent, doesn't that minimize long-term risk?

One of the major weaknesses with this study is the measurement of risk in terms of human deaths--more likely long-term effects from exposure to radiation wnuld be an increase in the mutation frequencies or increase in the incidence of cancer, and these effects will be difficult to measure and at least as unacceptable as actual human deaths.

No, the necessity of generating nuclear waste, which means the necessity of generating ever more electrical power to maintain and augment an unrealistic standard of living. And the necessity of generating what power is necessary from nuclear energy.

No, I suppose so but I feel unsatisfied; it is too simplified. I keep feeling I need a lot more information and a lot more reassurance that the scientists involved know what they are talking about.

The fact that by altering our life styles, we would not need to incur any of the inherent risks. Do we need 2 color TV's per capita? 
No, the only effect listed was loss of human life, not to total effect on environment.

Yes, can something be done constructively with this waste? Can these "blocks" of waste be stored and a low output of thermal energy be used, i.e., heating and redistributing of subsurface ocean waters to put the nutrients on the surface where the plankton can grow, etc. increasing fish populations. Detection and recovery for an "operated storage plant site". Risks would be the same as any other nuclear plant, cost in the long run might come back through environmental enhancement. There's so much to be thought about, this questionnaire barely scratches the subject. P.S. A lot of money is being wasted on this kind of survey and my time was wasted!

No, rating the factors in terms of human deaths per unit time is ridiculous. Life on the whole planet is involved.

No, dislinguish between short and long=term recovery.

Yes, but need to clarify difference between long-term safety and accident detection and recovery.

No, nuclear waste disposal and nuclear energy need to be compared to alternative sources.

No, other problems of nuclear waste--illness, and shortening of life and problems of storage, sabotage and biackmail.

Yes, I think so. Conservation of national resources should be considered as well as moral question of nuclear use. Manipulistic control of public and private power should be included. Question of whether growth is good and whether high standards of living can always be justified. Also, sharing, with poorer nations, power as well as other resources.

Yes, the relative factors--good.

I am not familiar with all the harmful effects of coal but do know that deaths have resulted from mining it, both cave-ins, and lung disorders. But how about after effects? Any similar to problem of nuclear wastes?

Long-term risks. These people supposedly have "no say" in the selection therefore I consider any death in this area unsatisfactory.

Cost. Would be willing to pay highest cost if risks were reduced by so doing. Also would have to know future costs of other sources of energy and their risks.

Cost. If the increase in cost means increase in safety, I'd vote satisfactory to all these costs. My bill goes up that much due to inflation--no benefits.

Disagree with your assessment of safety hazards in two areas. 1) Short run you have averaged the potential harm into number of deaths per year, rather than kept the more accurate and sombering figure of one out of a million 
chance that one million people will be killed - this is hypothetical..it is really a combination of both functions. I did base my answers on your figures however!!

2) I think you overestimate long term costs by understating the improvements of technology. I did not go by your figures in the questions dealing with long run hazards of disposal.

3) I also feel you should have discussed the hazards incumbent with storagebut c'est la vie.

All four factors are highly important, especially safe detection/recovery-only human selfishness makes me rank short more important than long term.

Cost is the very least of my concerns. The possibility of a globular "nuclear infection" eventually destroying life on this fair planet is an infinitely greater fear. 


\section{DISTRIBUTION}

No. of

Copies

OFFSITE

1 A. A. Churm

ERDA Chicago Patent Group

9880 South Cass Avenue

Argonne, IL 60439

1 F. P. Baranowski

ERDA Division of Nuclear

Fuel Cycle and Production

Washington, D.C. 20545

1 C. Kuhlman

ERDA Division of Nuclear

Fuel Cycle and Production

Washington, D.C. 20545

1 A. F. Perge

ERDA Division of Nuclear

Fuel Cycle and Production

Washington, D.C. 20545

1 R. W. Ramsey

ERDA Division of Nuclear

Fuel. Cycle and Production

Washington, D.C. 20545

1 H. P. Soule

ERDA Headquarters

Washington, D.C. 20545

27 ERDA Technical Information Center

20 J. A. Hébert

Battelle Memorial Institute

Human Affairs Research Center

Seattle, WA 98105

20 M. K. Lindell

Battelle Memorial Institute

Human Affairs Research. Center

Seattle, WA 98105
No. of

Copies

OFFSITE

20 S. M. Nealey

Battelle Memorial Institute

Human Affairs Research Center

Seattle, WA 98105

1 J. E. Rasmussen

Battel le Memorial Institute

Human Affairs Research Center

Seattle, WA 98105

ONSITE

2. ERDA Richland Operations Office

R. B. Goranson

F. R. Standerfer

29 Battelle-Northwest

J. W. Bartlett (5)

J. B. Burnham (15)

J. W. Finnigan

J. C. Fox

M. R. Kreiter (2)

A. M. Platt

Technical Information Files (3)

Technical Publications 